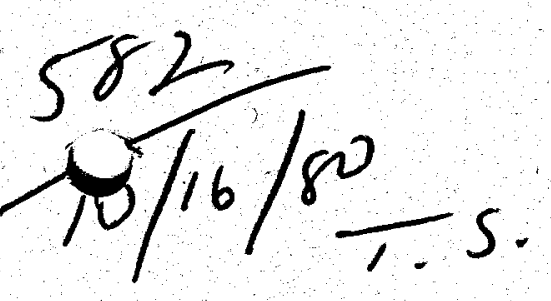

\title{
Demonstration of EIC's Copper Sulfate Process for Removal of Hydrogen Sulfide and Other Trace Contaminants from Geothermal Steam at Turbine Inlet Temperatures and Pressures
}

Final Report

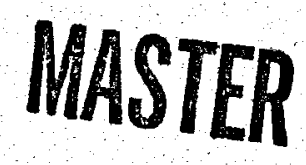

May 1980

Prepared for:

U.S. Department of Energy

Assistant Secretary for Resource Applications

Washington, D.C. 20461

Under Cooperative Agreement No. FC03-78ET27181 


\section{DISCLAIMER}

This report was prepared as an account of work sponsored by an agency of the United States Government. Neither the United States Government nor any agency Thereof, nor any of their employees, makes any warranty, express or implied, or assumes any legal liability or responsibility for the accuracy, completeness, or usefulness of any information, apparatus, product, or process disclosed, or represents that its use would not infringe privately owned rights. Reference herein to any specific commercial product, process, or service by trade name, trademark, manufacturer, or otherwise does not necessarily constitute or imply its endorsement, recommendation, or favoring by the United States Government or any agency thereof. The views and opinions of authors expressed herein do not necessarily state or reflect those of the United States Government or any agency thereof. 


\section{DISCLAIMER}

Portions of this document may be illegible in electronic image products. Images are produced from the best available original document. 


\section{NOTICE}

This report was prepared es an account of work sponsored by the United States Government. Neither the United States nor the United States Department of Energy, nor any of their employees, makes any warranty, express or implied, or essumes any legal liability or responsibility for the eccuracy, completeness, or usefulness of any information, apparatus, product, or process disclosed, or represents that its use would not infringe privately owned rights. Reference here in to any specific commercial product, process, or service by trade name, mark, manufacturer, or otherwise, does not necessarily constitute or imply its endorsement, recommendation, or fevoring by the United States Government or any egency thereof. The views and opinions of euthors expressed herein do not nocessarily state or reflect those of the United States Government or eny egency thereof.

\section{Avallable from:}

Rational Technical Information Service (NIIS)

U.S. Department of Comerce

5285 Rore Royal Road

Springfield, V1rginia 22161

Price: Printed copy: $\$ 9.00$

ucroflche: $\$ 4.00$ 


\section{Demonstration of EIC's Copper Súlfate Process for Removal of Hydrogen Sulfide and Other Trace Contaminants from Geothermal Steam at Turbine Inlet Temperatures and Pressures}

Final Report

May 1980

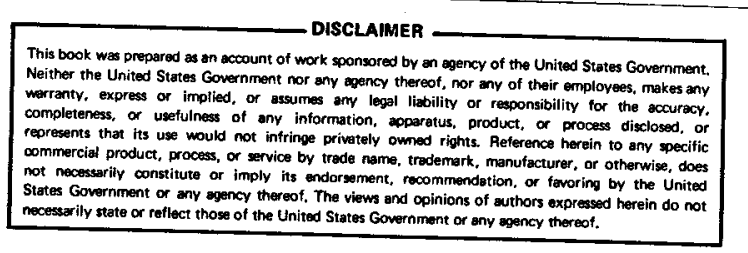

Prepared for:

U.S. Department of Energy

Assistant Secretary for Resource Applications

Washington, D.C. 20461

Prepared through:

EIC Corporation

Newtown, Massachusetts 02158

Under Cooperative Agreement No. FC03-78ET27181

Prepared by:

The Pacific Gas and Electric Company

Under Contract No. 5-36-78 
TABLE OF CONTENTS

$\underline{\text { Section }}$

$\underline{\text { Page }}$

vi

ACKNOWLEDGEMENTS .................. $\mathrm{x}$

1.0 INTRODUCTION ................. 1-1

2.0 BACKGROUND ................... 2-1

2.1 The Problem in Perspective. ... . . . . . . 2-1

2.2 Basis for EIC's Approach. . . . . . . . . 2-2

2.3 Initial Development Work............ 2-3

2.4 Objectives of the Subsequent Development

Work. . . . . . . . . . . . 2-4

2.5 Results of the Subsequent Development Work. . . 2-12

2.6 Detailed Test Objectives. . . . . . . . . 2-14

2.7 Overall Test Objectives . . . . . . . . 2-22

3.0 TEST RESULTS .................. 3-1

3.1 Field Test Facility Description .... . . . 3-1

3.2 Changes in the Test Set Up. ......... 3-7

3.3 Instrumentation and Analytical Techniques .... 3-9

3.4 Steam Composition ................. 3-11

3.5 Material Balance Considerations . . . . . 3-18

3.6 Hydrogen Sulfide and Ammonia Removal. . . . . 3-37

3.7 Scrubber Performance - Operability. . . . . . 3-40

3.8 Scrubber Performance - Efficiency . . . . . . 3-42

3.9 Scrubber Performance - Dynamics . . . . . . . 3-44

3.10 Scrubber Performance - Disentrainment . . . . 3-46

3.11 Operation of the Regeneration System. . . . . . 3-48

3.12 Regeneration Kinetics ............ 3-50

3.13 Liquid-Solid Separation Behavior. . . . . . 3-55

3.14 Purge Stream Treatment. . . . . . . . . 3-57

3.15 Fouling of Heat Transfer and Other Surfaces . . . 3-59

3.16 Materials of Construction Testing - Scrubber and Auxillaries ................. 3-61

3.17 Materials of Construction Evaluation - Other Components. . . . . . ...... 3-63

3.18 Materials Testing in the Scrubbed Steam . . . . 3-63

3.19 Corrosion of Downstream Piping. . . . . . . 3-65

4.0 UPDATED PROCESS DESIGN CRITERIA. . . . . . . . . 4-1 


\section{TABLE OF CONTENTS}

(continued)

Section

Page

5.0 UPDATED PLANT DESIGN AND COST ESTMMATE. . . . . . 5-1

5.1 Changes in System Configuration. ......... 5-1

5.2 System Description . . . . . . . . . . . 5-1

5.3 Capital and Operating Cost Estimates . . . . . . 5-4

5.4 Alternatives for Control of $\mathrm{H}_{2} \mathrm{~S}$ Emissions: . . . . 5-9 
LIST OF IILUSTRATIONS

Figures

$\underline{\text { Page }}$

1

Schematic description of the copper sulfate

process......................

2 Schematic description of 5 MW pilot plant. . . . . 3-2

3A Five MW pilot plant - scrubbing section. ....... 3-3

3B Five MW pilot plant - regeneration section . . . . . 3-4

3C Five MW pilot plant - neutralization section . . . . 3-5

4 Steam inlet conditions ................ 3-13

5 Steam inlet conditions .............. . . . . . . . . .

6 Hydrogen sulfide content of inlet steam. . . . . . 3-15

7 Ammonia content of inlet steam ............ 3-16

8 Boron content of inlet and outlet steams . . . . . . 3-17

9 Stoichiometry of the scrubbing reactions . . . . . 3-22

10 Stoichiometry of the scrubbing reactions . . . . . . 3-23

11 Boron content of makeup and purge. . . . . . . . 3-25

12 Aluminum content of makeup and purge . . . . . . 3-26

13 Arsentc content of makeup and purge. . . . . . . 3-27

14 Calcium content of makeup and purge. . . . . . . 3-28

$15 \quad$ Chromium content of makeup and purge . . . . . . . 3-29

16 Iron content of makeup and purge ......... 3-30

17 Magnesium content of makeup and purge. . . . . . 3-31

18 Nickel content of makeup and purge . . . . . . . 3-32 
LIST OF ILLUSTRATIONS

(continued)

Figure

Page

19

Potassium content of makeup and purge ..........

3-33

20

Silica content of makeup and purge. .......... 3-34

21

Sodium content of makeup and purge. . . . . . . . 3-35

22

$\mathrm{H}_{2} \mathrm{~S}$ content of the scrubbed steam . . . . . . . 3-38

23

$\mathrm{NH}_{3}$ content of the scrubbed steam .......... 3-39

24

Results of scrubber dynamics tests. . . . . . . 3-45

25

Results of a typical regeneration run ........ 3-49

26

0xygen pressure leach data. . . . . . . . . . . 3-51

27

Air pressure and ambient leach data . . . . . . . 3-52

28

Setting rate of purge slurry. . . . . . . . . 3-56

29

No. 7 Unit Conditions - 110 MW System ........... 5-2 
LIST OF TABLES

Table

Page

1

Task Descriptior for the Second Phase of the

Development Program. . . . . . . . . . . .

Sumary of Pilot Plant Measurements and Operational Information . . . . . . . . . . . . . .

Key Process Parameters to be Verified. . . . . . .

Copper Balance for the Test Campaign . . . . . . .

Amonium Sulfate Balance for the Test Campaign . . .

Trace Element Material Balances.

Scrubbing Efficlency Test of 10/7...........

Demister Efficiency Estimates. . . . . . . . . .

Regeneration Kinetic Data. . . . .........

Initial and Final Heat Transfer Coefficients . . . .

Coupon Corrosion Tests at Varlous Scrubber

Locations. . . . . . . . . . . . . . .

Corrosion In Scrubbed and Unscrubbed Steam . . . . .

Total Fixed Capital Investment Cost Estimate -

110 MW Commercial Plant. . . . . . . . . . . 
SUMMARY

This report discusses the results obtained during the operation of an integrated, one-tenth commercial scale pilot plant using EIC's copper sulfate process for the removal of hydrogen sulfide and other contaminants from geothermal steam at turbine upstream conditions. The tests took place over a six month period at Pacific Gas and Electric Company's Unit No. 7 at The Geysers Power Plant.

These tests were the final phase of a development effort which included the laboratory research and engineering design work which led to the design of the pilot plant. Broadly, the objectives of operating the pilot plant were to confirm the preliminary design criterla which had been developed, and provide data for their revisions, if appropriate, in a plant which contained all the elements of a comercial process using equipment of a size sufficient to provide valid scale-up data.

The test campaign was carried out in four phases: water testing; open circuit, 1.e., non integrated scrubbing, liquid-solid separation and regeneration testing; closed circuit short term; and closed circult long term testing. The steam was treated continuousiy at a rate of $100,0001 \mathrm{~b} / \mathrm{hr}$, In a 6 foot diameter scrubber. Make up copper sulfate was added and a purge flow of copper sulfide slurry was withdrawn continuously. The slurry was cooled and liquid-solld separation was carried out in a continuous decanter. Decopperization of the clear 1iquid purge was demonstrated in off line tests, but the thickened slurry was held in surge tankage for batchwise regenerations on site. Copper sulfate was regenerated, in two or three batches per day, in an agitated, jacketed 3500 gallon reactor using either compressed air or vaporized oxygen. About 50 tons of sulfide solids were regenerated over the course of the campaign, during which more than 125 million pounds of steam were treated in 1350 hours of integrated operation in 7 test serles.

It was determined early in the test campaign that the inlet steam conditions and compositions were highly varlable: direct calorimetry showed superheats as $\mathrm{high}$ as $18^{\circ} \mathrm{F}$, molsture contents as high as $1.1 \%$, and rates of change of steam enthalpy as high as one BTU/hr. Hydrogen sulfide and ammonia contents averaged approximately 250 and $150 \mathrm{ppm}$ respectively, but varied by as much as $\pm 50 \mathrm{ppm}$. The steam also contained approximately 40 ppm of boron, and lesser amounts of other elements of highly varying compositions.

Material balances carried out on the copper used in the process and ammonia scrubbed from the steam closed to within $2.2 \%$ and $2.6 \%$ respectively. 
The stolchiometry of the scrubbing reactions was shown, by materlal balance, to be consistent with the formation of sulfide solids with an average composition of $\mathrm{Cu}_{1.8} .8 \mathrm{~S}$ and the oxidation of an average of $10 \%$ of the hydrogen sulfide to elemental sulfur. Material balance calculations on the trace elements in the steam showed that approximately $75 \%$ of the arsenic, $50 \%$ of the boron, $40 \%$ of the potassium and silica, and $20 \%$ of the sodium in the inlet steam. were also removed.

Hydrogen sulfide removal efficiencies averaged approximately 97\% over the course of the test campaign: somewhat lower efficiencies were obtained during the earlier stages of testing while tray modifications were being carried out, while better results were obtalned as more operating experience was gained. Amnonia removal effictencles were lower, averaging $80 \%$, because the equilibrium back pressure of ammonia above the ammonium sulfate contalning scrub solutions limits the degree of removable possible. A serfes of scrubbing efficlency tests were carried out in which contact times were varied from 0.3 to 0.8 seconds. Hydrogen sulfide removal efficlencles ranged from $92.6 \%$ to $99.9 \%$ at tray pressure drops of $1 / 6$ PSI to $1 / 2$ PSI.

Scrubber operation was remarkably smooth throughout the campaign with no evidence of instability even during periods in which the steam condition was changing rapidly. A serles of dynamics tests were carried out In which steam flow rates were first reduced from full to half rate and then, after stabilization, from half to full rate in a matter of seconds. No instability occurred in these tests or in normal start up or shut down operations which usually required about one-half to one hour.

While the scrubber contact tray was shown to be stable over a wide range of operating conditions and not prone to fouling by precipitated sulfide solids, the tefion mesh demister originally provided was not effective in this service. Gaps developed between segments, disentrainment was Incomplete and relatively large amounts of acidic scrub solutions were carried Into downstream carbon steel piping causing severe corrosion. The amount of entrainment was eventually reduced by two orders of magnitude by using a titanium demister in series with the original one. Staged demisting with careful washing will be required in a comeircial scale system. Short term corrosion experiments carried out on both inlet steam and outlet steam after the Installation of the second demister indicated that the scrubbed steam was less corrosive to both stainless and carbon steels than the raw steam. Cycling-stress tests showed no difference in time to fallure between raw and scrubbed steam, but the blade materfals exposed to scrubbed steam were cleaner.

The scrubber and most trim. components were fabricated of C20cb3 alloy. This material did not prove to be suitable for this service, being subject to both crevice corrosion and corroston on the weld metal 
of joints which were not properly prepared. A slurry circulating pump, pipe spool, and tray blanking strips, as well as corrosion test coupons fabricated of titanium, were also evaluated and found to be entirely. suitable. All other components of the pilot plant which were exposed to process fluids at temperatures below about $250^{\circ} \mathrm{F}$ showed no evidence of corrosion, but titanium will be required in a commercial system for the scrubber and its trim.

Operation of the regeneration reactor and its auxiliaries met. or exceeded expectations in all respects. The regeneration reactions were rapid and essentially quantitative and no evidence of "rock dust" was found in the reactor effluent, although small amounts of sulfur and basic copper salts were present under some reaction conditions. Both compressed air and vaporized liquid oxygen were used in regeneration and the reaction rates are identical when the kinetics are normalized on the basis of oxygen partial pressure. Preleaching slurry in the reactor's surge tank at near ambient conditions was also shown to be effective. The use of an ambient preleaching step, and the elimination of the need for a polish leach reactor, will decrease costs in the regeneration section of a commercial plant.

Purge stream decopperization experiments were carried out off line in an ton exchange equipment vendor's pilot plant. These tests showed that at least $99.5 \%$ of the copper in the purge stream could be recovered using a weak anion exchange resin. This system is highly selective for copper, so that other impurities will be purged from the system. It can produce a highly concentrated stream of copper for recycle, and does not require the consumption of excessive amounts of chemicals for regeneration.

The operation of the decanter used in the liquid-solid separation of the purged slurry was without incident: no difficulties were experienced in restarting with settled solids in place after normal or emergency shutdowns. Overflow clarities were excellent, with solids contents below $10 \mathrm{ppm}$, at design conditions. Trouble-free operation was possible up to at least $30 \%$ above design overflow rates.

Severe fouling was observed on the hot end of the make-up copper sulfate side of the purge/make-up energy recovery exchanger due to the deposition of basic copper salts. Therefore, it will be necessary to restrict the maximum temperature of this stream to about $250^{\circ} \mathrm{F}$. No fouling was observed on any other heat transfer surface, or on the surface of any of the process vessels or piping throughout the plant.

While numerous minor changes were made in the pilot plant configuration to improve operability, none would have a major impact on the design criteria for a commercial plant. The possibility that titanium 
would be required in the scrubber and that a more elaborate demisting procedure would be needed had been foreseen. A significant result of the test campaign is the finding that while the inlet steam condition is highly variable, the process is stabla and can be controlled automatically to cope with a wide range of off-design conditions.

The design criteria derived from the operation of the pilot plant were used to estimate the capital and operating costs for a $110 \mathrm{MW}$ commercial plant for steam compositions at No. 7.Unit. The plant would consists of individual scrubbers for each $55 \mathrm{MW}$ turbine and a comon regeneration section to serve both. Capital costs were estimated to be $\$ 93 \mathrm{~kW}$ and are dominated by the cost of the titanium scrubber vessels. A more conservative approach to the fabrication of the scrubber vessels, using shop fabrication, and the use of additional disentrainment equipment would increase costs by $25-30 \%$.

Direct operating costs were estimated to be $1.2 \mathrm{mill} / \mathrm{kWh}$ and total operating costs, including capital charges at $18.5 \%$, were estimated to be $3.6 \mathrm{ml} 1 \mathrm{l} / \mathrm{kWh}$. While the estimated capital investment for the EIC process is somewhat higher than for alternative abatement techniques, both direct and total operating costs are significantly lower at comparable degrees of abatement.

All operations in the process have been demonstrated in the operation of a one-tenth commercial scale pilot plant. Consistently high degrees of hydrogen sulfide removal were obtained and the pilot plant proved to be stable and easy to operate. Operation of a commercial size demonstration plant for a longer period of time will be required, however, to verify the cost estimates, demonstrate that the proposed disentrainment technique is suitable, and provide further data on process parameters and reliability. 


\section{ACKNOWLEDGEMENTS}

The work presented in this report was carried out for The Pacific Gas and Electric Company under a cooperative agreement with the United States Department of Energy. The support of the Geothermal Energy Division of DOE and the United States Environmental Protection Agency in the funding of this work is gratefully acknowledged.

Mr. Gordon W. Allen of the Department of Engineering Research of PG\&E was program manager for this effort. The assistance of the following PG\&E departments is gratefully acknowledged: Civil Engineering, Electrical Engineering, Engineering Research, The Geysers Project Office, Law; Materials, Mechanical and Nuclear Engineering, North Bay Division, Plant Accounting, Siting, Station Construction, Steam Generation, and The Geysers Power Plant. The contributions of the Station Construction and The Geysers Power Plant departments in providing personnel for maintenance and operation during the test campaign were especially helpfull.

The Union 0il Company of California also supported these tests by supplying steam, services, and materials throughout.

Finally, the many contributions of the staff of the Engineering and Research Divisions of EIC Corporation, without whose support the program could not have been carried out, are gratefully acknowledged. 
This report describes work, carried out for the Pacific Gas and Electric Company under Contract No. 5-36-78, on the demonstration of EIC's copper sulfate process for the removal of hydrogen suifide and other contaminants from geothermal steam at turbine upstream conditions. The development of this technology has been carried out. In three phases. The basic process concept was demonstrated and preliminary kinetic data were obtained in the first phase, which consisted primarily of laboratory scale process development work. A second phase of work consisted of a complete series of experimental and analytical studies directed towards obtaining design data for the construction of a pilot scale plant. Operation of a small scale scrubbing unit on "real" geothermal steam at The Geysers was a key element in the second phase work. The third phase of the program, the results of which are reported here, comprised the procurement and construction of the pilot plant and its operation at PG\&E's Unit No. 7 at The Geysers Power Plant. The first two phases were sponsored by the Department of Energy (previously ERDA) while the third phase of the demonstration program was sponsored jointly by the Department of Energy and the Pacific Gas and Electric Company.

The results of the first two phases of the development program are reported in detail in the final report prepared for the Department of Energy under Contract No. EY-76-C-02-2730.*000, Control of Hydrogen Sulfide Emission from Geothermal Power Plants. Throughout this report, we will refer to supporting information presented in this earlier document in which the experimental and analytical design bases for the pilot plant are presented in great detail.

The program developed for the demonstration of EIC's copper sulfate process in an integrated configuration and at a size which is sufficient to obtain valid scale up data required the execution of 14 tasks.

Tasks 1 through 7 comprised the activities necessary to procure equipment, carry out the detailed engineering and prepare the site, insta11 the equipment and auxiliaries and carry out mechanical integrity testing.

Tasks 8 through 11 constituted the activities which took place during the field test work. The test phases included operator training and water testing, short term open and short term closed circuit testing, and long term closed circuit testing. 
Task 12 through 14 included the activities required for data reduction and analysis, post test equipment inspection, and preparation of a final report on the test work. The objectives of this final report are to fully document the configuration of the field test facility as finally installed and operated, summarize the test results obtained therein, and present updated final process design criteria and specifications for a commercial scale plant.

This report contains a brief summary of the background of the process development work and of the test objectives for the operation of the pilot plant. The test results are presented in detail for each unit process or operation in the integrated pilot plant and the revised process design criteria are presented. A comparative cost estimate has also been developed to illustrate the relative capital and operating costs for the EIC process vis-a-vis currently available alternatives.

Some of the process design criteria, and all economic considerations, are site specific and must be developed in detail based on the steam composition, site topography, hydrogen sulfide abatement requirements, and plant operating philosophy which are peculiar to each location. 


\subsection{BACKGROUND}

\subsection{The Problem in Perspective}

The most common gaseous contaminants of geothermal fluid are $\mathrm{CO}_{2}$, $\mathrm{H}_{2} \mathrm{~S}, \mathrm{NH}_{3}, \mathrm{H}_{3} \mathrm{BO}_{3}, \mathrm{CH}_{4}, \mathrm{H}_{2}$, and $\mathrm{N}_{2}$. Analyses vary widely from fleld to field but there is also a large variation from well to well in any given field and, over the course of time, for a particular well as fluid is withdrawn. In most cases however $\mathrm{CO}_{2}$ is the major constituent of the noncendensable gases. In addition, the steam contains varying amounts of inert, finely divided particulate material which tends to accumulate within the turbines reducing performance and eventually forces a shut down for removal.

In absolute terms the total daily discharge of hydrogen sulfide from an unabated geothermal power plant could be appreciable. However, the hydrogen sulfide would be dispersed so that toxic levels of this gas are not encountered in the air in the vicinity of the plants. Compounding the environmental affects of hydrogen sulfide emissions into the atmosphere is its well known corrosive behavior which leads to problems with the electrical and other gear in a conventionally designed plant.

The original power plants utilizing geothermal steam, whether dry steam as at Larderello or The Geysers or steam flashed from hot brine as at Wairake1 or Cerro Prieto, used relatively simple power cycles. Steam is expanded through a multi stage turbine and condensed in direct contact condensers. Mechanical draft cooling towers are used to remove the heat of condensation with excess water from the process blown down from the towers to reinjection in the steam field or to surface discharge. In these processes the hydrogen sulfide. becomes distributed among these streams: ejector vents, cooling tower evaporate, and cooling tower blow down.

If hydrogen sulfide is not removed from the steam prior to condensation, it must be removed separately from all of these streams. Processes for removing $\mathrm{H}_{2} \mathrm{~S}$ from the ejector vent gas, with Its high $\mathrm{CO}_{2}, \mathrm{H}_{2} \mathrm{~S}$, and water contents are widely known. These gases, which are at nearly ambient. conditions, can be treated effectively by techniques exemplified by the Stretford process. Unfortunately, in a direct contact condenser unit only about one-third of the hydrogen sulfide reports to the ejector vents and most of the remainder is stripped from the circulating water in the cooling tower and reports directly to the atmosphere to be dispersed. Attempts have 
been made to oxidize the dissolved sulfide in the circulating waters by using the ferric ion as an oxidation catalyst. While such techniques are capable of obtaining high degrees of abatement, severe operating difficulties are encountered by virtue of the deposition of iron sludges throughout the cooling tower and from corrosion problems.

In newer plants, a more complicated cycle is used in that the turbine exhaust is condensed on the shell side of a tubed condenser. This decreases the volume of condensate in contact with $\mathrm{H}_{2} \mathrm{~S}$ by more than an order of magnitude and forces a higher portion of the hydrogen sulfide into the ejector vent streams. However, a substantial portion of the hydrogen sulfide still dissolves in the condensate and supplemental abatement is required to obtain high degrees of overall hydrogen sulfide removal. Since the volume of condensate is lower and its hydrogen sulfide content is higher than in plants with direct contact condensers, more direct chemical oxidation schemes than those employing iron can be used, but most such approaches are inherently consumptive in expensive chemicals.

In any case, treatment of steam and condensate after passage through the turbines does not address the issue of pre-plant emissions. During the perlods in which an operating plant trips off line, steam is released directly to the atmosphere until such time as the steam supplier can shut in wells and/or divert steam to other operating power plants. If unabated, this steam can carry a significant amount of hydrogen sulfide into the atmosphere although such events are episodic. Nevertheless, an upstream abatement process, such as EIC's copper sulfate process, is inherently capable of coping with pre-plant emissions. Steam is vented to the atmosphere after passage through this scrubber Instead of being directed to the turbines.

\subsection{Basis for EIC's Approach}

The two properties of hydrogen sulfide which are obviously of use in constructing a process for its removal from geothermal steam are its relative ease of oxidation and ability to form slightly soluble solids with many simple metal tons. Hydrogen sulfide is also a weak acid and consequently may be removed efficiently. from a gas stream by a strong alkaline solution. While the latter approach is perhaps the most simple means of controlling hydrogen sulfide, the simultaneous absorption of carbon dioxide, which is generally present in large excess over hydrogen sulfide, makes this approach uneconomic unless careful attention is paid to the relative kinetics of the sorption of these two gases and/or a special situation exists with respect to the regeneration or disposal of used scrub solution. 
The Inftial process development efforts by EIC Corporation were based on removing hydrogen sulfide from geothermal steam at turbine upstream conditions with a solution of metal salt the cation of which would yield a very sparingly soluble sulfide precipitate. A relatively simple process could be configured which would consist of a scrubbing operation followed by a liquid-solid separation step to remove the precipitated sulfide. The scrubbing reagent would be regenerated by oxidation and recycled. Soluble reaction by-products and other materials removed from the steam would be purged from the process and, after suitable treatment, disposed of. A thorough review of the available data on the thermodynamics and kinetics of the sulfide system lead to the conclusion that copper is the most generally suitable metal for use in this application. In addition, a significant body of information existed on the hydrometallurgy of copper compounds which could be taken over and used to guide the process development effort.

\subsection{Initial Development Work}

The first phase of the development of the process consisted of laboratory scale studies in which geothermal steam was simulated by mixing hydrogen sulfide, amonia, and other gases from cylinders with steam raised in a small package boller. A two inch diameter scrubber was constructed and provided with auxiliaries to meter steam in and condense steam out and control the flowrate of makeup and recirculated scrub solution. Analytical techniques were developed to monitor and control the operation of the scrubber and analyze reaction products. A series of tests were carried out to obtain scoping information on the kinetics of the scrubbing step and to produce material for subsequent liquid-solid separation and regeneration studies.

Briefly, it was determined that the kinetics of the scrubbing reaction were extremely rapid and essentially quantitative removal of hydrogen sulfide could be obtained after passage through three or four feet of small diameter packing material. Maximum allowable velocities were far lower than would be predicted from conventional hydraulics correlations. These data, together with measured values of $\mathrm{k}_{\mathrm{g}} \mathrm{a}_{1}$ which were signiflcantly higher than calculated, lead to the conclusion that the system was surface active. This hypothesis was subsequently confirmed in runs with columns of larger diameter which were equipped with sight glass ports. After a number of trials on a variety of Internals styles, it was determined that a simple, single sieve tray containing $37 \%$ open area and fitted with a one inch diameter downcomer was capable of achleving both high scrubbing efficiency and reasonable steam velocities without showing a tendency to foul or accumulate solids. While depletion of copper sulfate in the recirculating scrub solution resulted in the cessation of hydrogen sulfide removal, no consistent effect on $\mathrm{H}_{2} \mathrm{~S}$ removal efficiency was found in solutions with copper concentrations varying from about 0.5 to $5 \mathrm{~g} / \mathrm{l}$. 
It was also determined that the hydrogen sulfide removal efficiency fell off significantly at scrub solution pHs below about one. Fortunately, the presence of amonium sulfate in the recirculating scrub solution, which results from the co-removal of ammonia from the steam, acts as a strong buffer at scrubber operating temperature to maintain the $\mathrm{pH}$ within the desired range. The concentration of ammonium sulfate cannot be allowed to increase without limit, however, due to hydrolysis and precipitation of basic copper sulfate compounds within the scrubber.

The physical characteristics of the sulfide solids formed are as significant as their chemical behavior in influencing the technical and economic feasibility of the process. As it turned out, the solids produced under scrubber conditions showed a natural tendency to flocculate and settle rapidly. Excellent overflow clarities were obtained along with reasonable underflow densities so that simple decantation could be used for liquidsolid separation. The ultimate particle size, however, was very small as would be anticipated for a rapid reaction between a dilute gaseous stream and a dilute solution constituent. Particle size analyses of sonically dispersed scrubber slurry showed the aggregates to have. sizes in the one to twenty micron range. The micro porosity of the scrubber solids rendered them prone to air oxidation in storage or drying, and they also proved to be relatively easy to regenerate by either oxygen-acid pressure leaching or by roasting under relatively mild process conditions.

Since the removal of soluble copper from a clear liquid purge stream was considered to be well known and documented technology, we demonstrated the essential characteristics of all steps in an integrated process which is shown schematically in Fig. 1.

\subsection{Objectives of the Subsequent Development Work}

The objective of the second phase of the development program was to obtain the mechanical and process design data needed for developing specifications for a demonstration scale plant. The laboratory data would serve as the bases for carrying out the detailed process and project engineering work leading to the specification of hardware for. the plant. In addition, process evaluation studies would be carried out to evaluate the technical and economic feasibility of alternative steps within the process and to insure that overall technical and economic viability would be assured.

To this end, a program consisting of 14 subtasks was carried out. The objectives, procedures, and output of each task are sumarized in Table 1.

Corrosion testing in the laboratory support studies was to be Iimited to austenitic stainless steels, since preliminary tests on these materials had been encouraging, and to scrubber conditions, which were felt to be the 


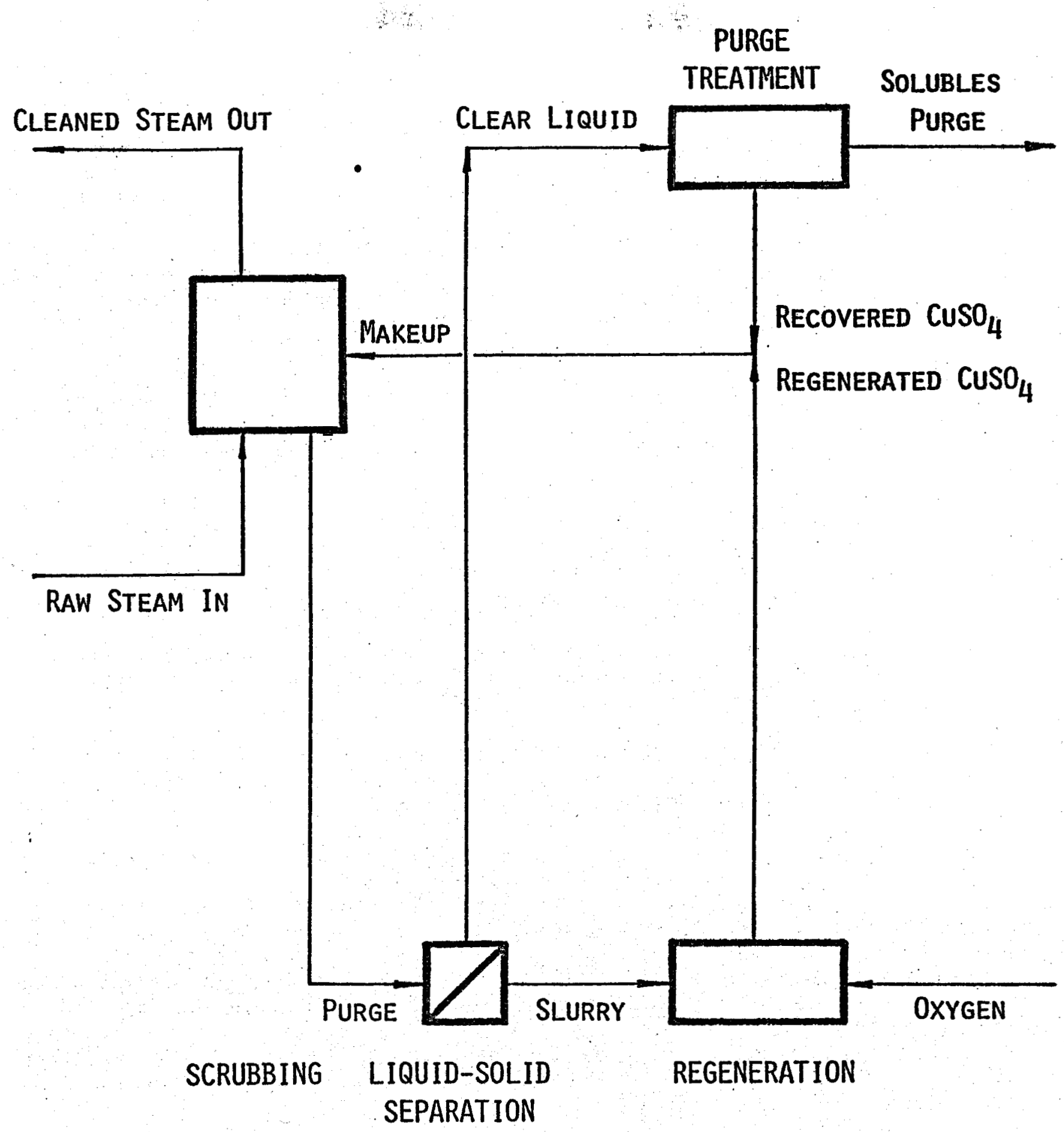

Fig. 1. Schematic description of the copper sulfate process. 
Table 1

Task Descriptions for the Second Phase of the Development Program

TASK A.1: Corrosion Studies of Austenitic Stainless Steels

Objective: To determine performance of austenitic stainless steels under scrubbing tower conditions, including stressed and welded materials.

Procedures: Coupon, volt-amperometric and corrosimeter testing in liquid and vapor compositions at conditions of temperature and pressure simulating the scrubbing tower.

Output: $\quad$ Reports of test and specification of materials of construction in the field unit scrubber

TASK A.2: Leach Regeneration Studies

Objective: To determine the rates and product stoichiometries for regeneration of $\mathrm{CuSO}_{4}$ from $\mathrm{Cu}_{n} \mathrm{~S}$ precipitated in the laboratory scrubber.

Procedures: Batch autoclave leaching of $\mathrm{Cu}_{n} \mathrm{~S}$ precipitated in the lab column under various temperatures, oxygen pressures, $\mathrm{pH}^{\prime} \mathrm{s}$ and salt concentrations.

Output: A report of test and specifications of design criteria for the field unit regeneration reactor.

TASK A.3: Filter-Leaf Filtration Studies

Objective: To determine the filtration rate for purge streams containing $\mathrm{Cu}_{\mathrm{n}} \mathrm{S}$ precipitated in the scrubber.

Procedures: $0.1 \mathrm{sq}$. ft. filter-leaf tests, with and without filter aid, on $\mathrm{Cu}_{\mathrm{n}} \mathrm{S} / \mathrm{CuSO}_{4} / \mathrm{H}_{2} \mathrm{SO}_{4}$-slurries produced in the $\mathrm{lab}$ column.

Output: A report of test and specifications for the configuration of the field unit filter system.

TASK A.4: Analytical Technique Development for Field Unit

Objective: To determine analytical techniques and procedures for process control and chemical analysis during operation of the field scrubber unit. 
(continued)

Procedures: Instrument and process control studies, vendor contact to set performance specifications, development of analytical procedures, as required, and calibration of instruments. on mixtures simulating various process streams.

Output: A report of tests and an analytical and control procedures document for the field test operating manual.

TASK B.1: Materials Testing

Objective: To identify suitable less expensive materials of construction for process equipment other than the scrubber tower.

Procedures: Coupon and corrosimeter testing in liquid and vapor compositions and at temperatures and pressures simulating all key process steps.

Output: A report of test and specifications of materials of construction for other process steps.

\section{TASK B.2: Roast Regeneration Studies}

Objective: To determine roasting conditions leading to control of extent of reaction and $\mathrm{CuO} / \mathrm{CuSO}_{4}$ ratio from roasting $\mathrm{Cu}_{\mathrm{n}} \mathrm{S}$ precipitated in the scrubber.

Procedures: Batch roasting in a laboratory oven under different temperatures and $\mathrm{SO}_{2} / \mathrm{O}_{2}$ pressures: Determination of roasting rates, $\mathrm{CuO} / \mathrm{CuSO}_{4}$ ratios and rates of solution In batch dissolution tests.

Output: A report of test with recommendations for conditions required in subsequent fluid-bed roasting tests.

TASK B.3: Liquid-Solid Separation Studies

Objective: To predict liquid-solid separation rates in thickeners, centrifuges, and vacuum filters.

Procedures: Liter-cylinder sedimentation tests, bench centrifugation tests, and vacuum filtration tests on $\mathrm{Cu}_{n} \mathrm{~S} / \mathrm{CuSO}_{4} / \mathrm{H}_{2} \mathrm{SO}_{4}$ slurries precipitated in the laboratory scrubber. 
Table 1

(continued)

Output: A report of test with recommendations for the optimum type of liquid solid separation device for commerclal use.

TASK B.4: Scrubber Configuration Studies

Objective: To determine the performance characteristics of alternative scrubbing techniques.

Procedures: Testing of alternative internals (packing and tray types) in a $4^{\prime \prime}$ laboratory column and of a venturi scrubber to determine mass transfer efficiency and fouling rates.

Output: A report of test and a technical and economic evaluation of the use of tested alternatives for commercial use.

TASK C.1: Program Definition

Objective: To determine the objectives for the field test unit, fix a site for design purposes, and set program schedules.

Procedures: Coordination and review with DOE personnel and a site operator by EIC Corporation project personnel.

Output: Selection of a test site, establishment of reporting procedures and resolution of interface responsibilities.

TASK C.2: 8" Column Design and Operation

Objective: To design, fabricate, install and operate an 8" scrubber at the field test site so as to confirm laboratory results for the design of the field test facility.

Procedures: Engineering work will be done to specify requirements for the system. A design/fabrication firm will be selected and the system purchased. Supervision will be provided for installation at the selected site, mechanical and process testing, and data reduction and analysis. 
Table 1

(continued)

Output: Delivery to the selected site of an 8" scrubber unit and its operation for a sufficient time to confirm preliminary criteria obtained from lab data. A report of data obtained from the unit and its relation to lab results and field test unit design.

TASK C. 3: Preliminary Project and Process Engineering

Objective: To determine critical operations, steps, design requirements, equipment deliveries, and needs for additional lab work and to develop a preliminary design for a field test facility.

Procedures: Engineering work done to: assemble preliminary design criteria from known practice; prepare preliminary flow sheets and material/energy balances; develop preliminary materials selection; evaluate the impact of alternative site compositions on process conditions.

Output: $\quad$ Preparation of the outlines of a process engineering specifications document with assignment of preliminary values to process design criteria.

TASK C.4: Detalled Project and Process Engineering

Objective: To carry out process and project engineering for the final, detalled design of the field test facility. Preparation of cost estimates and a bid package for the test unit.

Procedures: Engineering work done to review all data, leading to the final selection of materials, definition of final flow sheets and material/energy balances, specifications of all equipment and auxiliaries including plping and instrumentation diagrams, and preliminary definition of safety and operating procedures.

Output: Updating of the process engineering specifications with final criteria. A bid package(s) containing descriptions of all hardware and system requirements for use as a basts for RFP's. 
Table 1

(continued)

TASK C.5: Test Plan Preparation

Objective: To develop a test plan for the field test unit to obtain required scale-up information.

Procedures: Engineering work to develop a detailed test plan for operating the field test unit under a variety of conditions to obtain design and scale-up information. Analysis of the impact of alternative site compositions on system design and operation.

Output: An operating manual for the field test unit, including test schedules and procedures, safety requirements, analytical procedures, etc.

TASK C.6: Optimization and Economics Studies

Objective: To determine optimum system configuration for varlous sites and to develop the economics of the process for commercial use.

Procedures: Process engineering studies reviewing material/energy balances and design criteria impacts on system capital and operating costs.

Output: Final updating of the process engineering spectfications. Preparation of a formal cost estimate and process description document. 
most severe which would be encountered in the process. Emphasis would be placed on coupon testing of plain, welded, stressed, and creviced specimens in solutions with a range of composition which bracketed those expected in an integrated process.

Leach-regeneration studies were to be carried out batchwise in small autoclaves under conditions in which gas phase mass transfer would not limit reaction rates. Reaction stolchiometries would be used to develop the overall process material balance, and the kinetic data would be used to fix process conditions as well as to develop specifications for the regeneration reactor volume and agitator power.

The filtration studies, carried out with an $0.1 \mathrm{sq}$. ft. test leaf, would be used to obtain solid and liquid filtration rates and cake densities in order to develop specifications for the filtration cycle, filter area, and filter volume required for the demonstration plant.

Some analytical technique development was also required to insure that analytical procedures, sensing elements and control hardware required for operation of the demonstration plant would be avallable. Of particular concern were the requirements for rellable on-stream analysis and control of the scrubbing solution's copper content and acidity.

Materials testing in the process engineering studies, using coupon weight loss (gain) and stress-deflection tests, were to be directed towards determining the suitability of various materials under process conditions external to the scrubber. A variety of composite materials and elastomers was to be tested in order to find acceptable low cost alternatives to stainless steel.

A series of roast-regeneration studies was to be carried out to obtain scoping information on process conditions and kinetics. These data would be used as the bases for recomending operating conditions in subsequent small-scale fluid bed roasting tests and for economic evaluation studies. Additional liquid-solid separation studies would also be carried out to obtain design data for types of devices, e.g., centrifuges, not contemplated for use in the demonstration plant but which might prove suitable for use at a commercial scale.

Finally, a series of scrubbing tests would be carried out to determine the performance of alternative types of scrubbers or styles of scrubber internals. These data would be used in technical and economic evaluations to determine the optimum type of scrubber for comercial service.

The first engineering task to be carried out under the program just outlined would involve program definitions; a site was to be selected and 
objectives, criteria, schedules, and interface responsibilities fixed. Then, a small ( 8 " diameter) modular scrubber unit was to be designed, fabricated, and tested at the selected site in order to confirm the preliminary criteria developed from laboratory data by scrubbing "real" geothermal steam.

Data from the laboratory support studies and $8^{\prime \prime}$ scrubber field tests were to be used as the bases for the preliminary and then detailed process and project engineering work required for the design of the demonstration plant. Material and energy balances were to be developed, materials selection studies carried out, process flow sheets and piping and instrumentation diagrams prepared, equipment process and mechanical design criteria established, and required site preparation work and services defined.

This information would fully define the proposed demonstration plant in terms of configuration, design bases and mode of operation, and would permit a detailed cost estimate to be developed. The mode of operation would fix the manner in which the test operation would be carried out in verifying the assumed design criteria.

A- formal test plan and operating instructions document was to be prepared which would present the scope of the field test, its duration, test and data reduction procedures, start up and shut down instructions, safety requirements, etc. Finally, a series of optimization and economics studies was to be carried out to determine the optimum system configuration(s) at a cormercial scale of operation, the impact of operation on steams of differing composition, the estimated capital and operating costs for the process, and its performance vis-a-vis alternative hydrogen sulfide abatement technologies.

\subsection{Results of the Subsequent Development Work}

As a result of the experimental and analytical studies, it was shown that austenitic stainless steels could be passivated by the presence of 1-2 $\mathrm{g} / \mathrm{l}$ of copper at scrubber conditions if the acidity of the solutions is limited to $\mathrm{pH}>\sim \mathrm{I}$. Since $\mathrm{C} 2 \mathrm{CCb} 3$ alloy maintained passivity at higher acidities than other stainless alloys it was specified as the material of construction for the demonstration plant scrubber and its trim. However, all stainless steels were shown to be subject to crevice corrosion and titanium was specifled as a backup material. Type 304 stainless steel was shown to be suitable for all uses up to at least $250^{\circ} \mathrm{F}$, and composites of fiberglas reinforced vinyl esters were suitable for use at temperatures up to at least $120^{\circ} \mathrm{F}$ and for short term exposure to $210^{\circ} \mathrm{F}$.

The solids precipitated in the scrubber at turbine upstream conditions were found to consist of aggregates of fine particles of nonstoichiometric compounds with a composition $\mathrm{Cu}_{\mathrm{n}} \mathrm{S}$, with $\mathrm{n}$ v1.6-1.9. Copper sulfate can be regenerated easily from the solids under mild process conditions, e.g., 99\% 


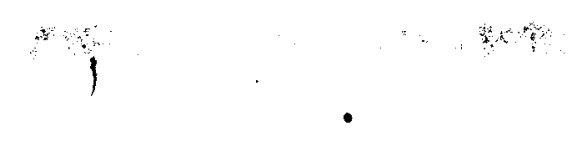

regeneration can be obtained in one and one half hours at $250^{\circ} \mathrm{F}$ under an oxygen partial pressure of 100 psi. An agitated pressure leach reactor was specified for the pilot plant which would be suitable for use with either compressed air or vaporized liquid oxygen. In addition, the slurry surge tank was fitted with a gas-liquid contactor which permitted a preleaching step to be carried out at near ambient conditions if desired. The material also proved to be amenable to regeneration by roasting under relatively mild process conditions, e.g., $800^{\circ} \mathrm{F}$, at 10 to 15 minutes residence time. However, the reaction products consisted of basic copper sulfate salts which would then have to be redissolved in hot acid prior to recycle, and the feed material would require dewatering to at least $50 \%$ solids to permit autogeneous roasting.

The solid aggregates settled rapidly and filtered easily but low slurry and cake densities were obtained. Cake moisture contents low enough to permit autogeneous roasting would require the use of centrifuges. Detention times of less than two minutes and up flow velocities as high as $30^{\circ}$ /hour would provide the required slurry densities and overflow clarities in a simple decanter.

The scrubber specifled for the pilot plant contained a single crossflow sleve tray since this style of contact has been shown to be least costly if high degrees of hydrogen sulfide removal are desired. Spray or shower tray columns or venturi contactors would also be operable and if a single stage venturi could achieve high removal efficiencles it would be a very attractive alternative to the use of a sieve tray column. Whatever style of contactor is used, it will be necessary to control the acidity and copper content of the scrub solution to maintain both high degrees of $\mathrm{H}_{2} \mathrm{~S}$ removal and the passivity of stainless steels. A Teledyne photometric analyzer had proved, in laboratory tests, to be an effective, stable device for measuring the copper concentrations of simulated purge streams. It was specified for use in the pilot plant to control the flow rate of makeup copper sulfate to the scrubber. A Great Lakes $\mathrm{pH}$ analyzer with a suitable Internal reference solution was to be used to monitor the $\mathrm{pH}$ of the purge stream, which would be in the range $\sim 1<\mathrm{pH}<2$.

A process engineering and economic evaluation of the process concept was carried out for a commerctal scale operation under The Geysers conditions. For a power plant consisting of two $55 \mathrm{MW}$ turbine generators, the system would consist of Individual upstream scrubbers, with individual heat exchange and liquid-solid separation components. A common regeneration faclitiy would serve two scrubbers. Regeneration would involve a sequence of near ambient air preleaching, oxygen pressure leaching, and a pollsh leaching step to purge insoluble solids from the system. Soluble impurities would be removed following neutralization of the purge stream with ammonia and decopperization by solid Ion exchange. 
Equipment descriptions were developed for a 110 MW plant based on its material and energy balance and the design criteria which were used for the construction of the pilot plant. Factored capital and detailed operating costs estimates were made and a preliminary evaluation of the performance and cost of alternative abatement techniques was carried out. Fixed capital investment for a commercial plant capable of obtaining $99 \%$ hydrogen sulfide removal, including removal from steam that is vented during tripouts, were estimated to be about $\$ 50 / \mathrm{kW}$ (1978 \$). Direct operating cost were approximately $0.6 \mathrm{mills} / \mathrm{kWhr}$ and total operating costs, including capital recovery charges, were about $1.8 \mathrm{mills} / \mathrm{kWhr}$. These costs were significantly lower than for downstream abatement processes at comparable degrees of $\mathrm{H}_{2} \mathrm{~S}$ removal, since the latter had to be supplemented by standby vent and supplemental condensate abatement processes.

\subsection{Detailed Test Objectives}

Development of a test program for demonstrating the process design criteria was carried out in the face of conflicting requirements. On the one hand, the tests had to be carried out at stable operating conditions for a sufficiently long period to demonstrate unequivocally the appropriateness of the preliminary design criteria: on the other hand, for reasons of economy, the test program had to be limited and a wide range of process conditions had to be investigated to demonstrate system operability over the potential ranges anticipated in commercial service. In response to these needs the pilot plant test campaign was carried out in four phases:

- Water test phase.

- Open circuit scrub, liquid-solid separation, and regeneration tests.

- Closed circuit, short term testing over a wide range of operating conditions.

- Closed circuit, long term testing at optimal operating conditions.

The measurements which were made during the test program, the information derived from them, and their impact of scale up are summarized in Table 2 .

\section{Water Tests}

In the first phase of testing, geothermal steam was passed through the scrubbing tower but "scrubbing" was done with water containing neither acids nor copper sulfate. The objectives of this test were to demonstrate system 


\section{Table 2}

\section{Summary of Pilot Plant Measurements and Operational Information}

\section{Measurements Made}

Steam and scrub solution flow rates, scrubber pressure, $\Delta P$ (water flow tests).

Steam, scrub, makeup, and purge flow rates. Steam quality (water flow tests).

Exft steam quality, steam flow rates, L/G ratio, scrub rate (water flow tests).

Purge, makeup flow rates and temepratures (water flow tests).

Steam flow rate and compositions, makeup and purge flow rates and compositions.

\section{Information Derived}

Pressure drops as a function of operating conditions for clean service.

Scrubber material balance.

Entraimment level as a function of operating conditions, demister design.

Energy balance on recovery exchangers and cooler.

System materlal balances for $\mathrm{S}^{\circ}, \mathrm{NH}_{3}, \mathrm{SO}_{4}=, \mathrm{Cu}, \mathrm{B}$, solids in steam, etc., as a function of operating conditions.

\section{Impact on Scaleup}

Establish a reference case for scrubber hydraulics, against which performance in service will be rated.

Establishes scrubber energy balance.

Determines extent of copper loss by this mechanism, as well as potential impact on corrosion of down stream equipment.

Establishes clean service heat-transfer coefficients for comparison with calculated values and as a reference for determining the rate of fouling.

Determines rates and extents of removal of $\mathrm{NH}_{3}, \mathrm{H}_{2} \mathrm{~S}$, and other impurities as a function of operating conditions and Internals design changes. Confirms rate data established on lab columns and influence of $\mathrm{pH}$, and $\mathrm{CuSO}_{4}$ content on scrubbing effectiveness. Determines influence of velocities, L/G ratio, temperature, etc., at a scale of internals design which permits reliable extrapolation to commercial size. 


\section{Measurements Made}

Tray and demister $\Delta P$ as a function of time. Visual inspection of tray and demister condition.

Composition and size distribution of precipitated sulfides.

Test coupon weight loss, corrosimeter reading. Buildup of precipitated solids in the tower.

Rates-of-change of flow rates, pressure drops, temperature/ pressure, etc. (water tests).

Rates-of-change of steam makeup, and purge compositions and rates.

\section{Information Derived}

Relation between extent of fouling and scrubber hydraulics. Rate of fouling.

Process chemistry. Influence of operating conditions, system composition on nature of products formed.

Rate of corrosion for test materials as. a function of operating environment.

Propensity of various materials to foul.

Scrubber dynamic response to upsets in controlled variables. Limits of stable operation.

Scrubbing system dynamic response to upsets in controlled variables. Influence of operating conditions on stability.

\section{Impact on Scaleup}

Determines operability of various internals designs. Establishes service requirements and provides information on the effects of operating conditions on the rate of fouling.

Determines extent to which scrubber operation may be manipulated to influence process conditions in the subsequent regeneration steps. Permits correlation between form and composition of precipitated and scrubbed solids and rate of fouling of tower internals.

Confirms laboratory tests establishing suitability of materials of construction. Provides information on the influence of trace constituents on corrosion rate.

Confirms suitability of proposed systemhydraulics control philosophy, in view of expected magnitude of fluctuations of steam rate and pressure and required delivery condition.

Determines capacity of proposed system to meet removal requirements in view of expected magnitude of fluctuations of steam rate and composition, and operating requirements necessary to insure compliance with performance specifications. 


\section{Measurements Made}

Flow rates and temperatures of makeup and purge streans.

Extent of buildup of solids. Loss of metal in pumps, valves, meters, Iines, tanks, etc.

Change in solids size distribution and character in storage.

Solids contents of over underflow streams from decanter.

Off-line tests on Iiquid/solid separation.

\section{Information Derived}

Energy balance on recovery exchangers and cooler under process conditions.

Extent and rates of fouling and corrosion of system components under operating conditions.

Effect of storage temperature and time on solids properties.

Settling rate and overflow clarity for scrüb solution produced under varying conditions and at various flow rates.

Solid settling rates and compression points in liter cylinders, influence of flocculants, etc.

\section{Impact on Scaleup}

Determines rate of fouling of heat transfer surfaces. Provides information on the influence of temperature, velocity, composition, materials of construction, and solids characteristics of fouling.

Confirms laboratory tests determining suitability of materials of construction. Provides information on the influence of velocity and compositions on corrosionerosion-buildup. Indicates suitability of control hardware.

Determines influence of holding conditions on subsequent process steps. Provides information on the influence of trace constituents.

Defines scaleup parameters for a con-" tinuous decanter. Indicates stability of system to upsets caused by varying over and underflow rates and inlet solids densities and purge solution compositions, temperature, etc.

Determines setting behavior on real slurries. Results can be scaled up to determine commercial-size requirements. 
Measurements Made

Filtrate compositions.

Separated solids physical properties: density, pumping Iimit, cohesion/stickiness, etc.

\begin{abstract}
Regeneration reactor slurry composition, temperature, pressure, $\mathrm{O}_{2} / \mathrm{air}$ flow rates, vent gas composition, agitation conditions.
\end{abstract}

Leached slurry flow rate and temperatures (water flow tests).

Leached slurry flow rate and temperatures.

\section{Information Derived}

Influences of operating conditions, characteristics of solids on clarity.

Influence of operating conditions on external properties for fresh/aged/wet/dried solids.

System material balance for $\mathrm{s}^{--}, \mathrm{S}^{\circ}, \mathrm{SO}_{4}^{--}, \mathrm{Cu}$, and others as a function of operating conditions. Rate and extent of regeneration of precipitated sulfides.

Energy balance on cooler.

Energy balance on cooler under process conditions.

\section{Impact on Scaleup}

Determines non-soluble copper loss at the liquid/solid separation step (done for both on- and off-line tests). Indicates necessity of subsequent treatment steps, e.g., neutralization, prior to disposal, as well as possible methods.

Will determine how separated solids will be transferred from separation to regeneration steps at commercial scale. Data derived from both on- and off-line tests.

Confirms laboratory data on the rates and stoichiometry of aqueous sulfide oxidation and influence of solution composition.

Establishes influence of agitation on mass transfer in equipment of scalable size. Provides information on the effects of trace constituents.

Establishes clean service heat transfer coefficients for comparison with calculated values and as a reference for determining the rate of fouling.

Determines rate of fouling of heat transfer surfaces. Provides information on the influence of operating conditions on the rate and extent of fouling. 
(continued)

Measurements Made

Leached solids size distribution and characteristics.

LIquid/solid separation behavior; polish filters flow rate, pressure drop.

Waste solids composition and properties.

Makeup copper, amonia, and ammonium sulfate addition rates.

Rates of water addition to process streams at all points of the system.

Power input to all motors.

Rate of removal of Cu from purge stream by solid ion exchange (off-IIne test).

\section{Information Derived}

Effect of regeneration operating conditions, system properties, cooling rate, etc., on solids properties.

Same as for liquid/solid separation of precipitated sulfides.

Physical and chemical stability of process solid wastes. Influence of process conditions on fresh/aged/wet/dried solids.

Material balance on $\mathrm{Cu}, \mathrm{NH}_{3}$, and $\mathrm{SO}_{4}^{--}$requirements.

System water balance.

System operating power requirements:

Materials consumption, degree of recovery of $\mathrm{Cu}$.

\section{Impact on Scaleup}

Determines influence of regeneration conditions on subsequent process steps.

Provides information on the influence of trace constituents.

Same as for liquid/solid separation of precipitated sulfides. Both on- and offline testing will be carried out.

Determines how waste solids will be transferred from separation to disposal steps at commercial scale as well as posstble methods of disposal. Information required on properties of solids generated in offIne tests as well. Provides data on effects of operating conditions on waste properties.

Confirms overall system material balances based on other stream composition measurements.

Fixes liquid waste purge requirements at commercial scale and the relationship to operating conditions, e.g., heat loss, demister wash requirements, etc.

Determines process power requirements, especially for leach reactor in gassed and ungassed conditions.

Defines loss of $\mathrm{Cu}$ in purge streams for this recovery technique, indicates need for further treatment. 
mechanical integrity with a minimum of safety hazards or other operational problems and to obtain data on the system in a clean condition. System behavior, when clean, would be used as a reference condition since it was anticipated that fouling might occur when precipitated sulfides were circulated throughout the system. Barring mechanical difficulties, it was anticipated that the duration of this phase would be relatively short, less than a month; it would be extended only if required for training operators or modifying equipment.

\section{Open Circuit Tests}

The second phase of testing involved open circuit demonstration of scrubbing, 1iquid-solid separation, and regeneration. Open circuit testing on the scrubber module, for instance, entailed use of makeup scrub solution derived directly from purchased copper and ammonium sulfate and continuous purging of depleted scrub solution without regard to the requirements of separation and makeup. The objectives of this test were to demonstrate stable operation of the. scrubber under carefully controlled conditions and to carry out a limited investigation of the effects of process conditions (temperature, pressure, 1iquid-to-gas ratios, copper content, $\mathrm{pH}$, etc.) on scrubber efficiency.

Open circuit liquid-solid separation tests were carried out in conjunction with the open circuit scrubbing tests. The objective of these tests was to determine the behavior of the solids produced by the scrubbing tower as a function of tower and decanter operating conditions such as temperature, slurry density, underflow density, etc. In addition, offline testing was carried out to obtain basic data on settling rates to confirm the fundamental design bases for the decanter.

Solids produced during the open circuit separation testing were used to determine the basic parameters for operation of the regeneration reactor. The effects of temperature, pressure, excess air, $\mathrm{pH}$, residence time, and agitation on reaction rates and stoichiometry were determined for solids produced under varying conditions in the tower. The effects of reactor operating conditions on the nature of residues produced and their liquid-solid separation characteristics was also determined.

Following the open circuit tests, the plant was run for a short duration in the water test mode to determine the rates of fouling and was cleaned and flushed prior to initiation of continuous, closed circuit testing.

\section{Closed Circuit, Short Term Tests}

Closed circuit, short term testing was carried out to demonstrate plant operability and dynamics under integrated conditions. Operating procedures 
were confirmed during this period to insure that longer periods of testing, scheduled to follow, could be carried out in an orderly manner. The plant was operated at the extremes of anticipated operating conditions in order to demonstrate operability and obtain scoping data for subsequent test work. The plant was operated in a closed circuit mode for a sufficient time, approximately one month, to systematically explore the effects of operating parameters on overall performance. An object of this phase of the program was to obtain data which might be used to extrapolate operation to conditions not considered "optimu" for the site chosen as well as to obtain copper sulfides in significant quantities for evaluation and off-line liquid-solid separation and regeneration testing if required. Water testing followed integrated closed circuit short term testing and the plant was inspected, cleaned, and modified as required.

\section{Closed Circuit, Long Term Testing}

The final months of the test program were to be devoted to a long term, continuous test under conditions controlled about the point determined as "optimum" for operation at the test site. The objectives of this test were to demonstrate plant operability, confirm design criteria, and measure rates of fouling under steady conditions, 1.e., without ambiquities introduced by operation under a variety of test conditions. In the event, it proved to be extremely difficult to achieve steady test conditions because of the extreme variability in steam condition and composition and the continuing need to make minor modifications to the plant to eliminate operating difficulties. These difficulties and their consequences will be discussed in more detall in the next section.

The data which were gathered, summarized in Table 2, provided overall material and energy balances for the process as well as a compilation of information on the operating characteristics of the key elements of the system; the scrubbing tower, decanter, and regeneration reactor. Flow rates, temperatures, and pressures were measured by instrumentation provided as a part of the pilot plant equipment package. Samples were drawn from the process streams, as appropriate, and analyzed in equipment Installed at the site to provide information for process control and interpretation of the results. Analytical instrumentation, including a portable corrosimeter, spectrophotometer, and required wet chemistry hardware were installed and calibrated in a field laboratory. The required experimental procedures were developed and confirmed the the laboratory prior to their use in the field. Speclalized analytical procedures, such as petrographic examination of precipitated sulfides, EDX analyses of solids, determination of the concentration of trace elements, etc. were carried out off site. 
A detailed description of the tasks required to achieve these objectives including procedures for startup, shutdown, operation, and data collection, reduction and evaluation is presented in the phase two final report.

A series of 45 determinations to be made during the test operations and the corresponding operational measurements to be carried out was developed. A data acquisition $10 \mathrm{~g}$, operating logs, and a troubleshooting guide were prepared and were used throughout the test with only minor modifications. Equipment performance correlations for data reduction, thermochemical data, instrumentation calibration procedures, spare parts 1 ists and maintenance instructions, manufacturers literature, and safety procedures were also developed and documented and used throughout the test campaign.

\subsection{Overall Test Objectives}

The immediate objectives of the operation of the pilot plant were to demonstrate the process concept and verify the assumed process and mechanical design criteria in equipment of scalable size. If the assumed criteria were found to be inapproprlate, data would be obtained which would lead to the development of supportable criteria for the design of a commercial plant. The laboratory and pilot scale tests work which had been carried out prior to operation of the pilot plant allowed a more confident definition for some of the criteria than others. Furthermore, the consequences of the revision to a more conservative criteria, e.g., halving maximum allowable velocity, would be more significant for some items than for others because of their relative costs and process significance. Doubling the required decanter area for example would cost little but increasing the scrubber diameter by $40 \%$ would be very costly. On the other hand, doubling the required froth height, to obtain the equivalent contact time at a fixed scrubber diameter, would not impose unacceptable cost increases. The key criteria which we were seeking to verify in the field tests, possible operating problems which we envisioned, and design alternatives are summarized in Table 3. The order in which they are listed is, roughly, the order of their importance from the economic and process operability points of view.

Because a key process objective is to obtain both high degrees of $\mathrm{H}_{2} \mathrm{~S}$ removal and high reliability, criteria which effect the scrubber design and operation are of critical importance. In particular, it was deemed important to demonstrate that the scrubber could operate with stability for long periods of time with a minimum of attention, maintain a high degree of $\mathrm{H}_{2} \mathrm{~S}$ removal efficiency during process upsets, and respond to control point changes necessitated by varying steam compositions of flow rates. The scrubber and its trim components must show adequate resistance to failure by corrosion whether from ambient $\mathrm{H}_{2} \mathrm{~S}$ or from process fluid, and prove not to be prone to operability problems brought about by fouling. In addition, operation of the 


\section{Table 3}

\section{Key Process Parameters to be Verified}

\section{Criteria}

Scrubber and Trim Materials of Construction.

Demister Specification

Scrubber Tray Design

Process Control Concept

Regeneration Reactor Effectiveness

Purge Decopperization Efficlency

Trim Components Mechanical Integrity

Heat Exchangers Fouling Factor

\section{Posstble Problems}

Crevice corrosion of $\mathrm{C2OCb} 3$.

Fouling, high pressure drop, inefficient operations.

Fouling, lower than expected efficlency, narrow operating range.

Narrow operating range, onIine analytical difficulties, intermittent operability problems.

By-passing of solids, low conversion efficlency, low gased density/frothing.

Poisoning by trace elements, poor chemical/mechanical stability.

Seal failure, erosion/corrosion.

Rapid fouling.

\section{Design Alternatives}

Redesign to eliminate crevices. Specify use of lining material or TI.

Revise washing schedule/technique. Specify lower velocity, alternative style. Redesign for external separator.

Revise tray layout, downcomer area, froth height, operating conditions. Specify alternative scrubber type.

Specify alternative hardware. Revise control philosophy.

Redesign Internals, reduce agitation intensity. Specify staged vessels or solids recycle.

Revise operating conditions. Remove trace elements. Specify alternative resin or alternative decopperization technique.

Specify alternative styles, materials.

Revise operating conditions. Forego energy recovery. 
leach regeneration and purge stream decopperization steps must be shown to be effective under wide variety of process conditions so that the results can be extrapolated to continuous operation at a commercial scale with confidence. It was possible to envision design alternatives which would rectify any potential operation problem brought about through the use of Inappropriate design criteria although some changes would have an adverse effect on process economics. The design of the pllot plant was carried out in such a way to permit maximum flexibility in its operation. It was anticipated that if unforeseen operating problems occurred they would be rectified quickly with the necessary plant design changes made with a minimum additional cost and loss of time. 


\subsection{TEST RESULTS}

\subsection{Field Test Facility Description}

A schematic description of the pilot plant, with the base case material balance, is shown in Fig. 2, Dwg. SD-0017A. Piping and instrumentation drawings for the system, as operated, are presented in drawings SD-0012-SD-0014, Figs. 3A, B and C.

The minimum sized equipment which could be used to derive data that would be useful for scale up to a commercial size system with confidence would require a steam flow rate of at least $20,000 \mathrm{lbs} / \mathrm{hr}$ ( $1 \mathrm{MW}$ ). It was felt that a facility designed to treat $100,000 \mathrm{lb} / \mathrm{hr}$ of raw steam (5 MW) would yield information at a higher degree of confidence. Not only would the equipment be closer to commercial scale but more raw steam would be processed in a test campaign of fixed duration. Material and energy balances carried out for such a facility called for a purge from the scrubbing tower of $\sim 7$ gallons per minute for the removal of $25 \mathrm{lbs} / \mathrm{hr}$ of hydrogen sulfide from the steam. This stream, carrying of the order of $90 \mathrm{lbs} / \mathrm{hr}$ of precipitated sulfides, was too small to treat in a continuous manner and yield reliable data on the kinetics of the regeneration step. Also, a father intensive labor input would have been required to monitor a continuous operation. Such an effort would have been incompatible with the scale of attention required for the operation of a continuous scrubbing system. Thus, based on the equipment limitations dictated by the scale of operation and on the requirement for developing a system with a maximum degree of flexibility, the field test facility was configured so as to consist of continuous scrubbing and liquid-solid separation and a batch regeneration step. Utilization of batch kinetic data for the design of continuous reactors is considered routine.

The system may be described conveniently as consisting of three modules: a scrubbing and liquid-solid separation module, a regeneration module, and a service module. The first module, shown in Dwg. SD-0012 consisted of a system for the continuous removal of hydrogen sulfide from geothermal steam, an energy recovery operation, and a liquid-solid separation step. Regenerated copper sulfate solution was transferred from tank T102 by pump P102 through energy recovery exchanger HX101 to the scrubbing tower. Hydrogen sulfide was removed from the steam in the scrubbing tower C101 by countercurrent contact with scrubbing fluid made up of fresh regenerated solution and recycled slurry transferred by pump P101.

The flow rate of steam to the system was controlled by ateam flow rate recorder controller loop FC101. The flow rate of recirculated scrubbing 


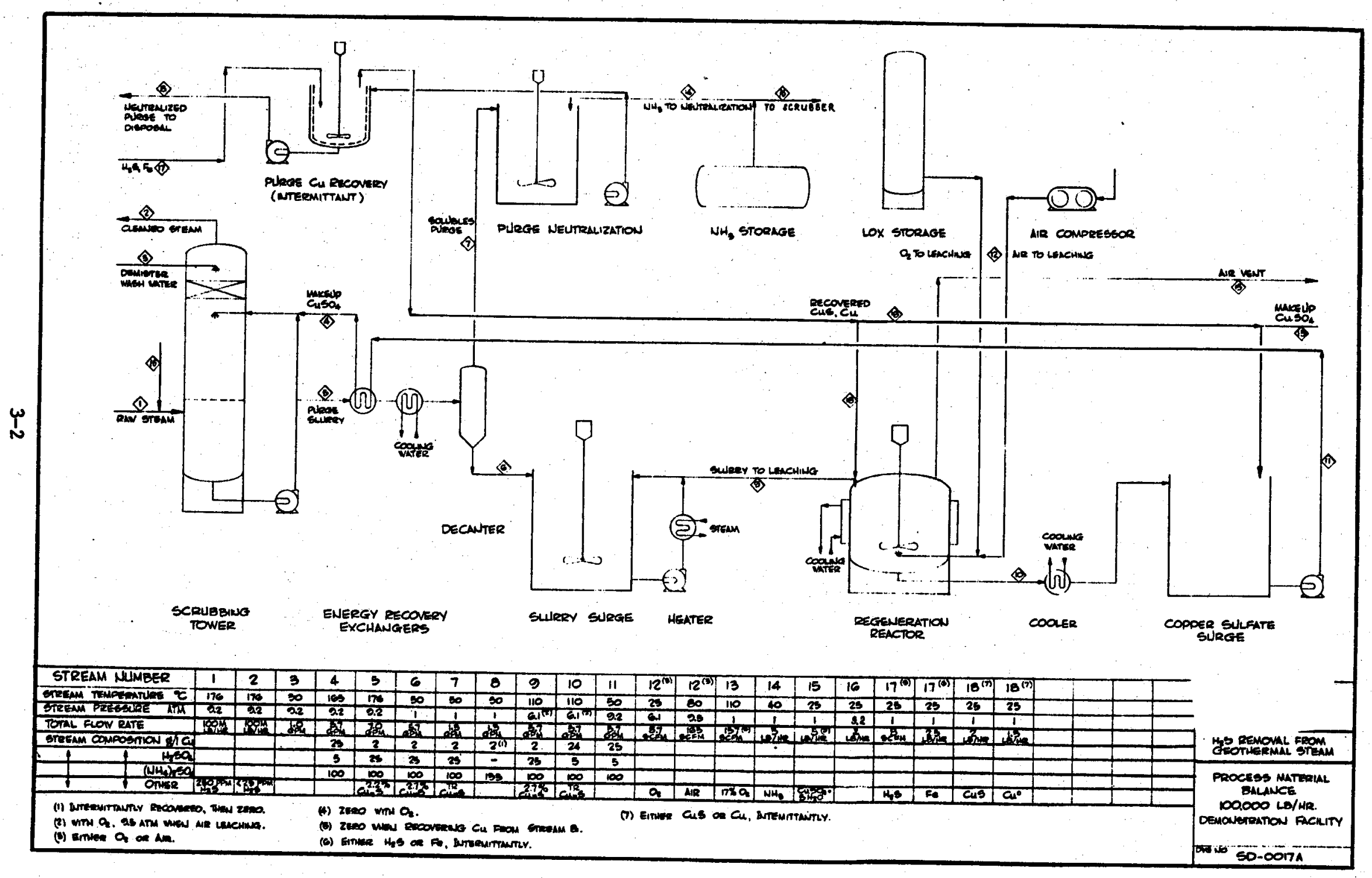

Fig. 2. Schematic description of 5 MW pilot plant.

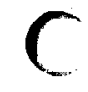




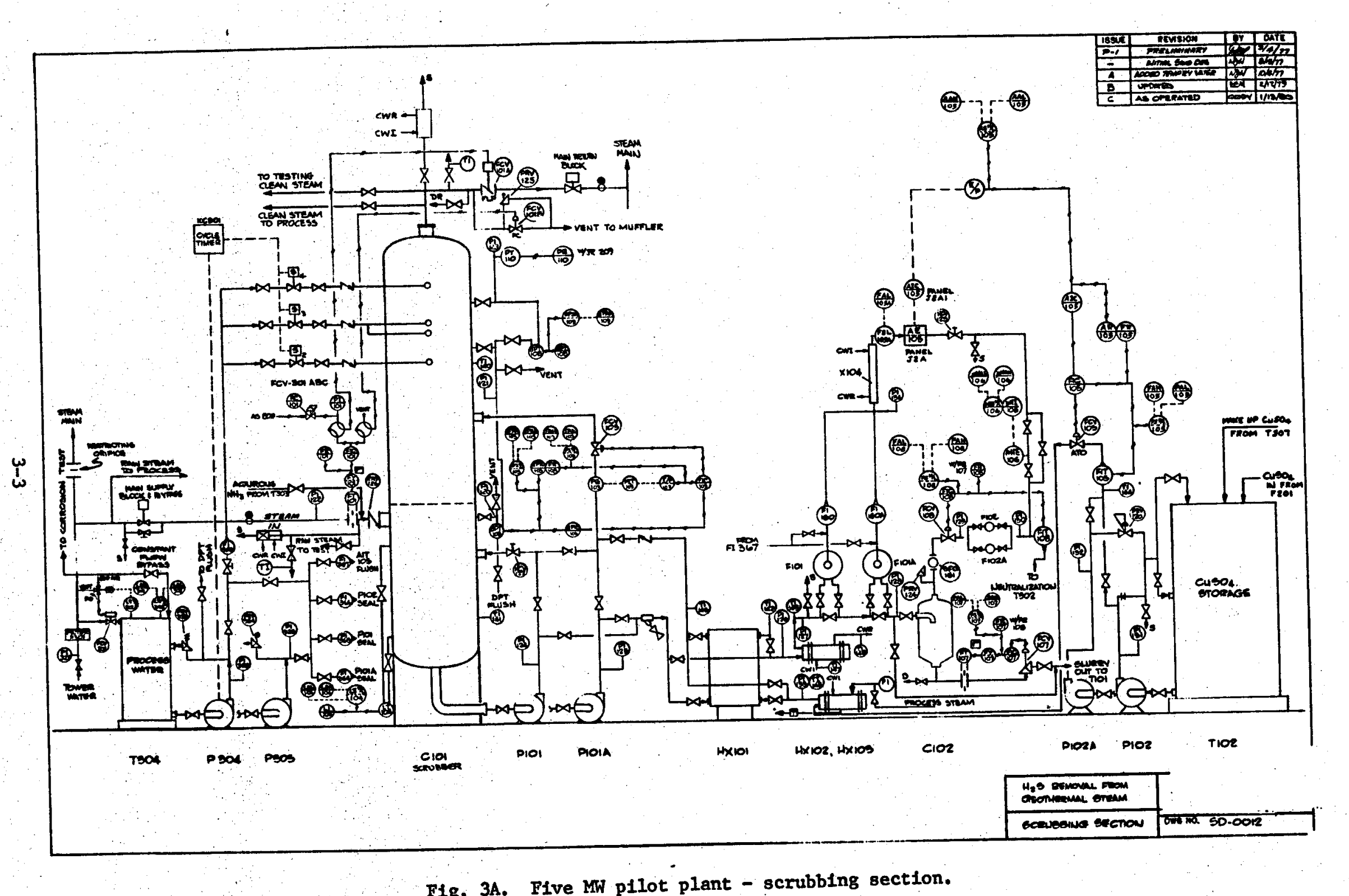




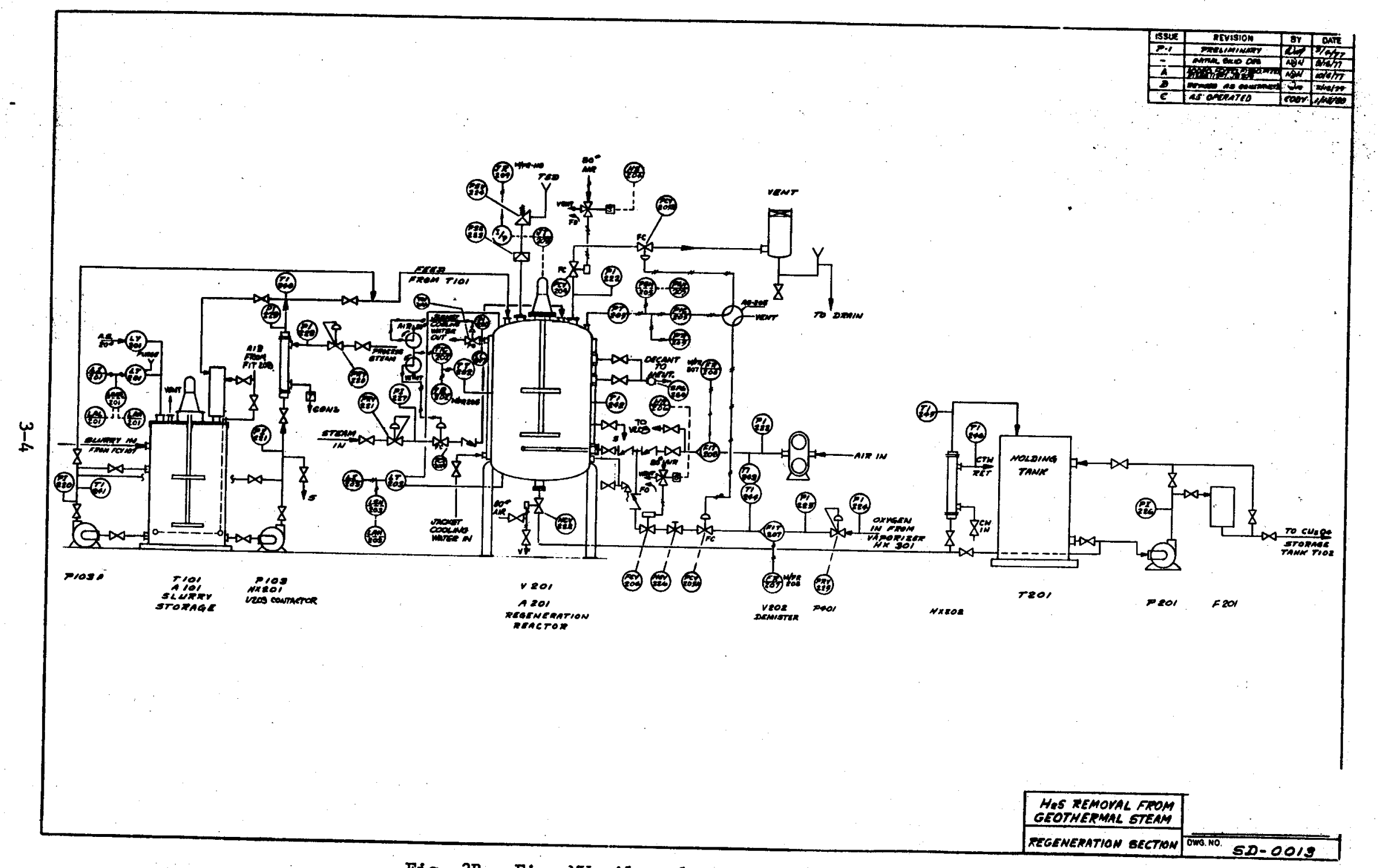

Fig. 3B. Five MW p1lot plant - regeneration section. 


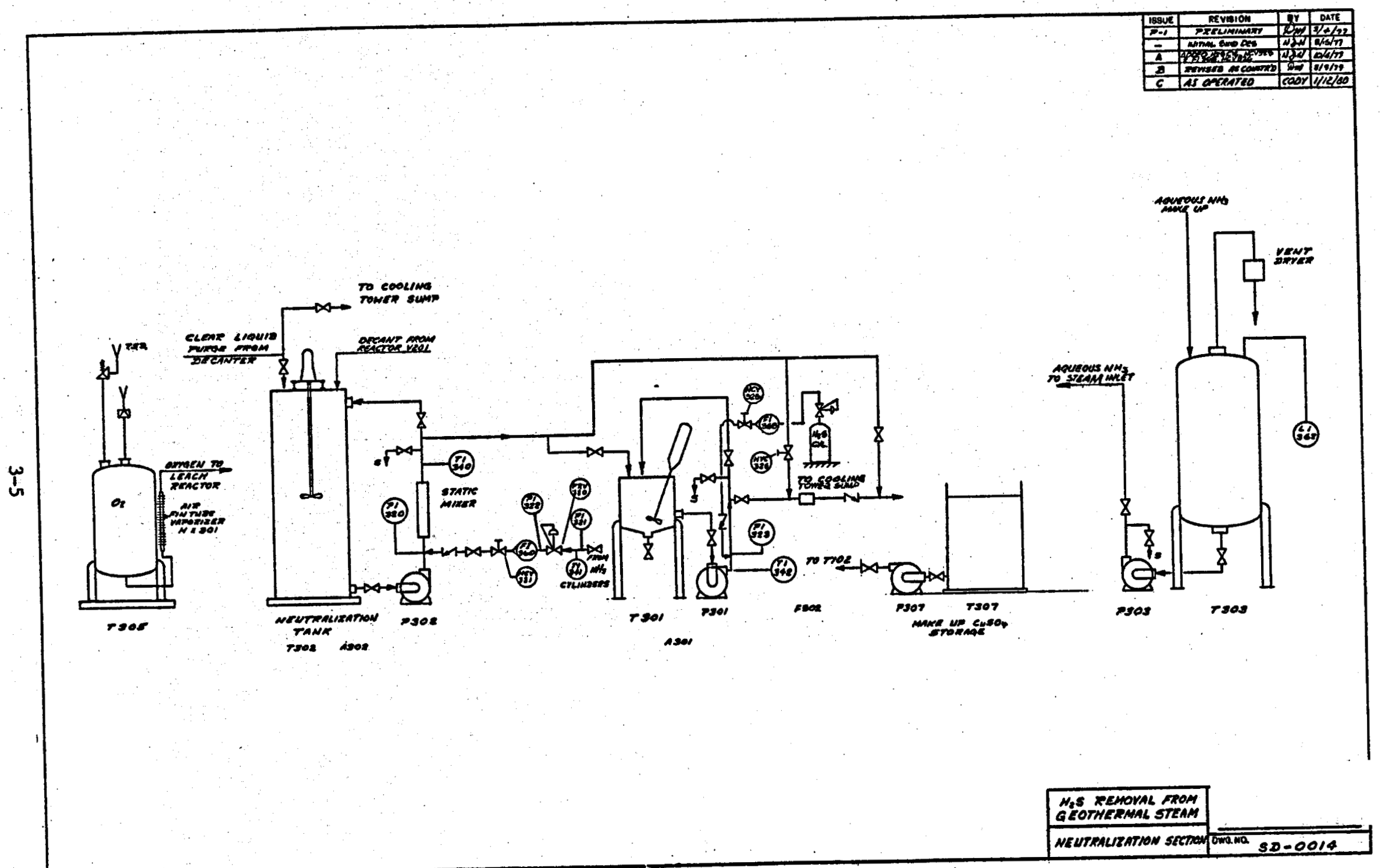

Fig. 3C. Five MW pilot plant - neutralization section. 
solution was controlled to obtain the required mass transfer results by flow rate recorder controller FC103, which could be operated off the scrubbing tray's pressure drop recorder DPR103 if desired. The proper amount of regenerated solution was made up to the system by maintaining composition control, 1.e., the copper content in the slurry purge stream, using composition recorder controller AIC105. Material balance control was achieved within the tower by maintaining the proper level in the tower sump with purge flow controllers FC107 and FC108. Scrubber operations were also monitored by observing pressure drops through the scrubbing and demisting sections with pressure drop indicators DPR103 and DPR104. The purge stream from the tower was passed through energy recovery exchanger HX101 and cooled further in HX102. An auxiliary cooler, HX103, was converted to a steam heater for the makeup copper sulfate solution when energy recovery exchanger HX101 proved to be prone to fouling on the high temperature end. Liquid-solid separation of the purge slurry was carried out in the continuous decanter $\mathrm{C} 102$ with sufficient clear liquid purge withdrawn by flow control FC108 to maintain the concentration of soluble compounds in the system at the desired leve1. The decanted solution passed to neutralization tank T302 while the thickened slurry passed to surge tank T101.

Makeup water for process use was obtained from the cooling tower sumps, filtered, and held in surge tank T304. It was transferred by pumps P304 and P305 to serve as demister wash water and as seal coolant and flush water for the circulating and feed pumps as required.

The scrubbing tower $\mathrm{Cl01}$ was of sufficient size and height to require a permanent, load bearing foundation. The pumps, piping, and equipment associated with the slurry circulating pumps $\mathrm{P} 101$, energy recovery and 1iquidsolid separation operations (heat exchangers HX101-HX103, decanter C102), and service water tank and pumps T304, P304, and P305 were of sufficient size to permit them to be prepiped in fabricator's shop and assembled as components of Skids No. 1, 2, and 5 respectively.

The regeneration module, shown on Dwg. SD-0013, was operated in a batch fashion one or more shifts per day. The purge slurry was held in suspension in surge tank T101 by agitator A101. The temperature of the slurry was raised prior to its introduction into the regeneration reactor by steam heated exchanger HX201. Purge slurry was transferred by pump P103, in two or three batches per day, to regeneration reactor V201. Addition of makeup copper, acid, or ammonium sulfate, if required, would be made to regeneration reactor V201 through its manway or directly to tank T101 prior to the initiation of the leach run. In addition, pre-leaching of the slurry could be carried out at near ambient conditions in tank T101, if desired. by blowing air through a sparge ring located in the bottom of the tank.

The precipitated copper sulfides were suspended in the sulfate solution in the reactor by agitator A201 and sufficient air was sparged through 
the reactor from compressor $\mathrm{P} 401$ to reoxidize the precipitated sulfides to copper sulfate in a two hour reaction cycle. The required oxygen partial pressure was maintained in the reactor by the pressure control loop PRC205. The reactor was held at the required temperature by the temperature control loop TRC202 which controlled the flow rate of cooling water through the reactor jacket. When leaching with high purlty oxygen Instead of air, oxygen was made up to the reactor through flow controller FC207 at a rate sufficient to maintain the desired total system pressure by pressure contoller PRC205. At the completion of a regeneration cycle, the reactor contents-regenerated copper sulfate solution containing unreacted solids were transferred from reactor V201 through cooler HX202 and f11ter F201 by autogeneous pressure within the reactor. A filtrate, containing the regenerated copper sulfate solution, was returned to tank T102 following sampling. Off gases from the regeneration reactor were passed through demister V202 to eliminate carryover when leaching with compressed air.

The final module, shown in SD-0014 consists of the required service equipment. This included an aqueous ammonia supply tank and transfer pump, neutralization and general purpose tanks and transfer pumps and liquid oxygen storage tank and vaporizers.

Because of their size, storage tank T101 and T102 and regeneration reactor V201 required permanent load bearing foundations as did the liquid oxygen storage tank T305 and surge and storage tanks T301, T302, T303, and compressor $\mathrm{P} 401$. Slurry and regenerated copper sulfate solution transfer pumps P103 and P201 and cooler HX202 were preassembled on Skid 3 and pumps and tank P301, P302 and T301 were preassembled on service Skid 4. An instrument control and alarm panel was provided, and placed at a central location, from which normal operations could be monitored and controlled. In nddition, a main motor control center, standby instrument air compressor and safety lights and showers were installed to service the operating area.

\subsection{Changes in the Test Set Up}

Most fleld changes in the Installed equipment configuration were relatively minor. A high pressure water flush system was installed to clear the high and low pressure legs of the scrubbing tray DP transmitter. This backflushing was required because the migration of solids or scrub solution to one or the other of the legs would cause a continuous change in the zero suppression. While this change permitted us to obtain reasonably consistent tray DP readings, it made it difficult to use the tray DP's signal in a cascade control loop to reset the flow rate of circulating scrub solution. Similar attempts were made to obtain consistent readings on the demister pressure drop transmitting loop but without much success. The total range of the instrument, $0-5$ " water, was so "low that even minor drifting in the suppression caused by migration to the filler legs or leakage in the three valve manifold caused a significant error in the indicated reading. 
It was found early in the run that the hot end of the makeup copper sulfate side of plate heat exchanger HX101 tended to foul very rapidly, within a few hours of the initiation of operation. The deposit, a tenacious scale of basic copper salts, proved to be very difficult to remove, and resealing the many gaskets of the multiplate unit also proved to be troublesome. Therefore, an auxiliary heat exchanger HX103 was converted from a cooler to a heater by bringing steam to it, through a pressure reducing valve and a hand control valve, and trapping the condensate. Since the exchanger was originally intended as a cooler, the shell side, to which the steam was put, was well baffled and condensate drainage was incomplete. Nevertheless, it proved adequate for the service and fouling was avoided by regulating the shell side pressure to insure that tube wall temperatures never exceeded $300^{\circ} \mathrm{F}$. Since, however, makeup copper sulfate temperatures were generally kept below $250^{\circ} \mathrm{F}$, the remaining heat up duty had to be supplied by condensing steam in the scrubber.

This extra condensation adversely effected the process water balance, and required us to purge rather more through the decanter overflow than originally anticipated. This compounded the water balance problem imposed by the necessity to cope with fluctuating steam inlet conditions and eventually lead to the installation of throttling calorimeters at the steam inlet and outlet sample taps so that the amount of moisture or superheat could be measured directly. Steam samples were obtained by inserting $\frac{1}{2}$ " stainless tubes into the center line of the 16" inlet and outlet steam mains. No attempt was made to obtain isokinetic sampling, and this technique would not adequately interpret the presence of the moisture in the steam, which would tend to be concentrated along the inlet and outlet piping walls. The consequences of this sampling problem will be discussed in a later section.

The high pressure seal flush water system was extended to pump P102 seals to improve reliability and the relatively simple thermosyphon seal coolant chambers on P103 and P103A were replaced by a more elaborate, pressurized cooling system to prevent deterioration of the ceramic seal faces. The makeup and metering system for sulfuric acid was never installed since it was determined that the steam would always be relatively low in ammonia and regular acid additions would not be required. Acid was added from time to time from 20 gallon carboys.

The major change to the original system configuration involved the installation of a titanium demister. The original demisting units were Teflon wire mesh pad type units which were segmental. Upon exposure to steam at scrubber operating temperatures the Teflon monofilament contracted and the woven mesh material shrank leaving gaps between segments. Steam would then preferentially pass through these gaps carrying entrained liquid and solids to the downstream carbon steel piping. The initial attempt to solve this problem involved installation of "sausages" of Teflon mesh material in the gaps between the segments. This proved to be only a temporary 
expedient since, in time, the sausages themselves deteriorated. Finally, a set of titanium wire mesh segmental pad type demisters was purchased and installed below the existing Teflon set. Simultaneously, the demister wash was changed to cope with the new configuration. One circuit of demister wash timer $\mathrm{KC} 301$ was used to control the flow of water to three wash nozzles located underneath the titanium pad. A second circuit controlled the flow of wash water to the top of this pad while the third circuit was used to wash either the underside or top of the Teflon pad. For most of the last half of the test campaign, the wash circuit on top of the Teflon demister pad was not used since it was felt that a significant amount of this water was simply reentrained from the scrubber and caused erosion/corrosion problems in down stream piping and valves.

The initial attempt to contact air and purge slurry for preleaching in tank T101 involved the use of a Kenics static mixer. This did not prove effective and it was replaced by a sparge ring wich was installed at the tank bottom. The "ring" consisted of four 7' long pipes connected with $90^{\circ}$ elbows. Air was brought to one side of the assembly and distributed through a serles of $3 / 16$ " diameter holes on 4 " centers.

Numerous other small changes, mostly with respect to the location of local pressure and temperature indicators and the installation of extra sample taps, were made throughout the course of campaign which did not materially effect the operation or the configuration of the system.

\subsection{Instrumentation and Analytical Techniques}

With the exception of the problems in zero point drift noted on the tray and demister pressure drop transmitters, all process instrumentation save $\mathrm{pH}$ element 106 functioned according to or exceeding expectations.

The $\mathrm{pH}$ sensing element had been subjected to an extensive series of laboratory tests in which it had proven to be remarkably stable, once the use of a proper reference fluid was inftlated. Continuing problems were experienced in the field, however, with drift in the output of this instrument. Frequent recalibration, with changes of up to $0.5 \mathrm{pH}$ units, was required. Some of the problem was associated with the use of a large sampling section through which only a small flow of purge solution passed. This occasionally led to the formation of air pockets and almost surely led to poor mixing and unrepresentative sampling within the 2 " $T$ assembly required to accept the $\mathrm{pH}$ probe. Eventually, a routine of draining and backflusing the sampling line was developed which greatly reduced but did not eliminate the drifting problem.

By contrast, operation of the copper analyzer control loop AIT105 was, with the exception of a problem in bulb stability, without incident. 
The special quartz lamps required for the instrument burned out more frequently than anticipated but the probable cause, voltage spikes in the $110 \mathrm{~V}$ power supply, can be ellminated through use of proper circuitry. The instrument was recalibrated several times throughout the course of the campaign and errors were always found to be less than $0.1 \mathrm{~g} / \mathrm{l}$.

Proper functioning of this control loop is a critical requirement since it is necessary to insure the required supply of makeup copper sulfate is being fed to the system to insure high degrees of hydrogen sulfide removal and passivation of materials of construction. The sensing instrument itself and its control loop proved to be remarkably stable even when sample filters F101 and F101A were not operating properly because of a deterioration in the paper thin filtering elements. During these times the passage of fines through the sensing element was coped with by the automatic turbitity compensating feature of the instrument and presented no operating problem. We conclude that an unnecessarily elaborate sampling filter is not required in this service. All of the process instrumentation, which consisted mainly of pressure and flow control loops, functioned without incident. Only the normal sequence of controller tuning to obtain appropriate reset and proportional bands was required to eliminate loop instability.

It was determined early in the test campalgn however that the makeup copper sulfate and purge overflow magnetic flow transmitters needed recalibration. The zero points for these instruments may have been lost during disassembly of the transmitters for shipment. Recalibration was carried out by comparing the indicated reading with the volumetric flow rate computed by observing the rates of change in tank T102 or by direct determination of the soluble purge rate via a bucket-and-stop watch technique. Recalibration of the decanter underflow flow transmitter was also required although the reason for the offset was never determined. This instrument, too, was recalibrated by comparing the Indicated flow with the flowrate from the change in level in tank T101.

No analytical technique development was required in the field, and the procedures developed in the course of laboratory work were found to be generally reliable. It was determined, however, that extreme care had to be taken in the determination of the ammoniun sulfate content of the purge and makeup streams. Prior to analysis, the soluble copper was removed from the samples by precipitation with sodium sulfide, and it was necessary to wash the precipitate exremely carefully in order to eliminate loss of ammonium sulfate. Poor technique inevitably resulted in an underestimation of the amonium sulfate concentration.

In addition, extreme care was required in the field for the accurate determination of the solids composition. It proved to be very difficult 
to dry solids in the field oven without some oxidation. This tended to result in the systematic overestimation of the initial weight of sulfide solids, which would then result in an underestimation of their copper content. Eventually, we came to regard the determination of solids content in the field as only generally indicative of the process stoichiometry and relied on analyses of samples sent back to the lab for workup under more carefully controlled conditions.

The analytical techniques used without incident for the measurements routinely made included:

- Sorption of steam condensates into aqueous ammonia solution followed by potentiometric titration with silver nitrate to determine hydrogen sulfide.

- Sorption of steam condensates into aqueous sulfuric acid/ potassium chloride solution followed by addition of caustic to release ammonia gas, the amount of which was then measured with a selective gas membrane electrode. A variation of this technique was also used to measure the ammonium sulfate content of process solutions following the removal of copper.

- Determination of the copper content of the process solutions by spectrophotometric measurement at the appropriate wavelength.

- Determination of the acidity of process solutions by direct titration with sodium hydroxide.

- Determination of boron and other trace elements in various samples by means of atomic emission spectrophotometry in outside laboratories.

Other measurements, Including $\mathrm{pH}$, temperature, specific gravity, etc. were carried out using standard laboratory techniques.

\subsection{Steam Composition}

The first measurements which were attempted in the mechanical integrity testing and water testing phases of the campaign involved the determination of the heat loss from the scrubber column and the molsture or superheat content of the steam. It soon became clear that the steam condition was highly varlable; it was impossible to obtain consistent readings for either heat loss or superheat by measuring the rate of change of liquid level in the scrubber sump under "steady" conditions.

Then, during the initial phases of open and closed circuit short term testing, extremely rapid changes in sump level (usually involving increases) were observed from time to time. These caused significant upsets in the system water balance and were a source of concern to the operators 
until means were developed to anticipate their occurrence and cope with them. We eventually came to associate step changes of a few psi in line pressure with a possible change in steam condition. Changes were also anticipated when we became aware that the steam supplier was switching wells in the steam field or diverting steam from other plants in response to unit trips there. This, and perceived sampling problems which will be discussed in more detail later, eventually lead to the installation of throttling calorimeters on both the inlet and outlet steam lines. The trace of inlet steam condition for a period of about three weeks towards the end of the test campaign is presented in Figs. 4 and 5.

The variability of the steam condition is evident. The decrease from $6^{\circ}$ of superheat to 0.4 percent moisture which occurred during a 6 -hour period on October 8, decreased the steam enthalpy by approximately $6 \mathrm{BTU} / 1 \mathrm{~b}$ and caused an imbalance in the system water inventory of approximately 1.3 gallons per minute. This is of the same order as the normal steady state purge rate. The generally lower degrees of superheat and/or higher moisture contents in late October and early November may have been associated with the onset of cold, wet weather. In any case, it will be necessary for a commercial process to be instrumented so as to be able to cope with changes in inlet steam enthalpy of as much as $20 \mathrm{BTU} / 1 \mathrm{~b}$.

A record of the hydrogen sulfide and ammonia contents of the inlet steam throughout the campaign and of the boron in both inlet and outlet steams are presented in Figs. 6,7 and 8 respectively.

It is obvious that the composition as well as the condition of the steam is highly variable and a process control strategy will have to be developed to cope with these rapid variations. As was the case with inlet steam condition, some of the changes could be associated with changes of the source of steam supply in response to operating problems in the field or at other plants. To some extent, however, it simply represents the natural variability of the resource. The average hydrogen sulfide and ammonia contents throughout the course of the run were 250 and $150 \mathrm{ppm}$ by weight respectively with a variation of $\pm 50 \mathrm{ppm}$ above and below the averages being common. The variability on any given day was much higher for ammonia than for hydrogen sulfide however. Indeed, replicated samples of ammonia could vary by as much as $20 \%$, probably because of problems with the sampling technique.

The boron content of the inlet steam averaged approximately $25 \mathrm{ppm}$ throughout the course of the campaign while the scrubbed steam boron content averaged approximately $20 \mathrm{ppm}$. However, a consideration of the material balance for the process on boron leads to the conclusion that one or both of these must be in error. The vapor-liquid equilibrium in the boron-water system has been measured independently, and a value of approximately $20 \mathrm{ppm}$ in the outlet steam is reasonably consistent with boron concentrations of 


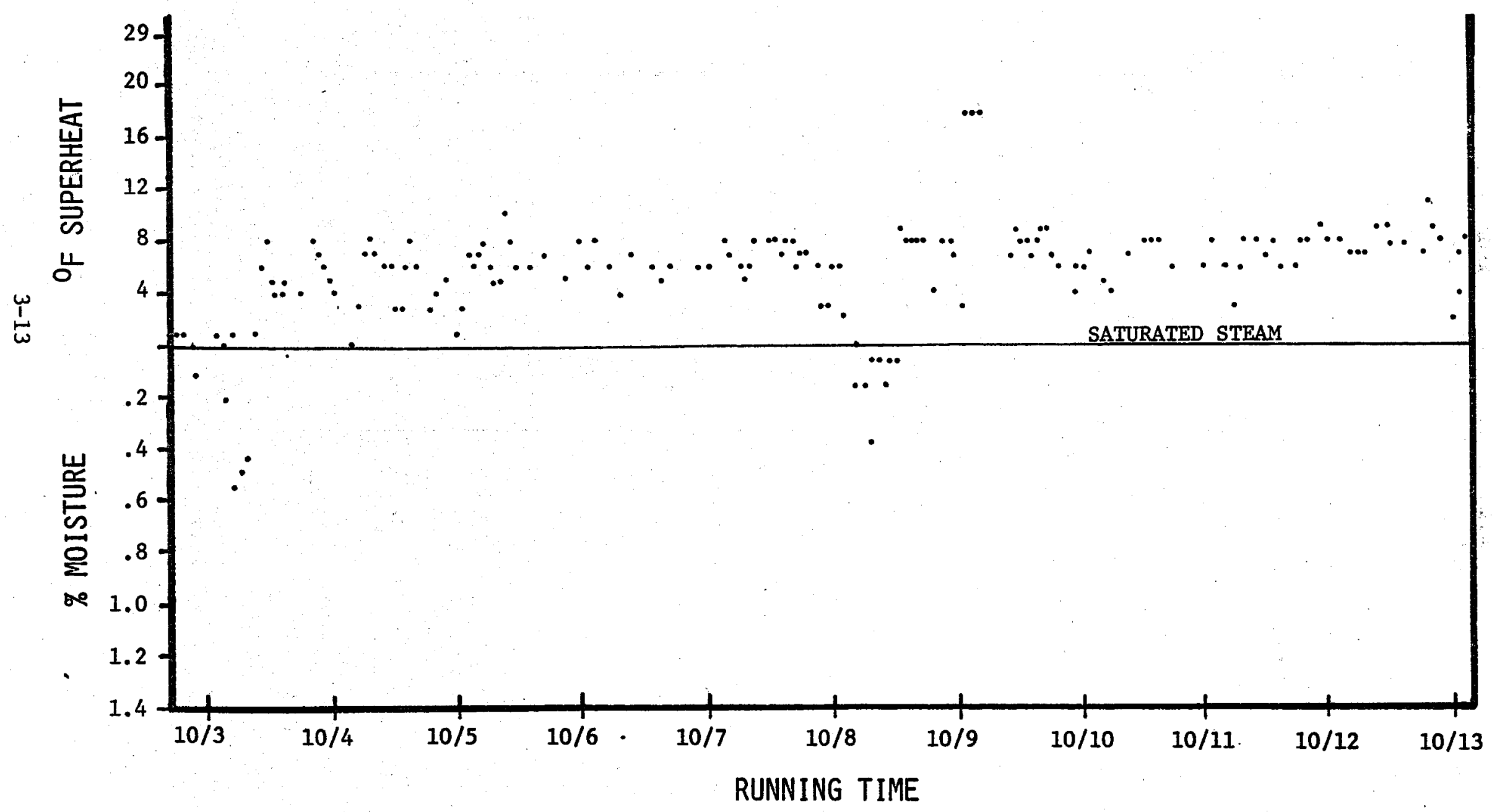

Fig. 4. Steam inlet conditions. 


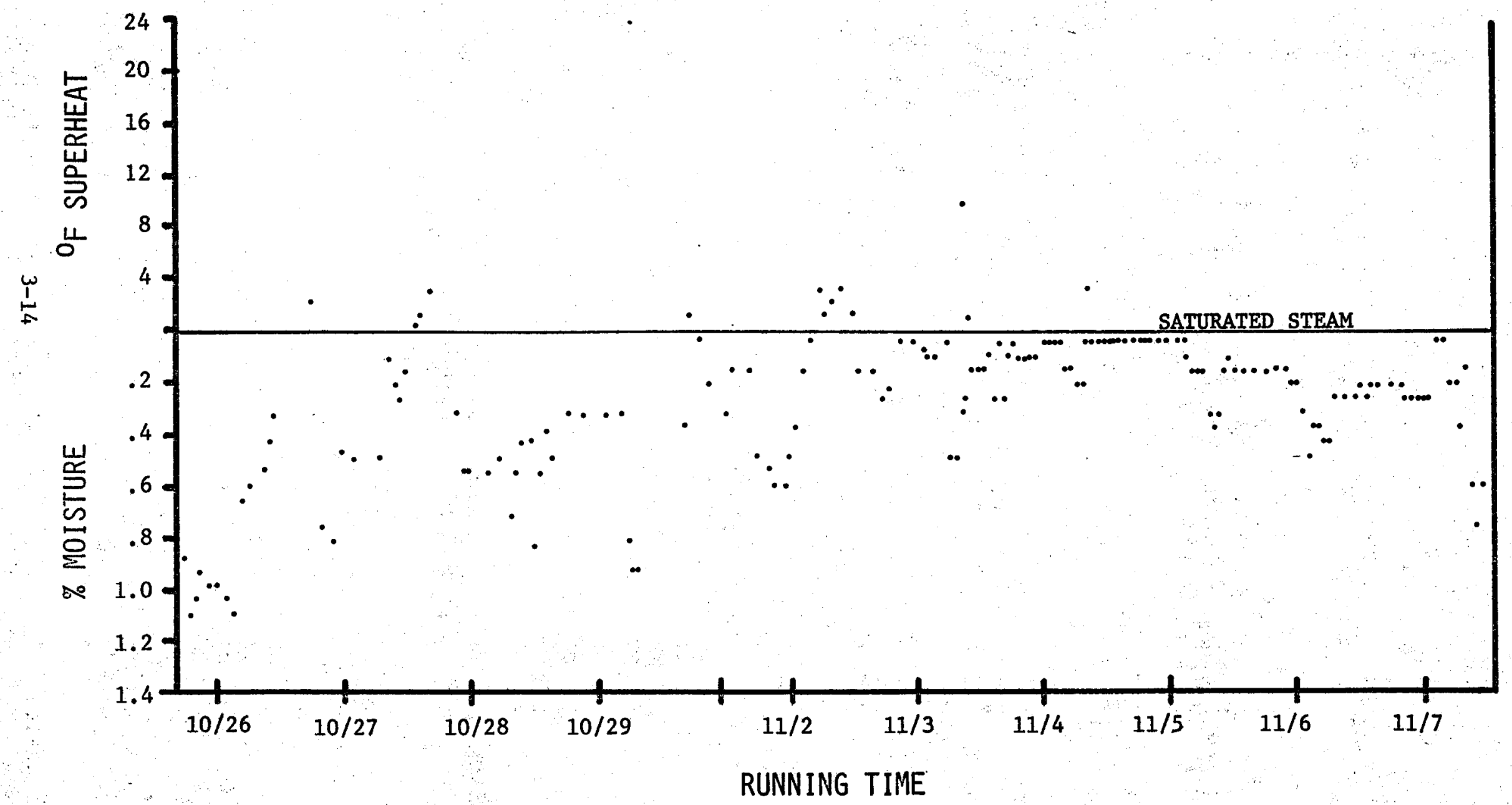

Fig. 5. Steam inlet conditions. 


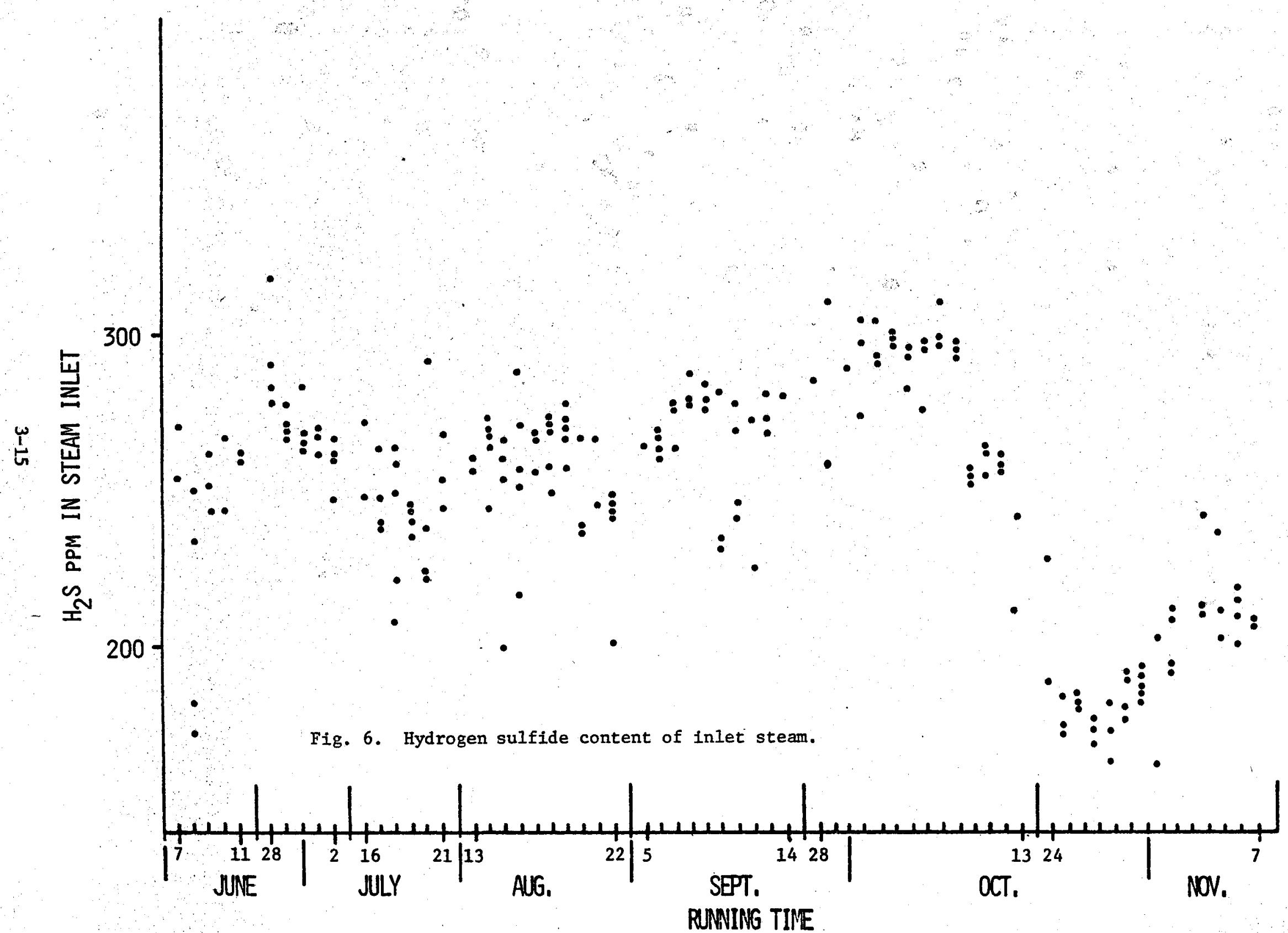




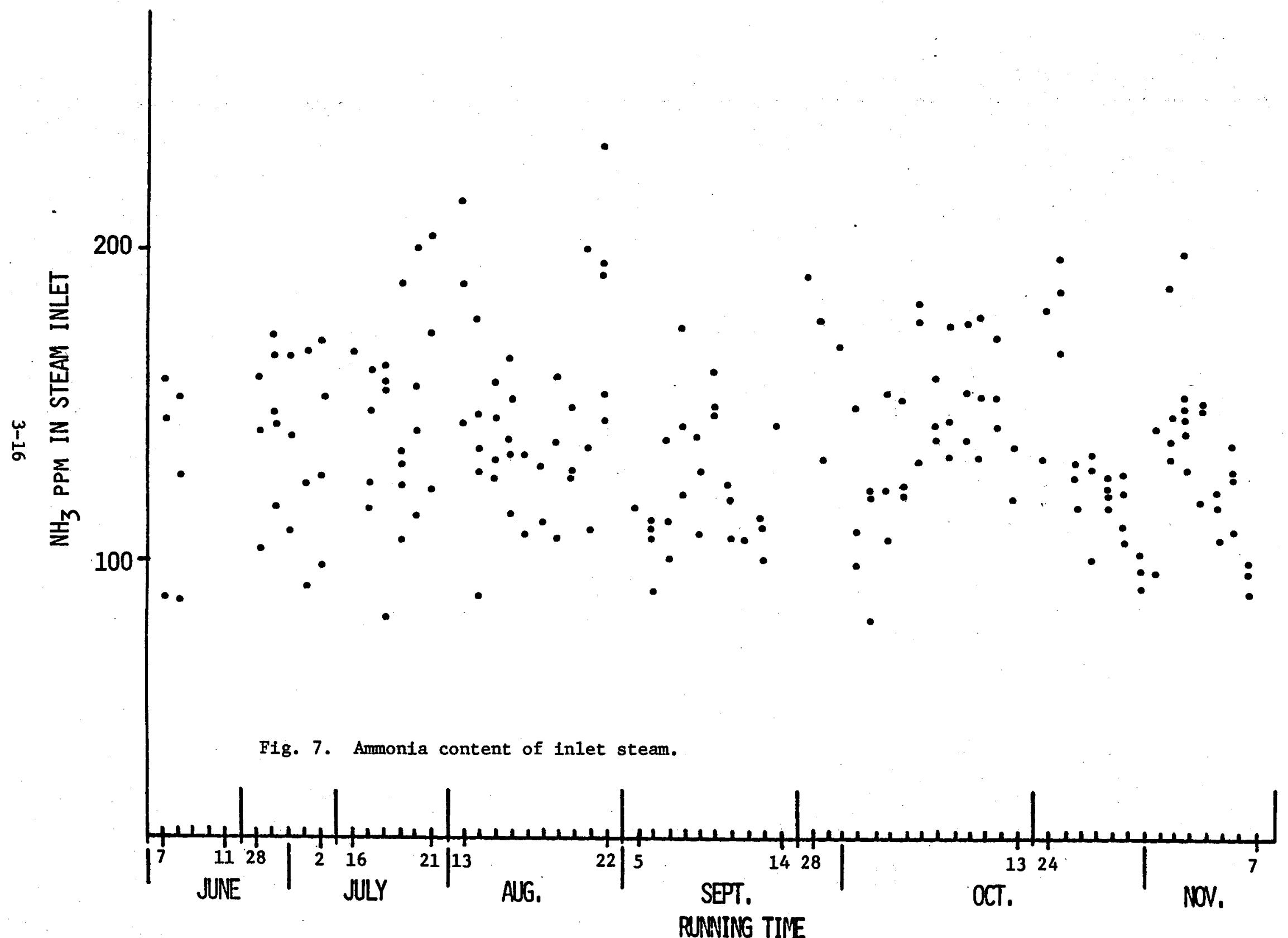


$C$

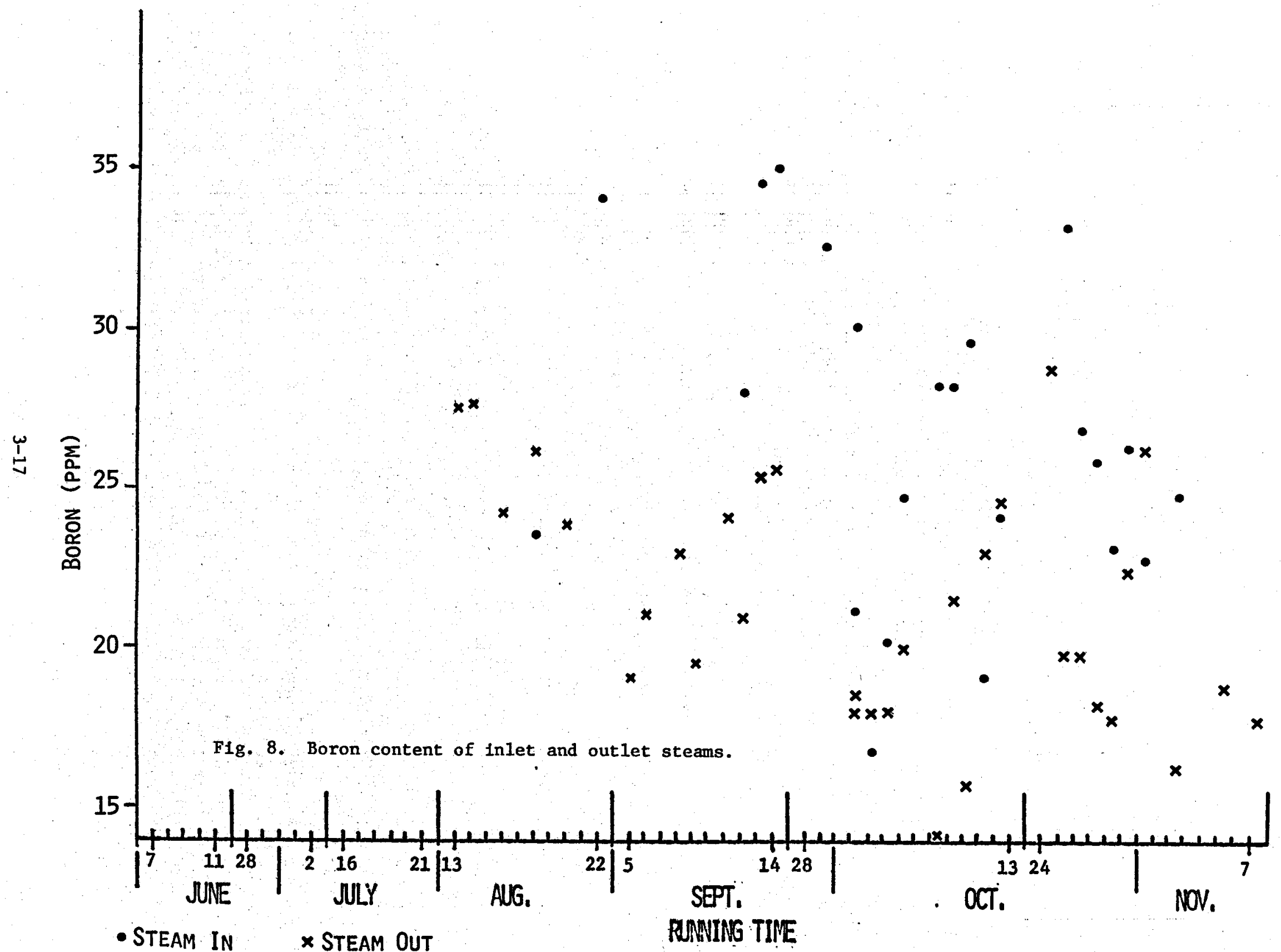


$2000 \mathrm{ppm}$ in the scrub solution in equilibrium with it. Thus, we conclude that the inlet steam sample is systematically underestimating the boron content of the total steam flow. The material balance implications for this, and other trace elements, are presented in the next section.

However, it is apparent that some care w111 be required in developing a steam sampling technique if more precise, rellable analyses of steam composition are required in future test work.

\subsection{Materials Balance Considerations}

A sumary of the copper balance for the test campaign is presented in Tabile 4. Eighty percent of the copper charged to the system was in the form of a $78 \mathrm{~g} / \mathrm{l}$ copper solution and the balance was added as solid copper sulfate penta hydrate. The amount of copper lost to the solubles purge was computed by integrating the product of purge rate and copper content while the amount of copper left in inventory was determined by gauging and sampling the surge tanks T101 and T102 at the end of the campaign. The copper in these categories could be determined with some precision, but the amount ascribed to losses is somewhat more uncertain. The major losses include four categories:

- A loss of 2000 gallons of regenerated solution when the bottom of surge tank T102 failed due to improper grouting,

- a loss of approximately 3000 gallons when the contents of holding tank T201 were inadvertently pumped to drain,

- a loss of approximately 3500 gallons of slurry when the bottom of surge tank T101 falled due to improper grouting and

- a loss of approximately 2100 gallons of sump solution during the flushing and cleaning operations carried out at the conclusion of each run during the campaign.

Miscellaneous losses include those sustained during small spills and sampling, an average of 15 gallons per day, as well as an allowance for copper loss associated with the entrainment of one ppm of copper in the scrubbed steam.

Overall, the copper balance closes as well as can be expected given the limitations and the accuracy of the measurement of the various loss terms.

The ammonium sulfate material balance is sumarized in Table 5. About $70 \%$ of the $\left(\mathrm{NH}_{4}\right)_{2} \mathrm{SO}_{4}$ entering the system was derived from the $\mathrm{NH}_{3}$ removed from the steam and neutralized with the $\mathrm{H}_{2} \mathrm{SO}_{4}$ formed in the scrubbing reaction. The balance was added as purchased food grade $\left(\mathrm{NH}_{4}\right)_{2} \mathrm{SO}_{4}$. Purge stream, inventory, and major and miscellaneous losses were calculated in the same way as the corresponding figures for the copper balance. 
$\underline{\text { Table } 4}$

Copper Balance for the Test Campaign

Input

Purchased $\mathrm{CuSO}_{4}$ solution

$7,150 \mathrm{Ib} \mathrm{Cu}$

Purchased $\mathrm{CuSO}_{4} \cdot 5 \mathrm{H}_{2} \mathrm{O}$ solids

$\underline{2,000} \mathrm{Ib}$

Total Input

$9,150 \mathrm{Ib} \mathrm{Cu}$

Inventory at End of Campaign

Slurry in T101

$1,550 \mathrm{Ib} \mathrm{Cu}$

Solution in T102

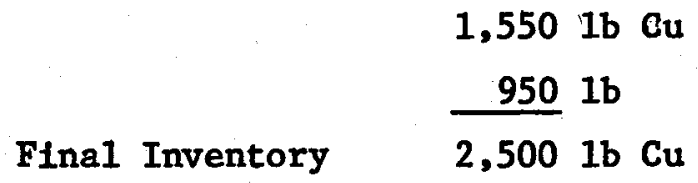

Purged from System

Average $1.75 \mathrm{GPM} @ 3.25 \mathrm{~g} / \mathrm{l} \mathrm{Cu}$

$3,850 \mathrm{Ib} \mathrm{Cu}$

Major Losses

Rupture of T101 bottom

$400 \mathrm{lb} \mathrm{Cu}$

Rupture of T102 bottom

$900 \mathrm{lb}$

Loss of T201 to drain (operator error)

$6001 b$

Losses in cleaning scrubber sump

$5001 \mathrm{~b}$

Total Major Losses

$2,400 \mathrm{Ib} \mathrm{Cu}$

Miscellaneous Losses

Sampling and small spills a 15 gal/day

$100 \mathrm{Ib} \mathrm{Cu}$

Entraimment losses @ 1 ppm

$1001 \mathrm{~b}$

Total Misc. Losses

$2001 \mathrm{~b} \mathrm{Cu}$

Total copper purged, lost, and in Inventory

$8,950 \mathrm{lb} \mathrm{Cu}$

Total copper in circulation throughout the campaign

$86,0001 b \cdot C u$ 
Table 5

\section{Ammonium Sulfate Balance for the Test Campaign}

Input

Purchased $\left(\mathrm{NH}_{4}\right)_{2} \mathrm{SO}_{4}$

$23,0001 b$

$\mathrm{NH}_{3}$ removed from steam, as $\left(\mathrm{NH}_{4}\right)_{2} \mathrm{SO}_{4}$

Total Input

$\underline{55,150} 1 \mathrm{~b}$

$78,1501 b$

Inventory at End of Campaign

Solution in T101

$2,2001 \mathrm{~b}$

Solution in T102

1,300 ib

Final Inventory $\quad 3,500 \mathrm{lb}$

Purged from System

Average 1.75 GPM C $60 \mathrm{~g} / \mathrm{l}$

$70,800 \mathrm{ib}$

Major Losses

Rupture of T101 bottom .

$1,9001 b$

Rupture of T102 bottom

$1,150 \mathrm{Ib}$

Loss of T201 to drain (operator error)

$1,2501 \mathrm{~b}$

Losses in cleaning scrubber sump

$1,0001 \mathrm{~b}$

Total Major Losses

$5,3001 \mathrm{~b}$

\section{Miscellaneous Losses}

Sampling and small spills e $15 \mathrm{gal} / \mathrm{day}$

$4001 b$

Entrainment losses @ 2 PPM

$2001 b$

Total Misc. Losses

$6001 b$

Total $\left(\mathrm{NH}_{4}\right)_{2} \mathrm{SO}_{4}$ purged, lost, and in inventory

Total $\left(\mathrm{NH}_{4}\right)_{2} \mathrm{SO}_{4}$ in circulation throughout the campaign

$80,2001 b$

$250,000 \mathrm{lb}$ 
The system $\mathrm{NH}_{3}$ balance closes remarkedly well in view of the analytical problems associated with sampling inlet and outlet steams and measuring $\left(\mathrm{NH}_{4}\right)_{2} \mathrm{SO}_{4}$ concentrations. The amount of $\left(\mathrm{NH}_{4}\right)_{2} \mathrm{SO}_{4}$ "lost" is approximately $5 \%$ of that in the system, versus about $30 \%$ for the copper balance, because of the large amount formed in the scrubbing reaction and purged. No such "makeup" term enters into the copper balance.

The excellent closure in this case lends credence to the overall process balance, particularly to the estimation of the loss terms. In an integrated commercial process, of course, at least $99 \%$ of the copper in the soluble purge stream would be recovered and recycled, and one would not expect to have losses of the magnitude encountered in the pilot plant.

The stoichiometry of the scrubbing reactions were determined from the data shown in Figs. 9 and 10. Initially, attempts were made to determine the " $n$ " of the solids composition by the direct analyses, but it proved difficult to achieve reliable, reproducible results as previously outlined. Therefore, the estimate of the solids composition was developed from a consideration of the leach reaction's stoichiometry. Since the ratio of copper dissolved to acid consumed in the regeneration step could be determined directly and with some precision, and since we found that essentially no elemental sulfur was formed during the course of the regeneration reaction, It was possible to determine the initial solids composition from the reaction as written below:

$$
\mathrm{Cu}_{n} \mathrm{~s}+(\mathrm{n}-1) \mathrm{H}_{2} \mathrm{SO}_{4}+\left(\frac{5 n-1}{2}\right) \mathrm{O}_{2} \rightarrow \mathrm{nCuSO}_{4}+(\mathrm{n}-1) \mathrm{H}_{2} \mathrm{O}
$$

The run for which the calculated $n$ was in the vicinity of 1.6 is associated with data which show relatively high copper and low acid concentrations entering the leach. This may reflect a higher than normal degree of preleaching having taken place at near ambient conditions in the slurry storage tank.

The ratios of the amount of copper consumed to hydrogen sulfide removed and hydrogen ion produced per unit of hydrogen sulfide removed were calculated by materlal balance. Hydrogen sulfide removal rates were calculated from total steam flow rates and inlet and outlet compositions. The amount of copper consumed was calculated from the measured flowrates and compositions of the makeup copper and total purge streams. The amount of acidity formied was calculated from the same data after taking into account the amount consumed in the formation of ammonium sulfate within the scrubber. Thus, a higher degree of uncertainty must be ascribed to the characterization of this ratio because of the analytical difficulties previously mentioned in the determination of the ammonia contents of incoming and outlet steams. 


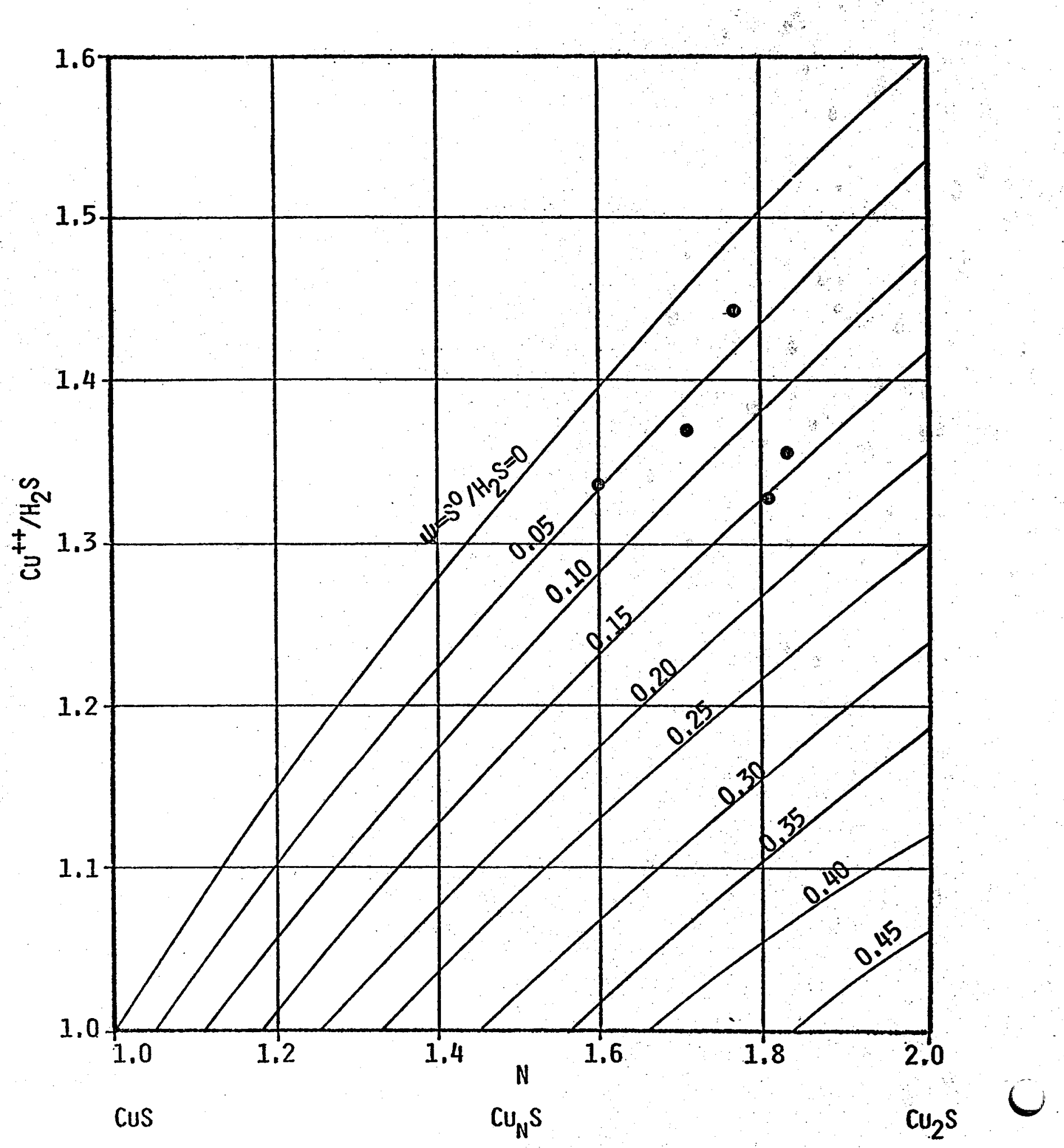

Fig. 9. Stoichiometry of the scrubbing reactions. 


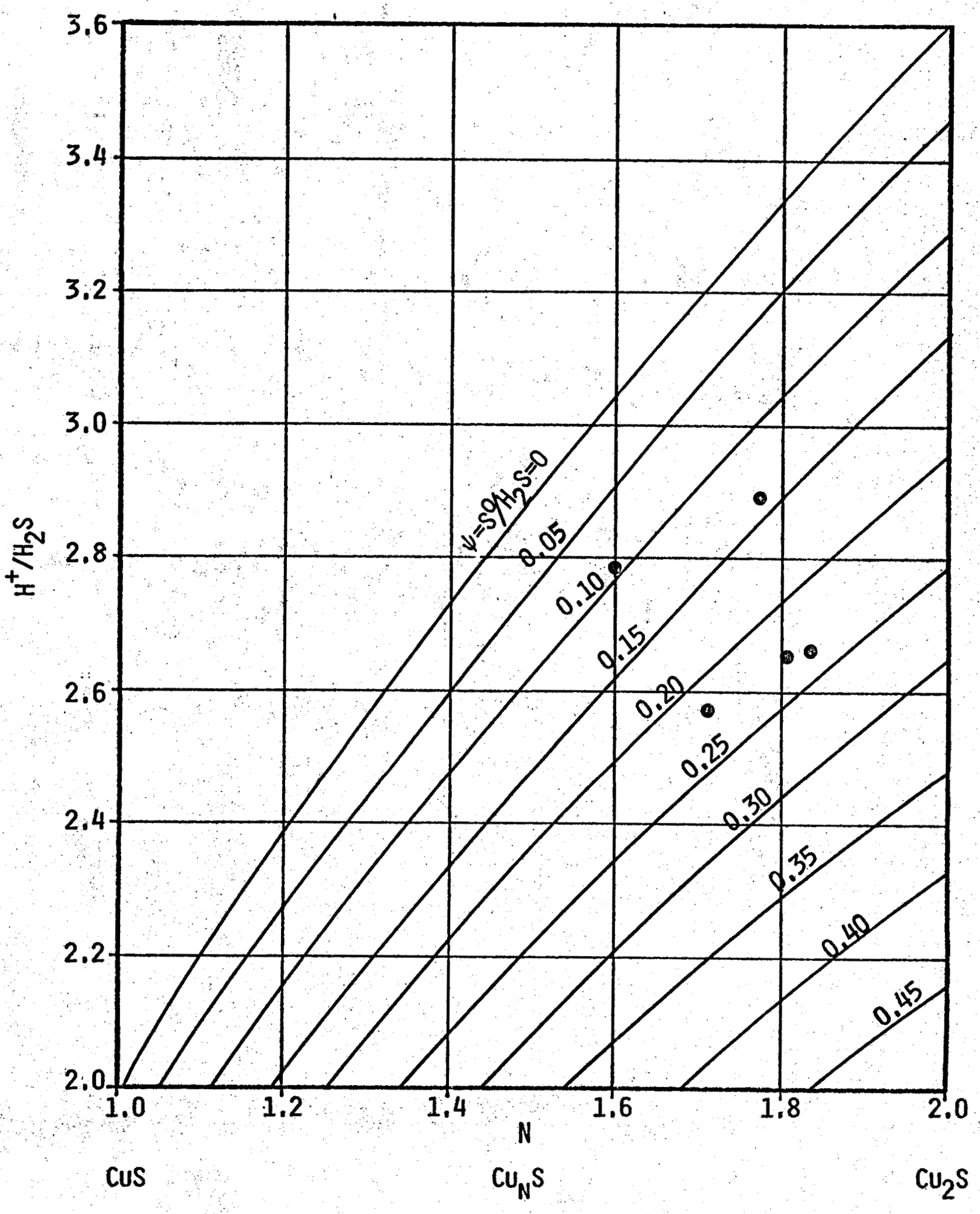

Fig. 10. Stoichiometry of the scrubbing reactions. 
Attempts to confirm the calculated ammonium sulfate production rates by measuring the compositions of makeup and purge streams also proved unsuccessful. This results from a combination of previously stated analytical difficulties in determining the ammonium sulfate content of the purge streams and the fact that, to close this balance, one ends up attempting to determine a small difference between large numbers. Thus, we belleve that the stoichiometry implied by the copper to hydrogen sulfide removal ratio is more likely to reflect the real performance of the scrubbing system and that the fraction of the hydrogen sulfide scrubbed which is oxidized to elemental sulfur lies between 5 and 15\%. An average of $10 \%$ has been taken for computing the scrubber material balance.

The concentrations of boron, aluminum, arsenic, calcium, chromium, iron, magnesium, nickel, potassium, silica, and sodium in the makeup and purge streams throughout the course of the test campaign are shown in Figs. 11-21. A summary of the overall material balance for these trace elements is presented in Table 6 .

We had several objectives in tracing the fate of these elements throughout the process. Some, particularly calcium, silica, and iron could cause serious fouling problems in the heat exchange steps in the process if they approached solubility limits. Also, the relative amounts of the various constituents might give some valuable clues as to the nature and amount of the elusive "rock dust" in the inlet steam. Others, particularly boron, play an important role in determining the rate and extent to which the turbines foul during service. Finally, the behavior over time would give us an additional means of determining whether the process had truly achieved a steady state since, at that time, compositions would no longer change and the makeup and purge stream compositions would be identical.

It is obvious from the data that true steady state was only approached in these tests. For some components, this was at least partly due to the discontinuous addition of makeup chemicals which carry the bulk of the impurities to the system. For others, it may be due to a widely varying element content in the inlet steam, whose composition may be more variable than reported due to the previously mentioned sampling difficulties. In any case, we conclude from these tests that the potentially scale forming elements are present at levels far below their solubility limits and should not cause fouling problems. This prediction was indeed confirmed in heat transfer tests as will be reported in a following section.

In the material balance summary we have attempted to calculate the origin of all the trace elements reporting to the purge stream. The elements, in general, have been removed from the steam during the scrubbing process, have been brought into the system with the demister wash water which ultimately reported to the purge stream, or have been brought in with the makeup 


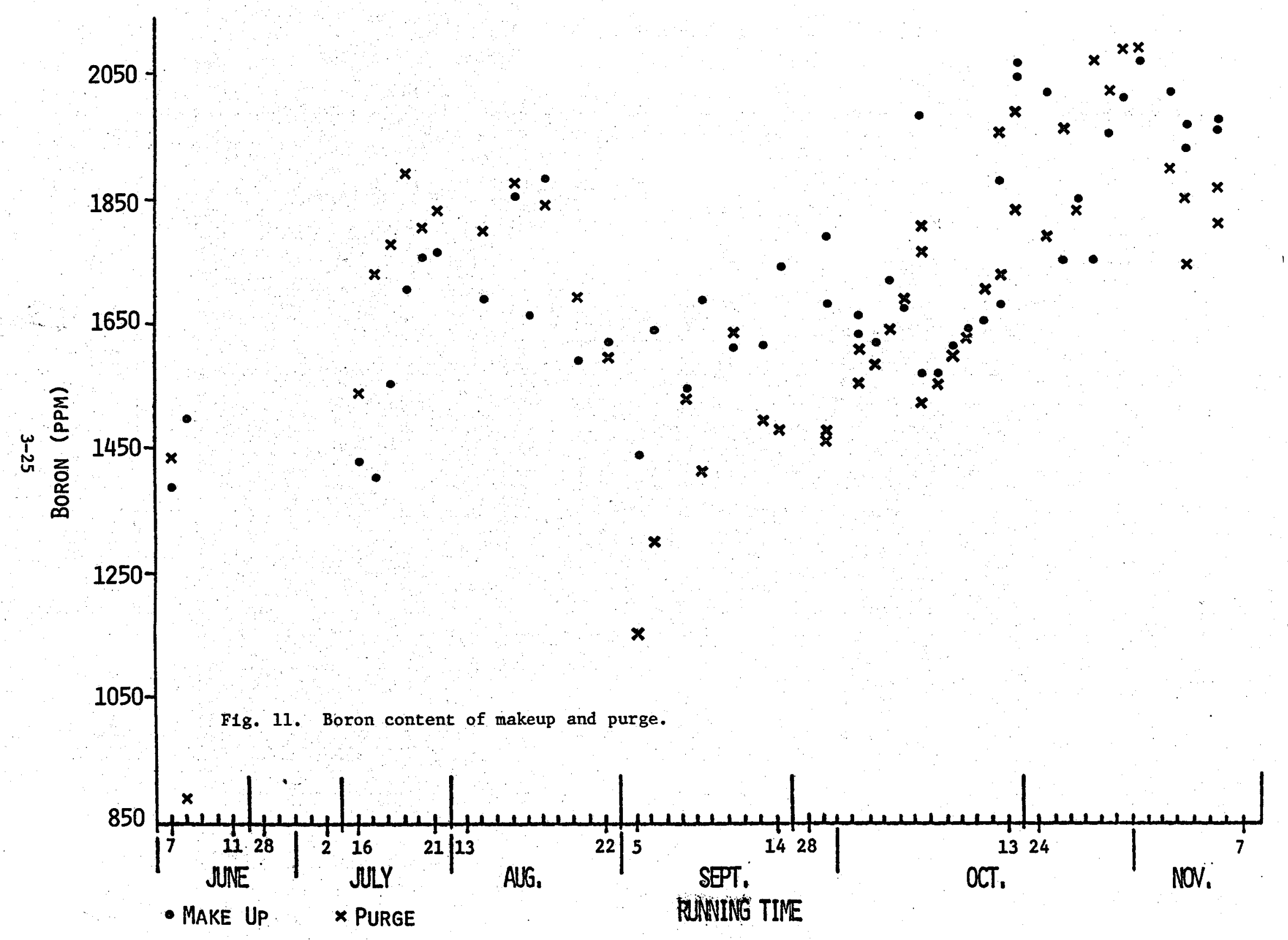




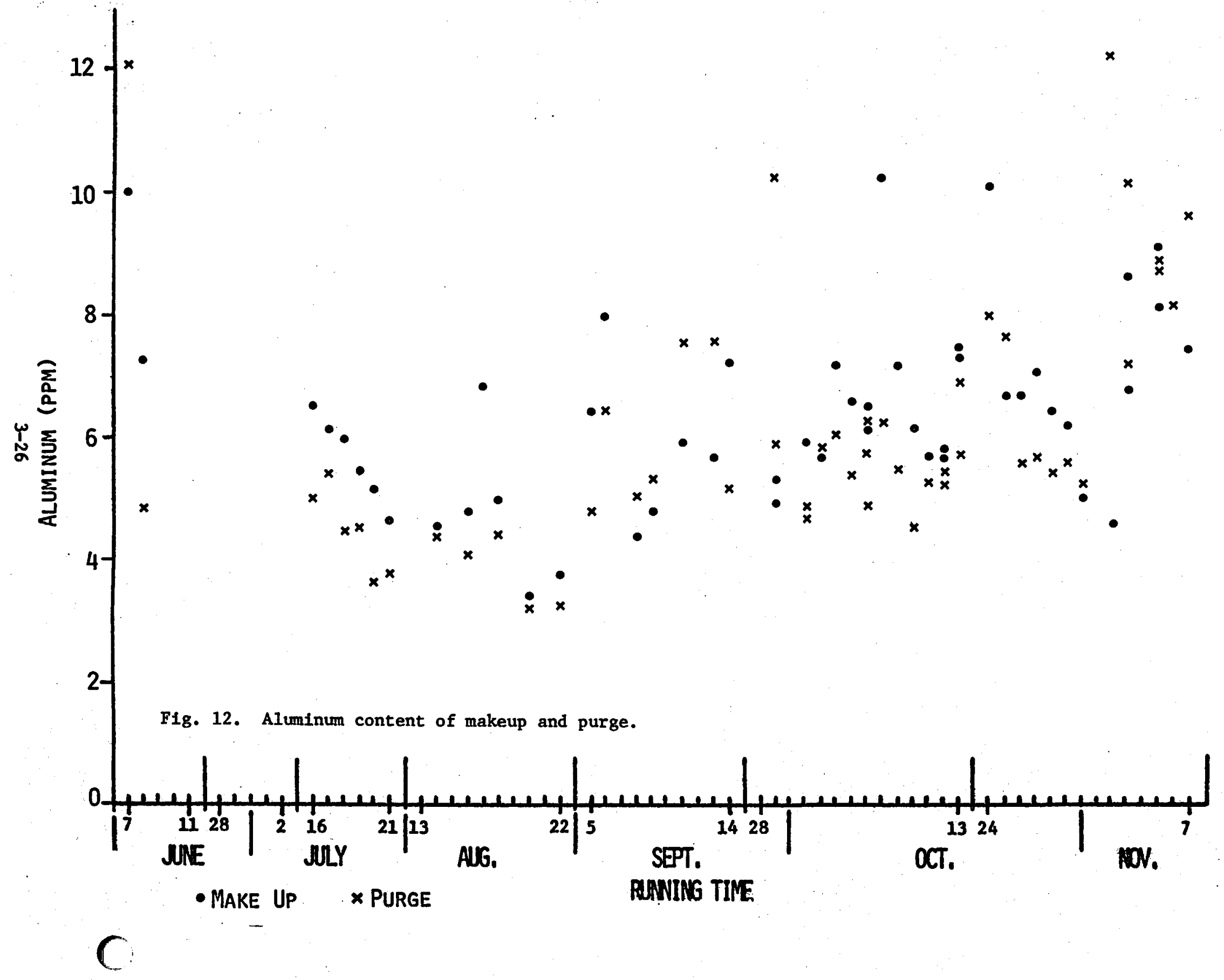




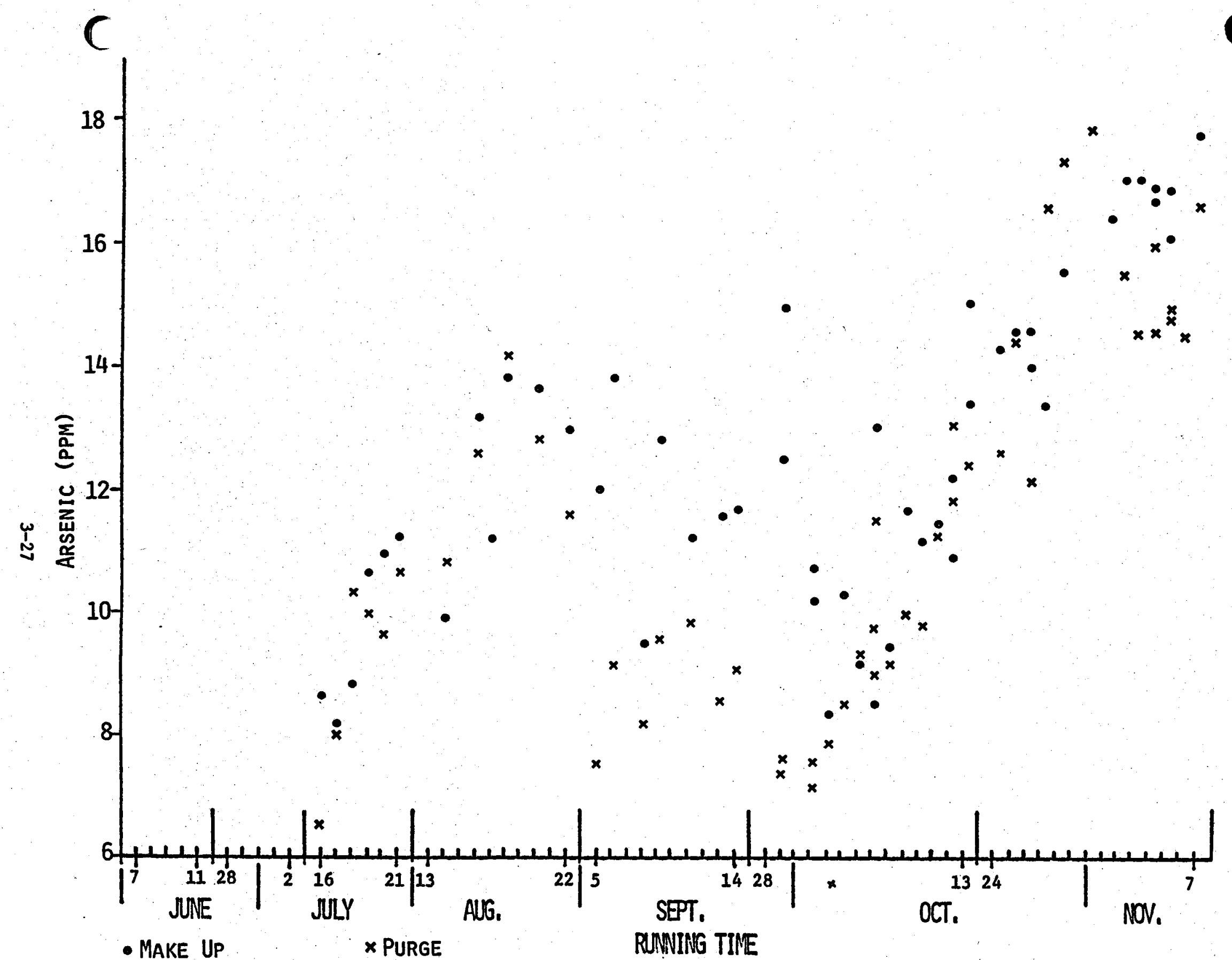

F1g. 13. Arsenic content of makeup and purge. 


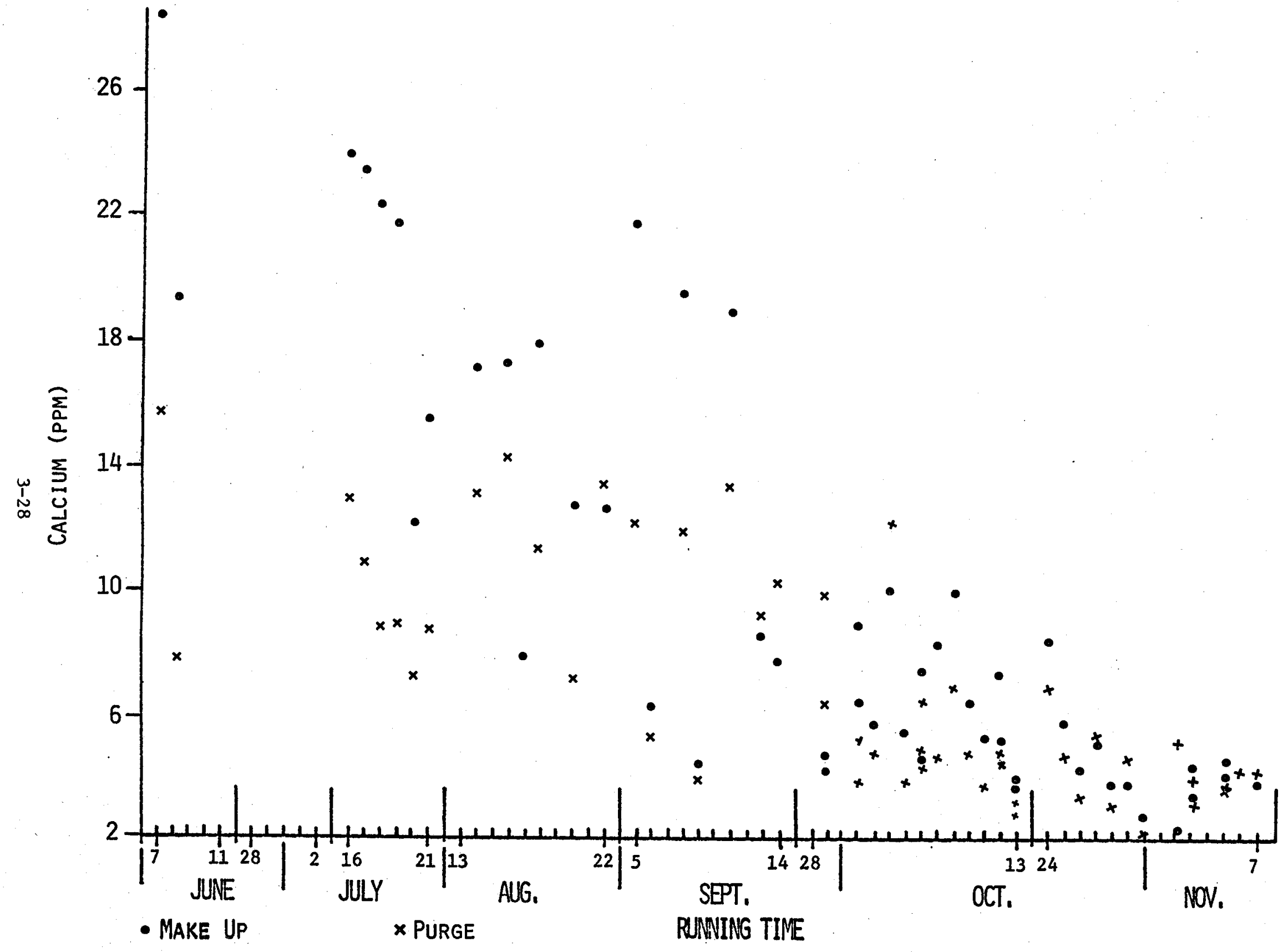

F1g. 14. Calcium content of makeup and purge. 


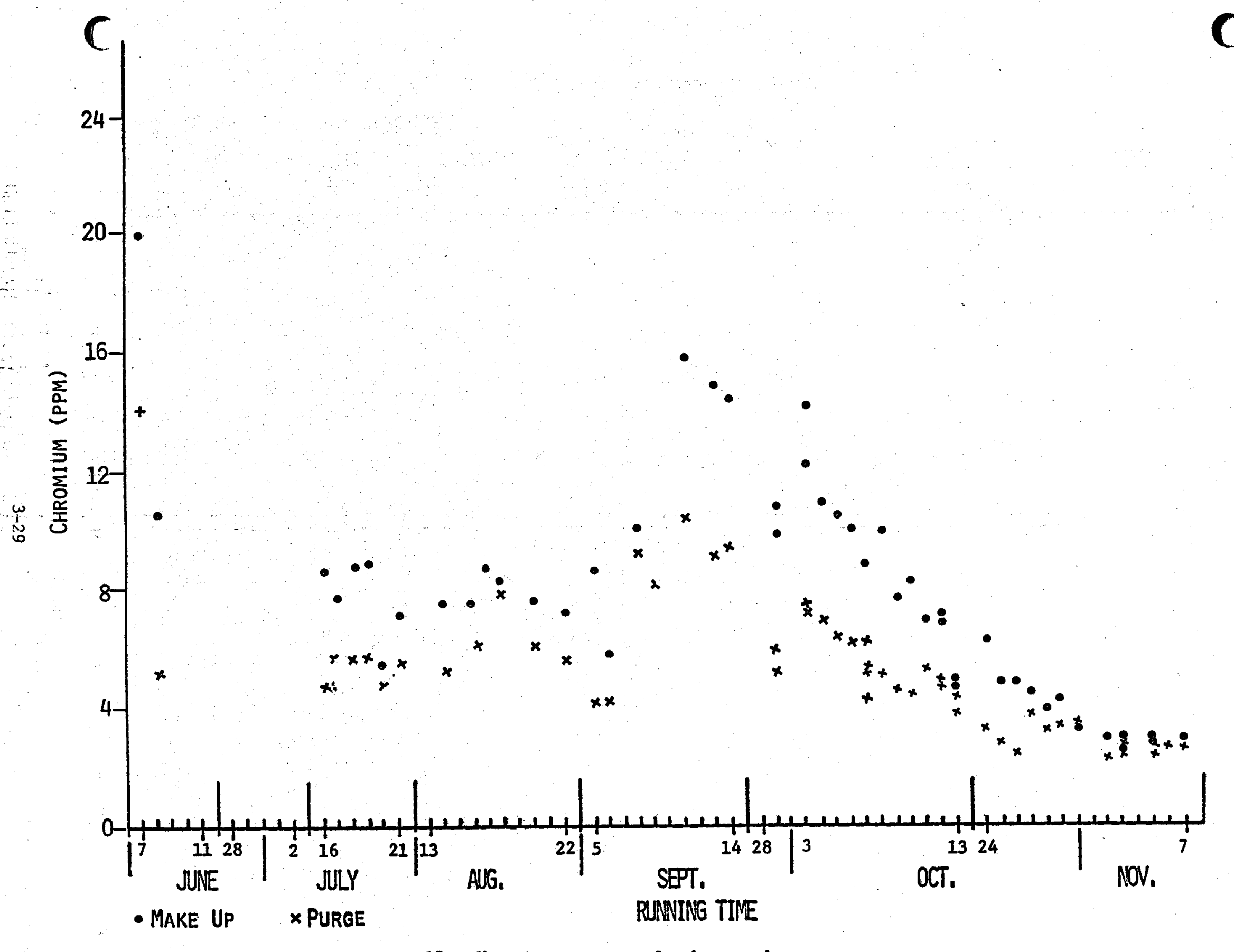

Fig. 15. Chromium content of makeup and purge. 


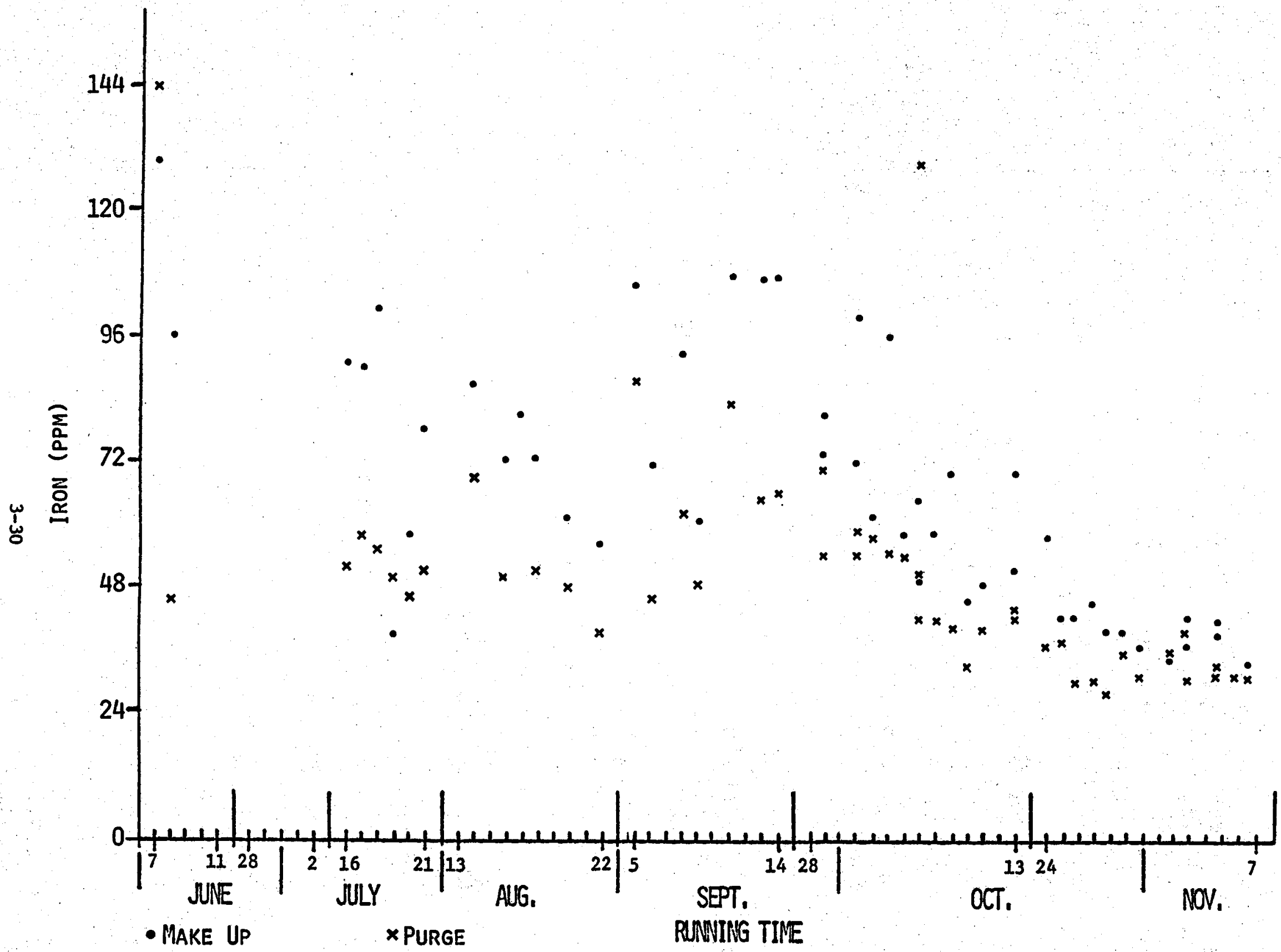

F1g. 16. Iron content of makeup and purge. 


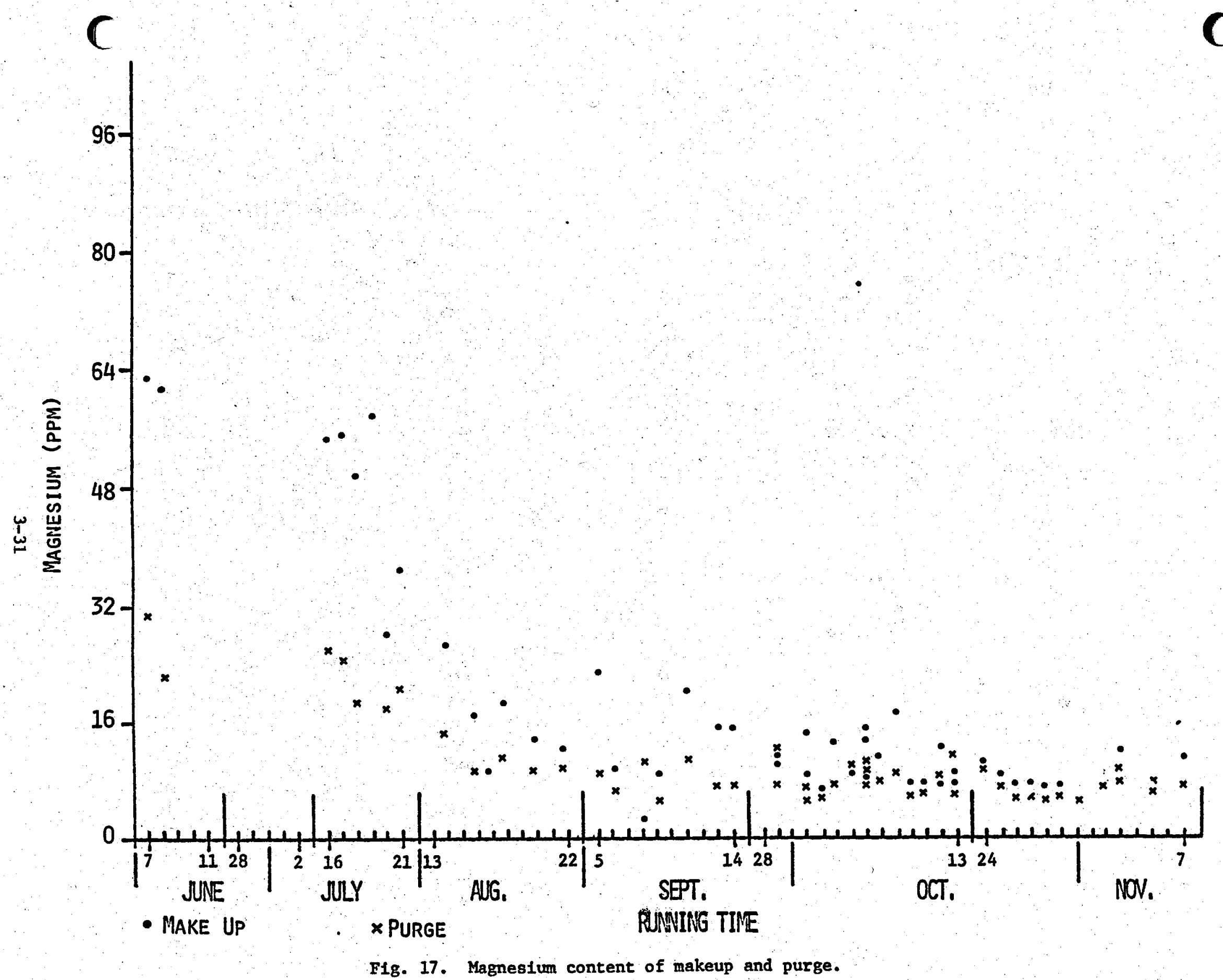




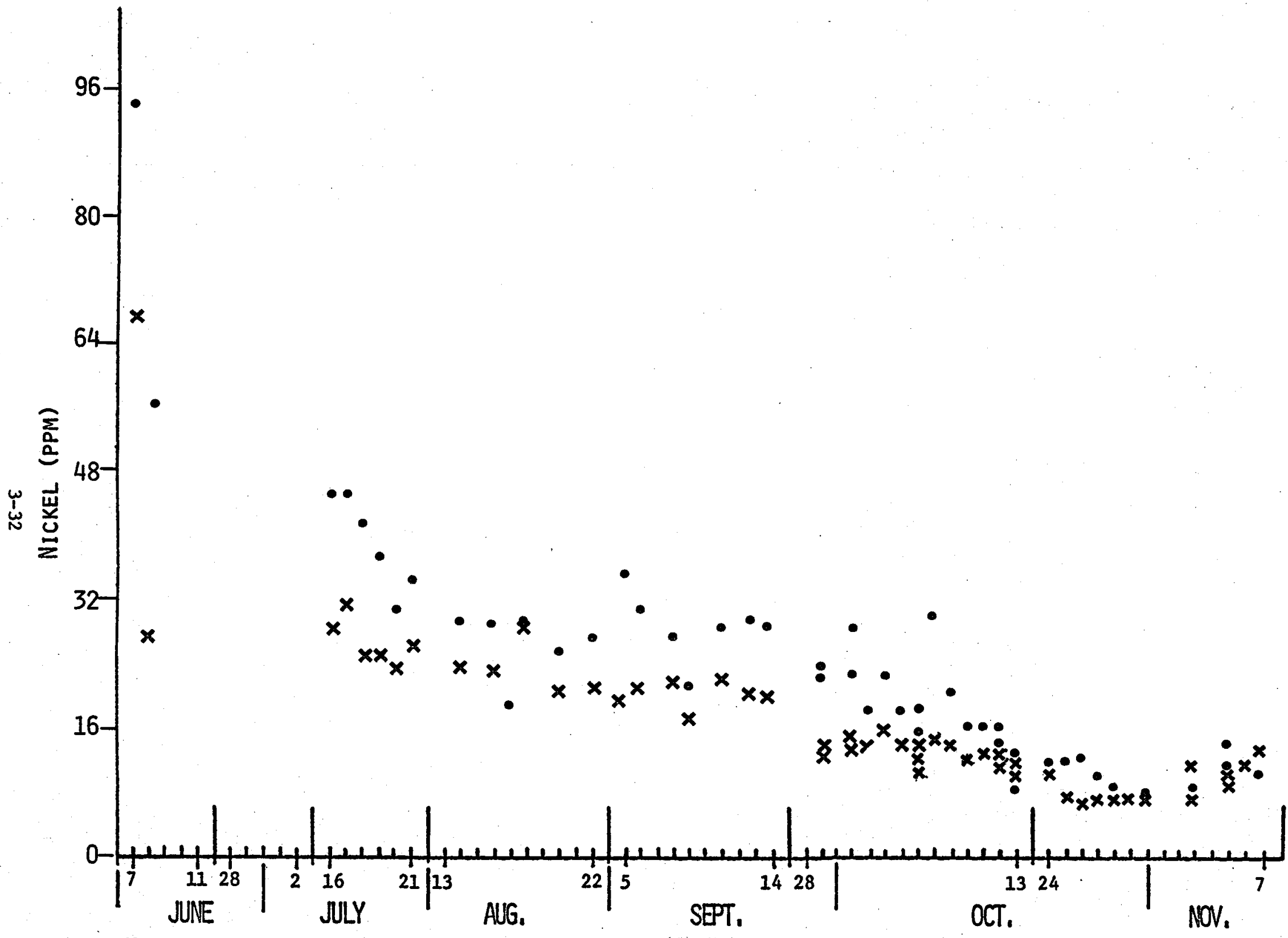

- Make Up $\times$ PuRge

RUINING TIME

Fig. 18. Nickel content of makeup and purge.

C 


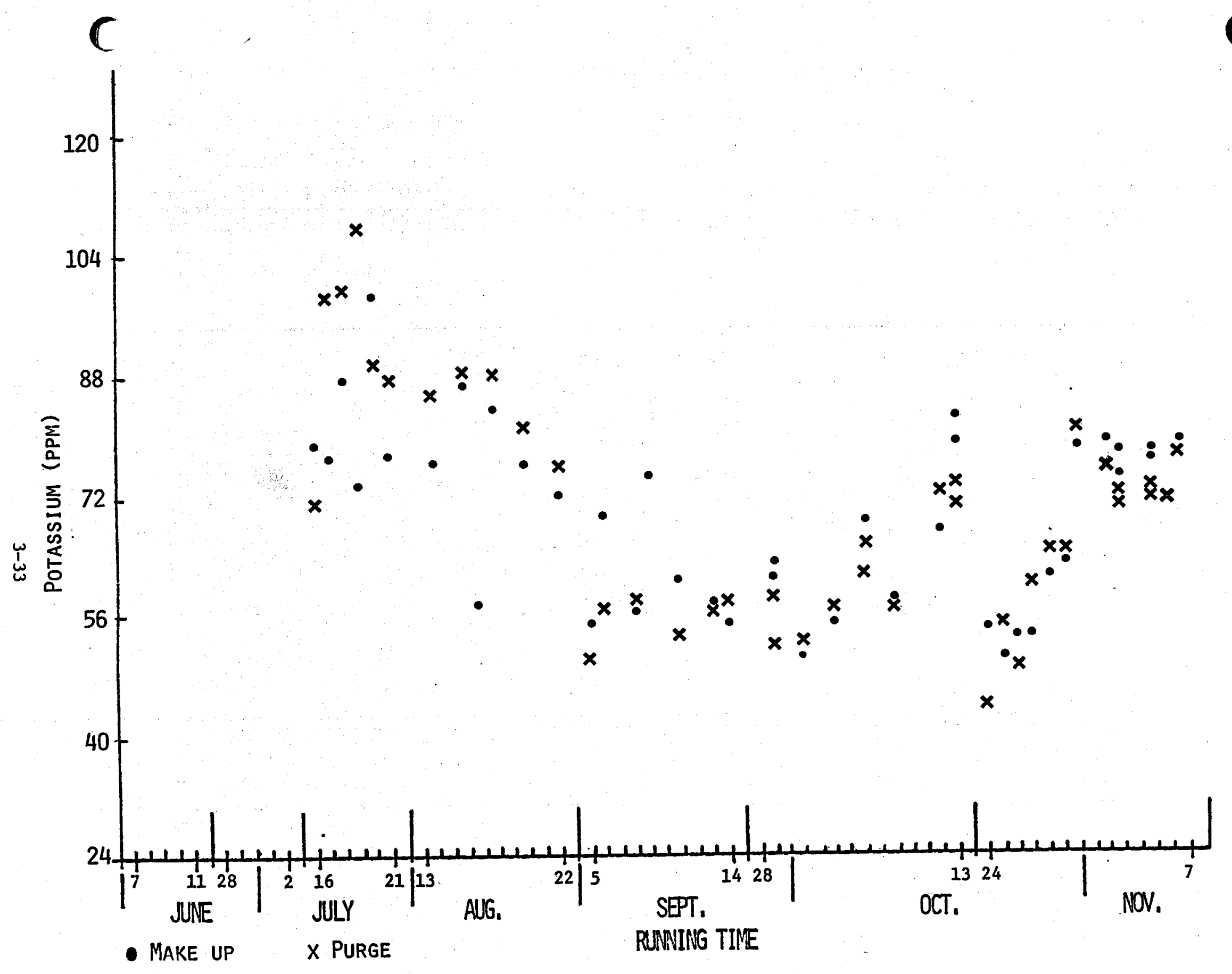

Fig. 19. Potassium content of makeup and purge. 


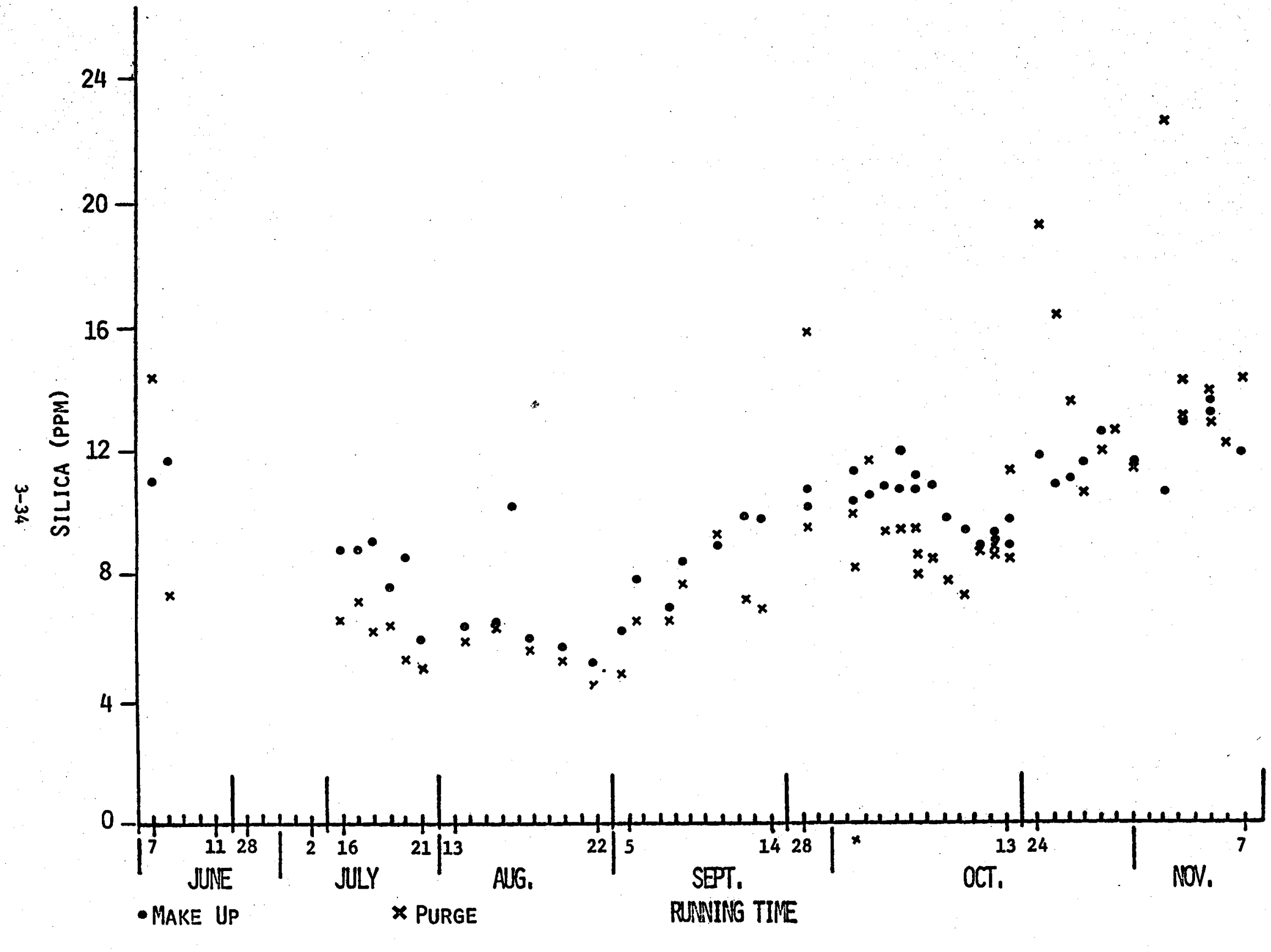

F1g. 20. Silica content of makeup and purge.

$C$ 


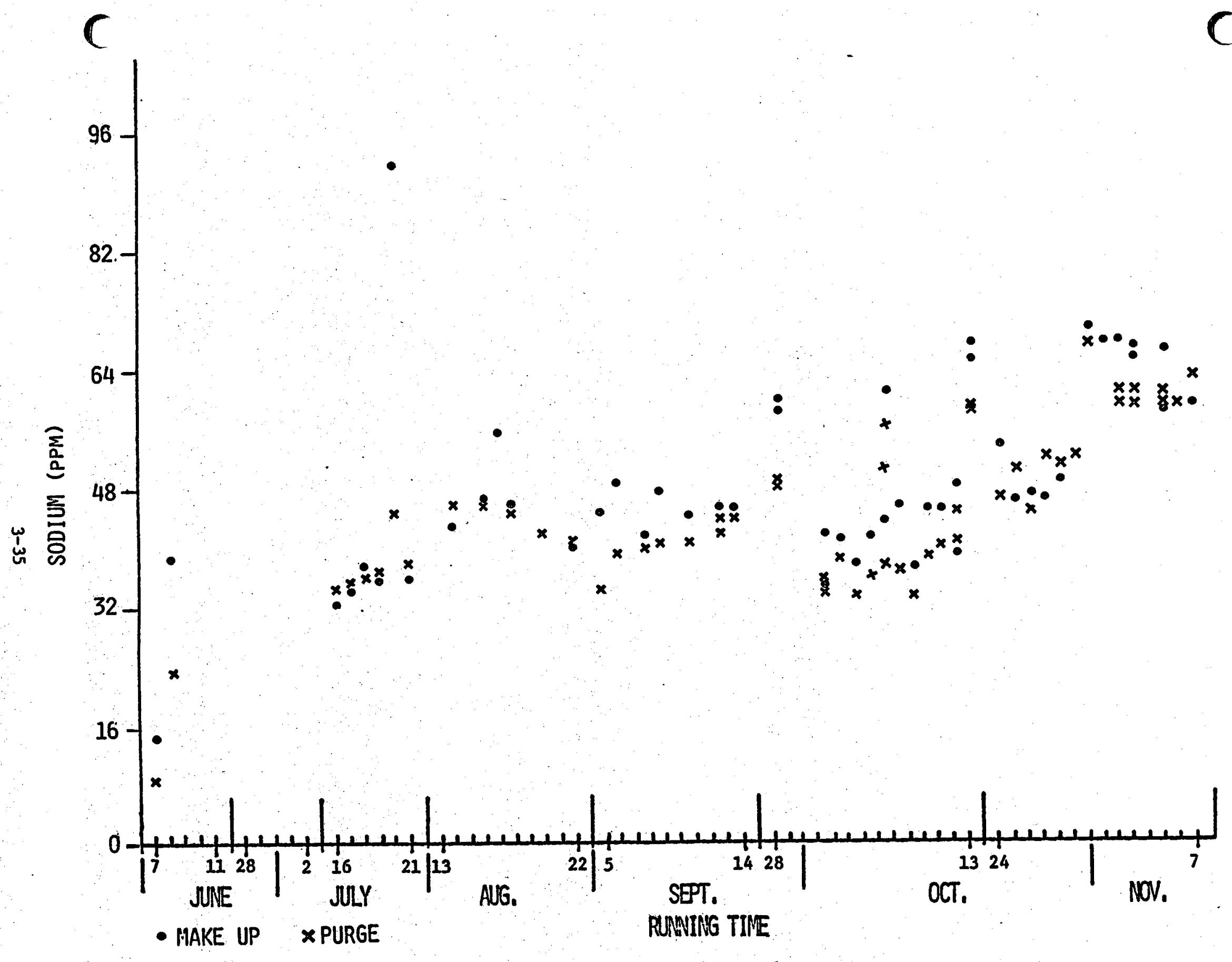

F1g. 21. Sodium content of makeup and purge. 
Table 6

Trace Element Material Balances

\begin{tabular}{|c|c|c|c|c|c|c|}
\hline E1ement & \multicolumn{2}{|c|}{$\begin{array}{l}\text { Steam Compositions, } \\
\text { Average PPM } \\
\end{array}$} & $\begin{array}{l}\text { From Steam } \\
\text { to Purge }(1) \\
\text { PPM } \\
\end{array}$ & $\begin{array}{l}\text { Makeup } \\
\text { Water } \\
\text { PPM } \\
\end{array}$ & $\begin{array}{l}\text { In with Make- } \\
\text { up Chemicals } \\
\text { PPM } \\
\end{array}$ & $\begin{array}{l}\text { Final Purge } \\
\text { PPM } \\
\end{array}$ \\
\hline B & $25.4^{(2)}$ & 21.5 & 355 & 147 & 2.3 & 1900 \\
\hline Al & 0 & 0 & 0 & 0.02 & 4.5 & 9 \\
\hline As & $0.1^{(2)}$ & 0.05 & 4.6 & 0.44 & 2.8 & 16 \\
\hline $\mathrm{Ca}$ & 0.12 & 0.12 & 0 & 0.39 & 5.1 & 4 \\
\hline $\mathrm{Gr}$ & 0.01 & 0.03 & -1.8 & 0.01 & 1.6 & 3 \\
\hline $\mathrm{Fe}$ & 0.02 & 0.02 & 0 & 0 & 54 & 33 \\
\hline $\mathrm{Mg}$ & 0.04 & 0.06 & -1.8 & 0.04 & 6.0 & 8 \\
\hline $\mathrm{N} 1$ & 0.01 & 0.03 & -1.8 & 0 & 18 & 12 \\
\hline $\mathrm{K}$ & $1.02^{(2)}$ & 1.02 & 0 & 6.1 & 3.0 & 75 \\
\hline Si & 0.25 & 0.15 & 9.1 & 0.33 & 5.5 & 13 \\
\hline $\mathrm{Na}$ & $2.18^{(2)}$ & 2.15 & 2.7 & 5.8 & 13 & 62 \\
\hline
\end{tabular}

\footnotetext{
(1) For the average steam and purge flow rates for the campaign.

${ }^{(2)}$ Reported low because of sampling difficulties, see text.
} 
$\mathrm{CuSO}_{4}$ and $\left(\mathrm{NH}_{4}\right)_{2} \mathrm{SO}_{4}$ fed to the system to offset purge stream losses. Unfortunately, only the material balances for $\mathrm{Ca}, \mathrm{Mg}$, and $\mathrm{Si}$ close reasonably well using data derived from measured compositions. The balances for $\mathrm{Al}, \mathrm{Cr}, \mathrm{Ni}$ and possibly $\mathrm{Fe}$ might have closed better if sampling of the makeup chemicals had been more frequent. As it was, only two samples were taken and the analyses differed by as much as $30 \%$. The data suggest that essentially all of the $\mathrm{Al}, \mathrm{Ca}, \mathrm{Cr}, \mathrm{Fe}, \mathrm{Mg}$, and $\mathrm{NI}$ in the purge stream were derived from the makeup chemicals fed to the system. Of the remaining elements, most of the boron, arsenic, potassium and sodium as well as the majority of the silica must have come from the steam which was scrubbed. A consideration of the overall balances also shows that either the reported average steam inlet or outlet compositions must be in error for boron, arsenic, potassium and sodium. If the measured steam outlet compositions are taken to be correct, the calculated inlet compositions must be increased to $40.7 \mathrm{ppm}$, $0.20 \mathrm{ppm}, 1.75 \mathrm{ppm}$, and $2.65 \mathrm{ppm}$ for these elements respectively. On this basis the approximate removal efficiencies were $75 \%$ for arsenic, $50 \%$ for boron, $40 \%$ for potassium and silica, and $20 \%$ for sodium. Independent measurements by PG\&E place the boron content of the inlet steam at about $40 \mathrm{ppm}$ which confirms the estimate presented here. We believe that underestimation of these elements resulted from improper sampling: they may have been dissolved by the molsture which was present in the steam from time to time and which, preferentially flowing along the walls of the inlet pipe, was not picked up by the center line probe. This mechanism might also explain the higher variability of ammonia than hydrogen sulfide reported in Figs. 6 and 7 .

\subsection{Hydrogen Sulfide and Ammonia Removal}

A record of the hydrogen sulfide and ammonia contents of the scrubbed steam throughout the course of the test campaign is presented in Figs. 22 and 23. The calculated percentage removal is based on the average inlet compositions for the entire campaign so that, on any day, the percentage removal may actually have been higher or lower than indicated depending upon the inlet composition.

The average hydrogen sulfide removal efficlency, for all points obtained during the campaign, was approximately 97\%. During the last two run series, average removal efficiencies exceeded $98 \%$ and removal efficlencies exceeding $99 \%$ could be obtained at will. Since obtaining very high degrees of abatement was not a primary objective of this campaign, and since we were interested in demonstrating rellability and operabllity, no special attempts were made to achieve high degrees of abatement except during the scrubbing efficlency tests which are described in more detall in a following section. The relatively high $\mathrm{H}_{2} \mathrm{~S}$ contents of the outlet steam obtained during July and 


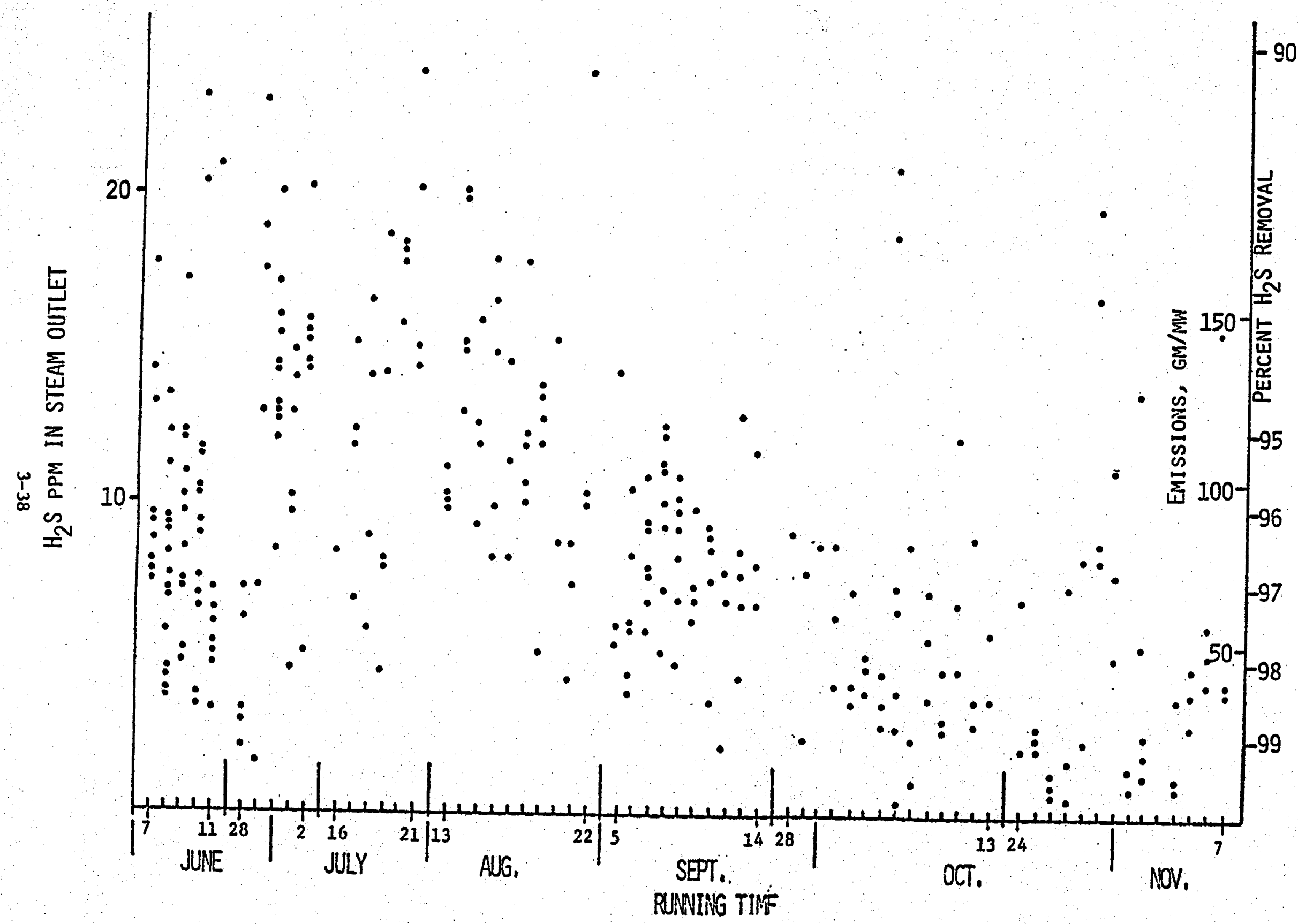

F1g. 22. $\mathrm{H}_{2} \mathrm{~S}$ content of the scrubbed steam. 


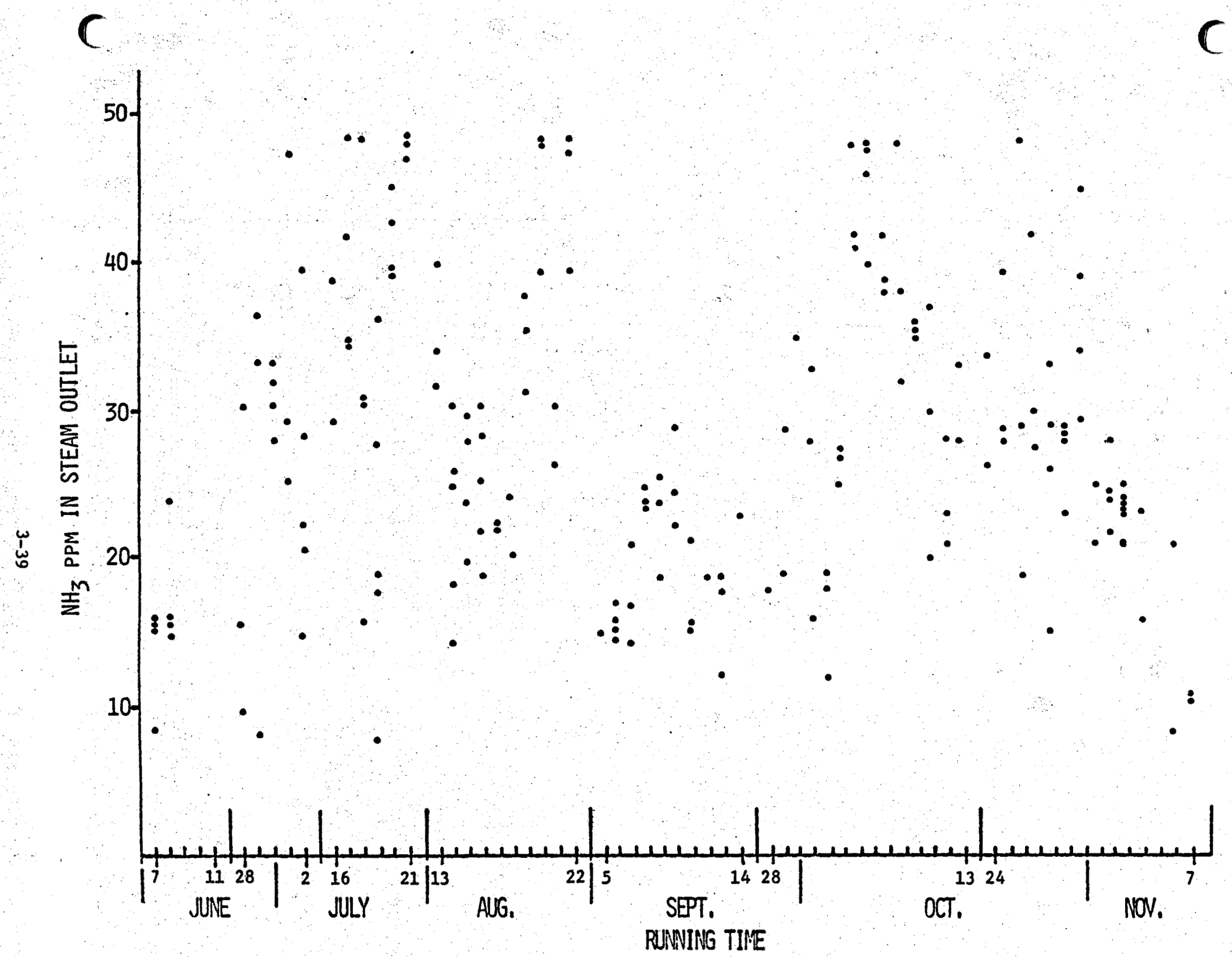

FIg. 23. $\mathrm{NH}_{3}$ content of the scrubbed steam. 
early August were due in part to a series of test runs whose prime objective was to investigate the effect of tray modification on scrubber stability and the ability to operate without the retention of solids on the tray. More stable scrubbing operations were obtained during the latter half of the test campaign as attention was refocused on solving demisting problems and this is reflected by the improved removal efficiencies of both hydrogen sulfide and ammonia. The relatively poor ammonia removal efficiencies reported in early October result from a test campaign during which an additional 60 ppm of amonia were injected into the inlet steam to modify its composition. A fraction of the ammonia passed unremoved through the scrubber which increased the values in the outlet steam. As is the case with the inlet steam, the scatter is rather greater for the ammonia than for the hydrogen sulfide. This may be due to operating problems since, in the case of outlet steam, any entrained scrub solution would contribute material amounts of ammonium sulfate to the outlet steam sample. This would be plcked up by the analyses and reported as the equivalent amount of ammonia. In any case, the average reported amonia removal efficiency is approximately $80 \%$.

It is clear from the data that, given proper tray hydraulics and solution compositions, it will be possible to achieve a $97 \%$ or higher degree of hydrogen sulfide removal efficiency. Indeed, it is possible to conceive of a staged scrubbing operation in which essentially quantitative removal would be possible; the key design factor is simply to provide suitable contacting to allow the rapid kinetics to proceed.

The situation is less clear with respect to ammonia however. A significant backpressure of ammonia exists above ammonium sulfate solutions at the $\mathrm{pH}$ and temperatures at which the scrubber operates. Thus, both kinetics and equilibrium must be considered in attempting to predict ammonia removal efficiency. It would be necessary to obtain some fundamental thermodynamic data on the activity coefficients in these solutions in order to predict equilibrium partial pressures for an assessment to be made of the relative importance of kinetics and thermodynamics in ammonia removal. About all that can be said is that ammonia removal efficiencies will certainly exceed $70 \%$ in most cases but are unlikely to exceed $90 \%$ unless extremely effective scrubbing, low ammonium sulfate, and high acid concentration are employed in an integrated system. Since, in general, this will adversely effect the efficiency of hydrogen sulfide removal, the relative costs of purchasing additional neutralizing agent must be weighed against the benefits of achieving higher hydrogen sulfide removal efficiencies on a case by case basis.

\subsection{Scrubber Performance - Operability}

The scrubber operations proved to be remarkably stable in the face of changes in steam composition and condition shown in Figs. 4-7. The copper composition control loop automatically adjusted for changes in 
inlet steam $\mathrm{H}_{2} \mathrm{~S}$ content with at most a slow drift of $\pm .2-.3 \mathrm{~g} / \mathrm{l}$ Cu until the steady state was reestablished. Changes in the process acid balance forced by a varying $\mathrm{NH}_{3} / \mathrm{H}_{2} \mathrm{~S}$ ratio were accommodated by varying the decanter overflow-to-underflow rate once a day or so if required. Only the occurrence of slugs of moisture in the inlet steam (see Fig. 4, day 10/8) tended to be troublesome, since they could result in increases in sump level of as much as an inch in ten minutes. Eventually, we came to associate some of these occurrences with small step changes in steam pressure and began to initiate corrective action as soon as it became clear that level changes were not the result of normal fluctuations. Late in the campalgn our operators claimed they could recognize diurnal changes in steam quality and correct accordingly to purge more moisture - or less superheat - at night. In a commercial system, of course, this function would be handled automatically on level control.

Start up of the scrubber was rapid and routine. Once mechanical integrity had been assured the system was heated and brought to line pressure by opening a 4" steam bypass valve slightly. Heat up usually was completed in $1 / 4$ and $1 / 2$ hour, during which time the circulation of scrub solution was established and a "heel" of makeup $\mathrm{CuSO}_{4}$ solution was introduced into the sump. A small flow of purge slurry was initiated to provide a signal to the purge stream copper analyzer which then automatically controlled the flow of makeup required. The steam flow rate was then increased in 20,000 1b per hour steps until the operating flow rate was reached. This typically took about $1 / 2$ hour but could have been carried out much more rapidly had the steam supplier been able to maintain turbine throttle pressure. Once steady steam, scrub, makeup, and purge flow rates had been obtained ususally within an hour of startup - changes in the measured system variables occurred quite slowly.

Normal shutdown procedure Involved essentially a reversal of the steps taken during startup. Steam flow rates were reduced to essentially zero as rapidly as changes in the turbine inlet pressure could be accommodated, and the slurry purge rate was increased to drain the sump as fast as possible. When a minimum sump level was reached, before the onset of cavitation in the circulating pumps, the demister wash timer would be reset to $100 \%$ to flush the system prior to depressurizing. Shut down, flushing and depressurizing normally required a few hours - mostly for flushing/ draining, and the vessel would be cool enough for entry and inspection 12 hours after inlet and outlet blinds in the steam line had been rotated.

The previously noted problems in eliminating drift in the demister pressure drop transmitter prevented an accurate determination of the rate of fouling by accumulation of solids. Such fouling would cause local velocities to exceed the maximum allowable for efficient performance. We came to Infer fouling by the occurrence of large flows of condensate from a low point drain on the outlet steam line or a low condensate $\mathrm{pH}$. No evidence of slow 
fouling of the scrubber's tray was noted during the campaign. At times, a slight increase in tray DP, of the order of a few inches, was noted in the first day's operation but steady conditions were always obtained within 24 hours.

A variety of tray configurations were tested during the campaign, with downcomer areas being changed by as much as $50 \%$ and tray hole areas by as much as $25 \%$. The objective of making these modifications was to determine the limits of tray operability for the expected range of steam flow rates and $L / V$ ratios. We found that if the downcomers were overly restricted, solids would be retained on the tray in the form of softball sized accretions which apparently grew from the froth and did not pass through the downcomer. When proper hydraulics were obtained, stable froths and good scrubbing efficiency were obtained at reasonable liquid circulation rates. At these conditions, the tray would be found to be clean at shutdown, or at worst a few golf ball sized accretions would be present on the tray and in the sump.

The bottom of the scrubber sump section was a six foot elliptically dished head with an 8 " center drain nozzle. Superficial velocities of the recirculated scrub solutions were lower than the settling velocity of the solids, so that the sump tended to act as a decanter. Sollds build up always occurred over the first day of a run, although modification of the configuration of the recirculation nozzle reduced its extent. This accumulation did not appear to adversely effect scrubber operation, although "ratholing" was evident between the bottom of the downcomers and the drain. About 200 gal of thick slurry were always found in the sump at the end of a run. The majority was pumped with flushing to T101 and increased the copper content of the first few batches regenerated at the start of the next run.

\subsection{Scrubber Performance - Efficiency}

A key objectlve of these tests was to demonstrate operability, since It was known that high removal efficiencies could be obtained almost at wi11. Thus, the better than $98 \%$ removal efficiency obtained during the last months of the campaign may be considered as a reasonable design goal achievable with normal operator attention and without modification of the steam composition at No. 7 Unit.

A series of scrubbing efficiency tests was carried out on 10/7/79, however, to investigate the effects of tray hydraulics. on performance. The tests, sumarized in Table 7, were carried out by varying the steam and scrub solution flow rates while maintaining the scrub solution copper content in the vicinity of $3 \mathrm{~g} / \mathrm{l}$. No attempt was made to control acidity, and the reported variation in $\mathrm{pH}$ is within the range of fluctuations normally 


\section{Table 7}

Scrubbing Efficlency Test of $10 / 7$

\begin{tabular}{|c|c|c|c|c|c|c|c|}
\hline Trial & 1515 & 1615 & $\underline{1415}$ & 1715 & 1315 & $\underline{0803}$ & 1215 \\
\hline $\begin{array}{l}\text { Steam Flow } \\
10^{3} \mathrm{lb} / \mathrm{hr}\end{array}$ & 90 & 110 & 90 & 110 & 90 & 90 & 90 \\
\hline $\begin{array}{l}\text { Scrub Solution Flow } \\
\text { GPM } \\
\mathrm{g} / \ell \\
\mathrm{pH}\end{array}$ & $\begin{array}{l}200 \\
3.1 \\
1.2\end{array}$ & $\begin{array}{l}200 \\
2.9 \\
1.4\end{array}$ & $\begin{array}{l}300 \\
3.1 \\
1.2\end{array}$ & $\begin{array}{l}400 \\
3.0 \\
1.2\end{array}$ & $\begin{array}{l}400 \\
3.2 \\
1.2\end{array}$ & $\begin{array}{l}500 \\
3.1 \\
1.4\end{array}$ & $\begin{array}{l}700 \\
3.0 \\
1.3\end{array}$ \\
\hline $\begin{array}{c}\text { Tray Pressure Drop } \\
\text { Inches } \mathrm{H}_{2} \mathrm{O}\end{array}$ & 4.5 & 7.5 & 6.8 & 10.0 & 8.0 & 10.5 & 13.0 \\
\hline $\begin{array}{c}\text { Contact Time } \\
\text { Seconds }\end{array}$ & 0.5 & 0.7 & 0.7 & 0.9 & 0.9 & 1.2 & 1.4 \\
\hline $\begin{array}{l}\text { Steam Out } \\
\text { PPM } \mathrm{H}_{2} \mathrm{~S} \\
\text { PPM NH} 3\end{array}$ & $\begin{array}{r}21.2 \\
58\end{array}$ & $\begin{array}{r}18.8 \\
53\end{array}$ & $\begin{array}{r}11.9 \\
53\end{array}$ & $\begin{array}{r}7.4 \\
40\end{array}$ & $\begin{array}{r}6.5 \\
46\end{array}$ & $\begin{array}{r}2.6 \\
55\end{array}$ & $\begin{array}{r}0.4 \\
50\end{array}$ \\
\hline $\begin{array}{l}\text { Percent } \mathrm{H}_{2} \mathrm{~S} \\
\text { Removal }\end{array}$ & 92.6 & 93.4 & 95.8 & 97.4 & 97.7 & 99.1 & 99.9 \\
\hline
\end{tabular}


observed at steady conditions. After recording operating data and taking duplicate samples of outlet steam, the flow rates of steam and scrubbing solution were readjusted for the next test series. Tray pressure drop restabilized within $15 \mathrm{~min}$, and purge copper content restabilized within $1 / 2$ hour. The system was allowed to run at least $1 / 2$ hour before resampling. The composition of the replicated steam samples agreed to within $\pm 10 \%$ ( $<1 \mathrm{ppm}$ ) for $\mathrm{H}_{2} \mathrm{~S}$ and within $\pm 20 \%$ (<10 ppm) for $\mathrm{NH}_{3}$.

Clearly, longer contact times - higher froth heights and/or lower steam flow rates - improved $\mathrm{H}_{2} \mathrm{~S}$ removal efficiency. The exact relation between froth height, scrub solution flow rate, and steam flow rate is fixed by the tray layout. Higher hole velocities and downcomer flow rates tend to increase froth height at fixed flow rates, but the variation is not linear, and upper and lower limits are fixed by the onset of entrainment or solids retention and weeping respectively. Higher copper contents also promote increased $\mathrm{H}_{2} \mathrm{~S}$ removal, but at the expense of a more costly purge stream decopperization operation.

The raw steam's average $\mathrm{H}_{2} \mathrm{~S}$ and $\mathrm{NH}_{3}$ contents for the $10 / 7$ test series were 285 and $150 \mathrm{ppm}$ respectively. However, an additional $60 \mathrm{ppm} \mathrm{NH}_{3}$ was injected into the inlet steam so that $\mathrm{NH}_{3}$ removal was of the order of $75-80 \%$ throughout. Addition of $\mathrm{NH}_{3}$ raised the scrub solution's $\mathrm{pH}$, which also would increase $\mathrm{H}_{2} \mathrm{~S}$ removal efficiency all else being equal. These results demonstrate that near quantitative degrees of $\mathrm{H}_{2} \mathrm{~S}$ removal may be obtained if one is willing to pay the costs associated with maintaining the scrub solution's $\mathrm{pH}$ and copper content and circulating flow rate in the appropriate ranges.

\subsection{Scrubber Performance - Dynamics}

A limited series of scrubber dynamics testing was carried out when the scrubbed steam was being passed to the turbine. It was not possible to perform these tests when venting steam to the mufflers because changes in flow rate had to be coordinated with the steam supplier and could not be effected rapidly. Copies of the controller charts produced during the dynamics tests which were started at 2:30 PM on 11/4 are shown in Fig. 24 .

The test procedure involved coming to steady state at $90 \%$ of the design flow rate and then changing the set point of FCV101A, on manual control, to drop the flow rate in half in a step fashion. No other changes were made and the system was allowed to regain steady state. The simultaneous drop in tray DP and increase in sump level results from the dumping of some of the froth to the sump at lower steam velocities.

The increase in copper content is due to controller lag: lower froth height reduced $\mathrm{H}_{2} \mathrm{~S}$ removal efficiency thereby decreasing demand, but the 

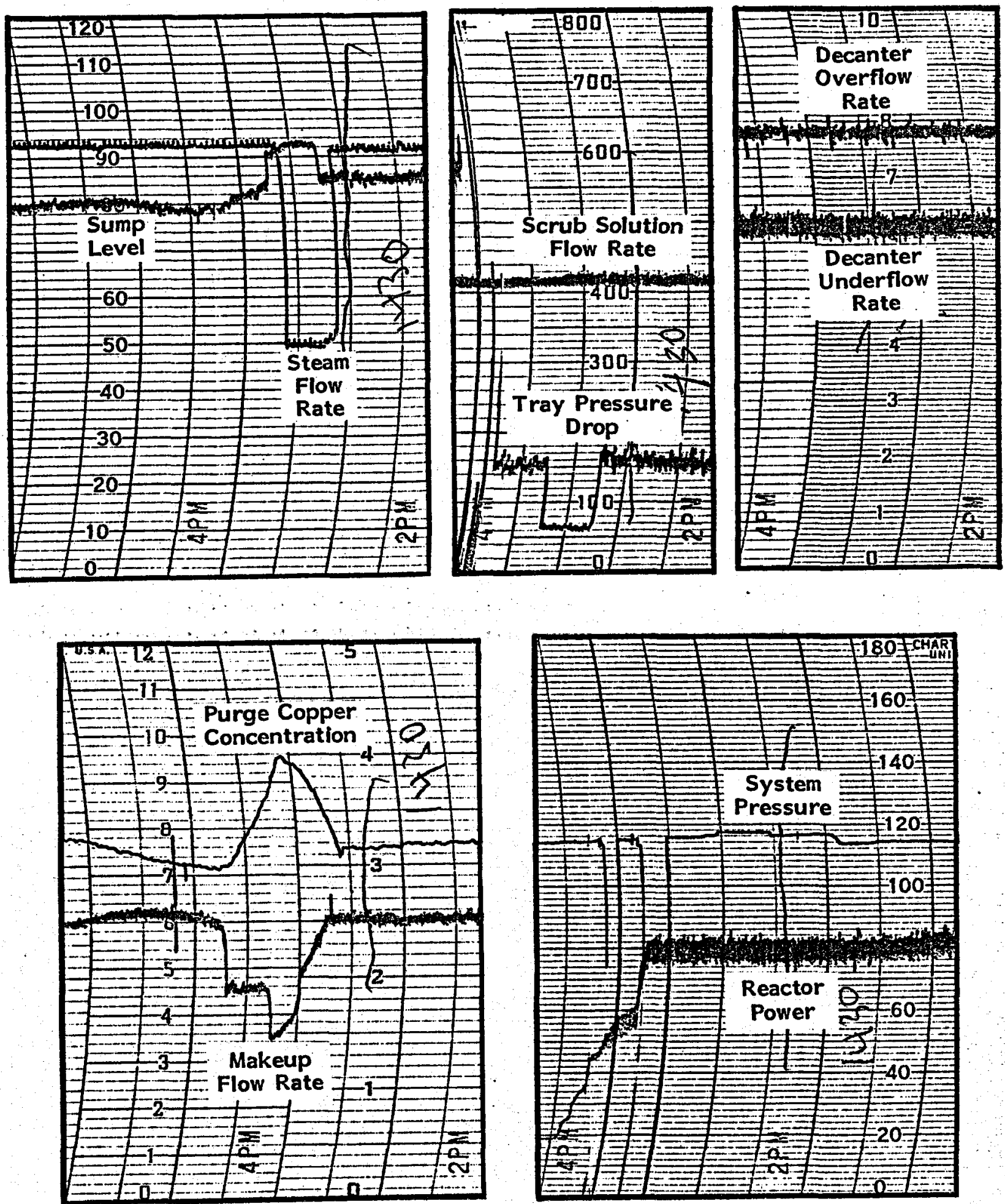

Fig. 24. Results of scrubber dynamics tests. 
cascade control of the makeup scrub solution set point was slow to respond. No change in outlet steam $\mathrm{pH}$ or condition (calorimeter temperature) was observed, but the $\mathrm{H}_{2} \mathrm{~S}$ content did rise as would be expected.

Once steady state had been attained again, at about $3 \mathrm{PM}$, the steam flow was increased to $90 \%$ of design in a step fashion. This was considered to be a more severe test of the systems stability because of the potential for causing upsets which would lead to severe entrainment. In fact, none was observed and the changes were simply the expected reverse of those which occurred in the downward adjustment. These rates of change were much higher than normally encountered during a routine change of load on the turbines and approached those experienced during a trip out. The smooth, stable response of the scrubber was encouraging, and we see no problem coping with the dynamics of normal turbine operation, load adjustments, or trips.

\subsection{Scrubber Performance - Disentrainment}

The mechanical problems associated with the use of a Teflon mesh pad type demister have been described earlier. The improvements brought about by the use of Teflon "sausages" and than a titanium demister are summarized in Table 8.

The amount of entrainment was not measured directly, but was determined from the ratio of the measured concentration of a "tag" element in the outlet steam and in the scrub solution, which was the source of the entrainment. It was not possible to use $\mathrm{B}, \mathrm{Ca}, \mathrm{K}$, or $\mathrm{Na}$ for this purpose since they were present in the demister wash water in considerable quantities. The entrainment estimates derived from the measurement of the other cations are averages of all measured values. For some tests, the differences in estimated entrainment exceeded an order of magnitude, which may reflect poor sampling technique or chemical changes in the sampling train - e.g., due to precipitation, sorption, etc. While the low levels of sulfate reported also proved difficult to measure, we feel they are more consistent and reliable for estimation of entrainment.

Removal effictencies of these types of demisters in normal service are of the order of 99 to $99.9 \%$ depending on particle size distribution, and we had expected entrainment to be of the order of $<0.0005$ pound per pound of steam. While these levels were ultimately obtained, much higher levels persisted for the first $40 \%$ of the campaign with serious consequences which will be described in a following section. Furthermore, the bottom sections of the pads were found to have retained significant amounts of solids at the end of each run, although none were ever found above the pads. If such buildups were allowed to continue, the maximum allowable velocities through the pads would eventually be exceeded and entrainment from the scrubber would increase dramatically. 
Table 8

Demister Efficiency Estimates

\begin{tabular}{|c|c|c|c|c|c|}
\hline Test & $6 / 30$ & $9 / 11$ & $10 / 5$ & $11 / 2$ & $11 / 7$ \\
\hline Demister Style ${ }^{(1)}$ & $\mathrm{T}$ & $\mathrm{T} / \mathrm{S}$ & $\mathrm{T} 1 / \mathrm{T}$ & $\mathrm{Ti} / \mathrm{T}$ & $\mathrm{Ti} / \mathrm{T}$ \\
\hline $\begin{array}{l}\text { Steam Flow } \\
10^{3} \mathrm{Ib} / \mathrm{hr}\end{array}$ & 100 & 90 & 90 & 90 & 120 \\
\hline $\begin{array}{l}\text { Steam Out } \\
\text { PPM } \mathrm{SO}_{4}\end{array}$ & 750 & 20 & 10 & 9 & 14 \\
\hline $\begin{array}{l}\text { Entrainment, } 1 \mathrm{~b} / 1 \mathrm{~b} \text { st } \\
\text { From measured } \mathrm{SO}_{4}\end{array}$ & 0.015 & 0.0004 & 0.0001 & 0.0002 & 0.0003 \\
\hline $\begin{array}{l}\text { From measured } \\
\mathrm{Al} / \mathrm{As} / \mathrm{Cr} / \mathrm{Fe} / \mathrm{Mg} / \mathrm{Ni} / \mathrm{Si}\end{array}$ & 0.044 & 0.0016 & 0 & 0.0018 & 0.0008 \\
\hline
\end{tabular}

(1) T - Original Tefion demister.

$T / S$ - Teflon with sausages.

$T i / T$ - Titanium plus Teflon demister. 
A different approach to disentrainment would be required to Insure long tern operability in a commercial scale system. Stagewise disentrainment would be justified, in which the lower demister would have high vapor capacity and the ability to tolerate solids loads without fouling even if removal efficiencies were not high. Then, a lower capacity - higher efficiency demister would be used to remove residual entrainment. The lower demister could be washed continuously, but the final one need not be. Also, the use of a second disentrainment vessel might be considered.

\subsection{Operation of the Regeneration System}

Operation of the regeneration system met or exceeded our expectations and was generally without incident.

We found in early test work that regeneration was rapid and essentially quantitative, but that there was rather more variability in the final copper content of the batches than had been anticipated. This could only have resulted from transferring different initial slurry densities from T101 to the reactor, and might have been troublesome if not corrected because of the widely differing final pHs which resulted. We eventually solved the problem by holding transfers of batches from T101 to the reactor until the level in the slurry tank exceeded about 10 feet. As has been pointed out in a previous section, the only major equipment revisions in the regeneration system involved the installation of a sparge ring in the bottom of T101 in place of a static mixer for ambient preleaching.

After our initial test period we determined that optimum kinetics would be obtained if the reactor were filled to a level of about nine feet - which was the location of the upper decant nozzle - for an agitator level of about eight feet. Good vortexing and gas-liquid dispersion was obtained at a power consumption of about $3.5 \mathrm{HP} / 1000 \mathrm{gal}$. The pump around heat exchanger on T101, HX201, was used to keep the contents of the slurry tank at $160-180^{\circ} \mathrm{F}$, and the reactor could be filled with $180-200^{\circ} \mathrm{F}$ slurry in preparation for leaching in about $1 / 2$ hour. The temperature could be ralsed further in the reactor, if desired, by direct sparging of steam. Cooling water in the reactor jacket could be used to maintain an isothermal leach for test purposes, but for routine operations the exothermic heat of reaction was allowed to heat the contents of the vessel to 230$250^{\circ} \mathrm{F}$.

For normal operation, a flow of vaporized oxygen was initiated as soon as the reactor was full. The total pressure in the vapor space would rise until the set point, typically $100 \mathrm{psig}$, was attained at which point the flow of oxygen would begin to be throttled. The reaction would be completed within $1 \frac{1}{2}-2$ hours, at which point the flow of oxygen would cease. The charts recorded during a typical regeneration run are presented in Fig. 25. 

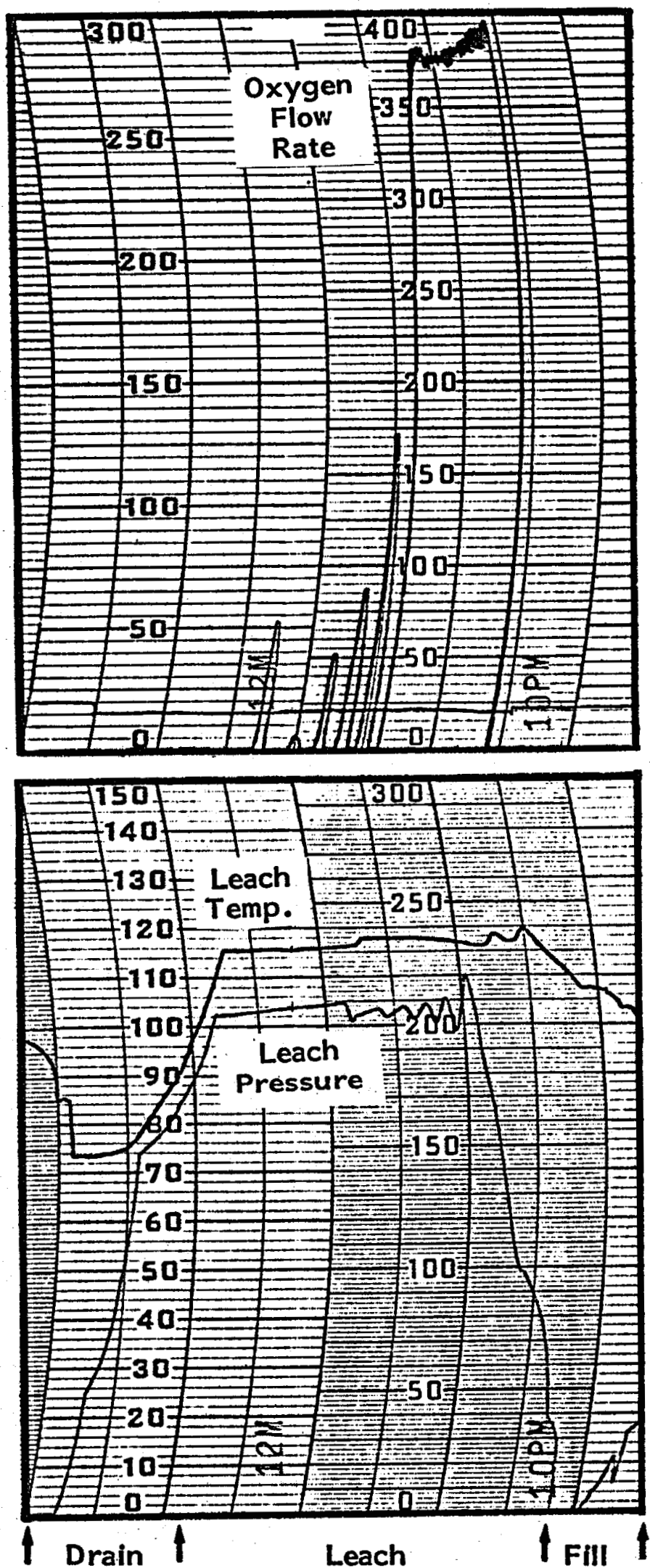

Fig. 25. Results of a typical regeneration run. 
Normally two, or from time to time three, batches were regenerated per day with essentially quantitative oxidation of copper sulfide to copper sulfate. On eccasion, if too high a slurry density were changed, all the acid in the regeneration reactor would be consumed and the $\mathrm{pH}$ of the solution would rise to about $\mathrm{pH}$ 2.5. At this point, basic copper sulfate solids, which were greenish in color and very fine, would be formed. They would blind filter F201 very rapidly, but would redissolve readily if suspended in a solution at $\mathrm{pH} \lesssim 2$. At no time were more than about 10 pounds formed per batch from an initial charge of about 1000 pounds of solids.

More than 50 tons of copper sulfide solids were formed and regenerated throughout the test campaign with only negligible residues being produced, of the order of a few pounds per day. This material was found to be essentially all finely divided elemental sulfur, and in fact could be oxidized in the reactor if desired by allowing the contents to "soak" at temperature and pressure for $1 / 2-1$ hour following the end of recorded oxygen consumption. During this time no additional copper appeared in solution, but measured acldities would increase by a few tenths of a gram per liter.

At the completion of the test campaign the reactor and auxiliaries were inspected carefully. No evidence of corrosion or fouling by deposition of solids was noted. Only negligible amounts of fine, undissolved solids were found on the bottom of tanks T102 and T201. Therefore, it does not appear that undissolved "rock dust" will accumulate in a commercial scale system and a polish leach step to separate undissolved sulfides from rock dust will not be required.

\subsection{Regeneration Kinetics}

Kinetic data were obtained, from time to time, by maintaining the reactor in a more nearly isothermal condition and sampling its contents more frequently to measure solution copper contents and acidity. In addition, rate data were obtained while compressed air was being blown through the reactor and during the course of ambient leach experiments in T101. Some kinetic data are presented graphically in Figs. 26 and 27, which represent the fraction reacted as $1-(1-x) 173$ to linearize it according to the form suggested by a shrinking core model.

The reported oxygen partial pressures are mass reacted averaged values. In the early stages of a regeneration run, the solids were so reactive that the oxygen was consumed at a rate faster than it could be supplied from the vaporizer. Later on, the delivery capacity exceeded the consumption rate and the pressure rose towards the set point as shown in Fig. 25, and the reaction rate tended to increase somewhat as we11. This accounts for the break in the curves shown for runs on $7 / 1$ and $9 / 4$, and perhaps for some of the derivation from linearity on $7 / 5$, 


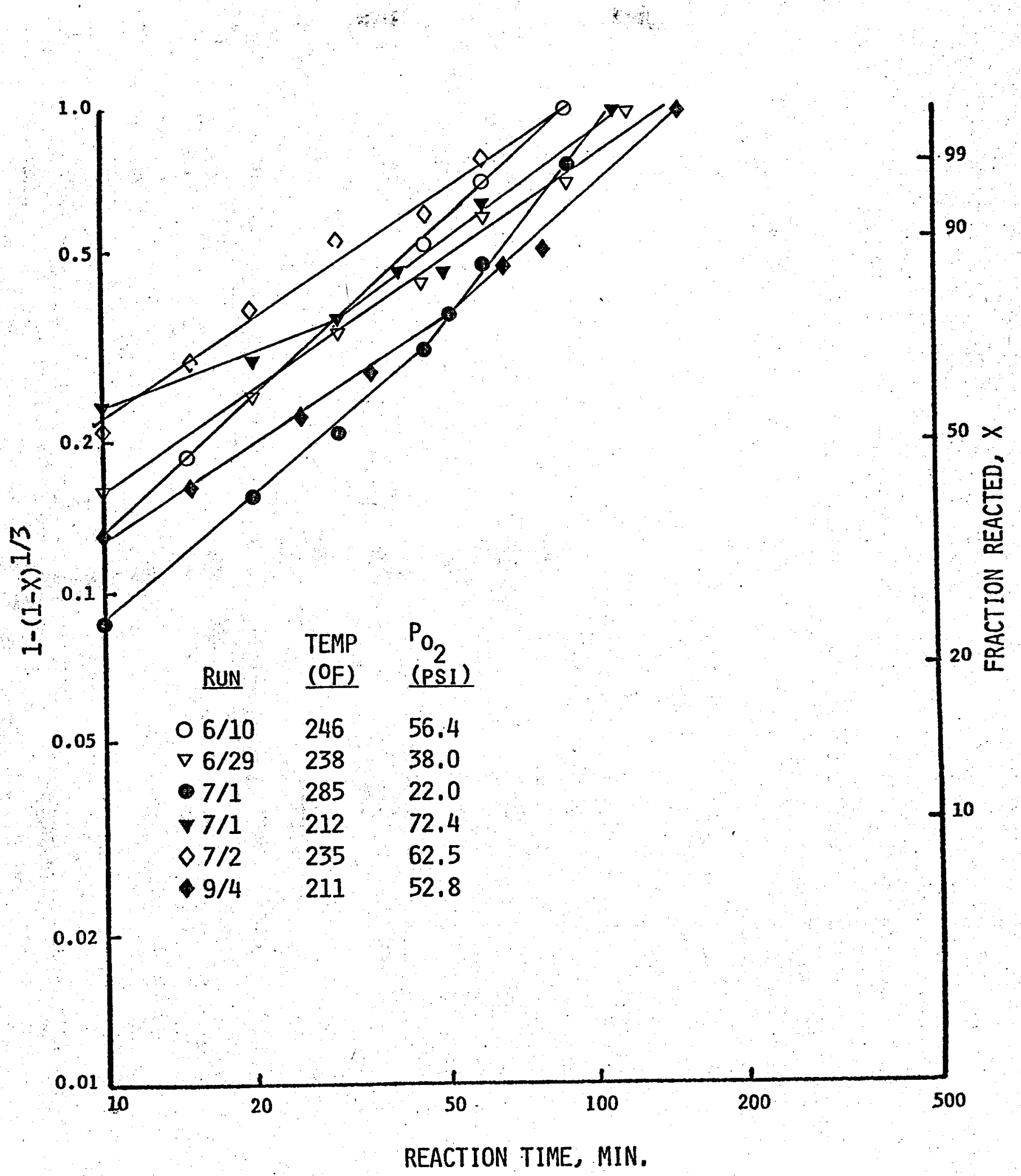

Fig. 26. Oxygen pressure leach data. 


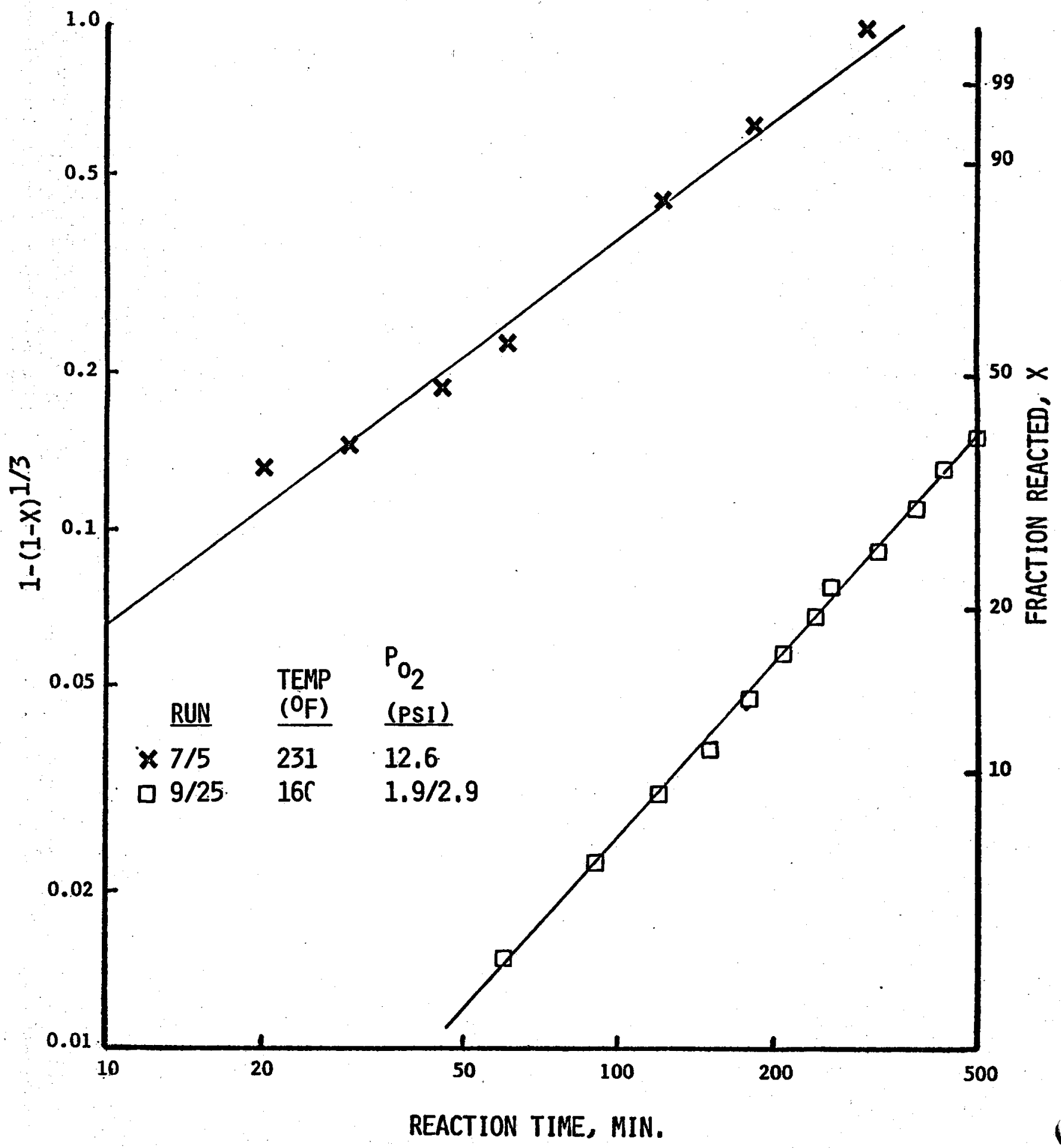

Fig. 27. Air pressure and ambient leach data. 
although in the latter case the total flow rate of oxygen (but not its partial pressure) was constant.

The oxygen pressure leach data show that in many cases the regeneration reaction was almost $50 \%$ completed by the time the first sample was taken, within 10 minutes of the initiation of oxygen flow. Thus, even though the final oxygen partial pressure may have been of the order of $100 \mathrm{psi}$, the weighted average would be much lower since total system pressures were usually of the order of 20-30 psig after 10-15 minutes. The reaction rates for regeneration with air were slower than when using pure oxygen since the maximum attainable oxygen partial pressure from compressed air at $125 \mathrm{psig}$ and reasonable temperatures was about $20 \mathrm{psig}$. The regeneration rate for the ambient leach of 9/25 in T101 was lower still, both because the temperature and oxygen pressure were lower and the mass transfer efficiency was not as good. An oxygen utilization of about $15 \%$ was obtained in T101 at a power input of $0.2 \mathrm{HP} / 1000 \mathrm{gal}$, while up to $50 \%$ utilization was obtained with air pressure leaching in the reactor.

The kinetic data for a number of regeneration runs for which data were obtained are summarized in Table 9. The data are remarkably consistent considering the difficulties involved in carrying out carefully controlled experiments in the field and the wide variety of conditions under which the solids were produced in the scrubber. They show that, normalized for oxygen partial pressure, there is no difference between the use of pure oxygen or oxygen derived from compressed air. The average value for the constant $k$ of $6 \mathrm{~min} \cdot \mathrm{psi}$. Indicate that the reaction will go to completion in one third the time previously estimated from laboratory experiments. This may be due to more effective gas-liquid contacting in the large regeneration reactor, since particle size distribution analysis showed the same type of distribution as for solids produced in laboratory tests. The average particle size was of the order of 2-3 microns, with a few percent distributed around 20 microns and none below one micron. Under ambient conditions, about $40 \%$ of the solids may be regenerated in an eight hour residence time. Then, at modest process conditions of $250^{\circ} \mathrm{F}$ and 100 psig the reaction can be completed within an additional $3 / 4$ hour if pure oxygen is used. Thus, the normal amount of liquid surge capacity usually provided in a process plant can be used for preleaching, and the regeneration reactor in a commerical plant would be about the same size as the one tested in the pilot plant. If compressed air were used, the reactor size would have to be increased to accommodate holding times of 4-5 hours.

The original test plan for the field campaign included an off site test of regeneration by fluid bed roasting. However, since regeneration by oxygen pressure leaching was found to be rapid, quantitative, and trouble free, the roasting tests were not carried out. 


\section{Table 9}

Regeneration Kinetic Data

\begin{tabular}{|c|c|c|c|c|c|}
\hline Run & $\begin{array}{l}\text { Average } \\
\text { Temp. } \\
\left(^{\circ} \mathrm{F}\right) \\
\end{array}$ & $\begin{array}{c}\text { Average } \mathrm{O}_{2} \\
\text { Pressure } \\
\text { (psi) } \\
\end{array}$ & $\begin{array}{l}\text { Time to } 99 \% \\
\text { Regeneration } \\
\text { (min) }\end{array}$ & $\begin{array}{l}\text { Constant } \\
(1) \\
(k, \text { min·psi) }\end{array}$ & Comments \\
\hline $6 / 10$ & 246 & 56.4 & 70 & 6.7 & Oxygen pressure leach \\
\hline $6 / 11$ & 251 & 46.1 & 80 & 6.6 & 1 \\
\hline $6 / 28$ & 245 & 54.4 & 100 & 9.2 & . \\
\hline $6 / 29$ & 238 & 38.0 & 100 & 6.0 & \\
\hline $6 / 30$ & 235 & 29.1 & 80 & 3.6 & · \\
\hline $7 / 1$ & 285 & 22.0 & 90 & 4.7 & \\
\hline $7 / 1$ & 212 & 72.4 & 80 & 7.1 & \\
\hline $7 / 2$ & 235 & 62.5 & 60 & 5.8 & 1 \\
\hline $7 / 5$ & 231 & 12.6 & 220 & 4.1 & Alr pressure leach \\
\hline $7 / 13$ & 252 & 9 & 320 & 5.2 & 1 \\
\hline $9 / 4$ & 211 & 52.8 & 115 & 7.4 & Oxygen pressure leach \\
\hline $9 / 25$ & 160 & $1.9 / 2.9(2)$ & 2100 & 4.3 & Ambient (air) preleach \\
\hline $11 / 13$ & 235 & 43.9 & 70 & 4.7 & Oxygen pressure leach \\
\hline
\end{tabular}

(1) For the relation: Time to $99 \%=\mathrm{k} \mathrm{e}^{(2500 / \mathrm{T})} / \mathrm{P}_{\mathrm{O}_{2}}$.

${ }^{\text {(2) }}$ Pressure at the top and bottom of the tank respectively. 


\subsection{Liquid-Solid Separation Behavior}

Reliable, stable operation of the decanter (or another device) in making a liquid-solid separation of the purge slurry is essential for proper operation of the process. The decanter used in these tests functioned at or above design conditions throughout the campaign without operating problems or attention.

Restart after shutdown was direct; no flushing was required and no tendency to plug was noted. No influence of scrubber operating conditions on decanter performance was noted. While difficult to spot at times, the operating pulp height was at or below the design point even when underflow rates exceeded design.

Overflow solids contents were measured by welghing the solids collected in overflow polish filters F102 and F102A. When operating at design rates, the filters would be changed about once per'day, and measured solids contents were 5-10 ppm. If overflow rates exceeded the design by about $30 \%$, the solids content increased significantly, to perhaps $50 \mathrm{ppm}$, and the filters had to be changed more frequently.

The settling behavior of solids produced in these tests is shown by the data in FIg. 28. These solids, which were produced and purged under normal scrubber operating conditions, show a compression time of about one minute which is at the high range of times for solids produced under lab conditions. The settling rate, about $60 \mathrm{ft} / \mathrm{hr}$, is at the lower range for laboratory solids, but the required upflow velocity and solids detention times are within the design range anticipated for commercial scale equipment, and the observed overflow clarity was better than expected.

We also carried out a series of settling tests on partially leached solids and found, as expected, that the final dilutions decreased as the extent of reaction increased. The settling rate also decreased with the extent of reaction, particularly above about 50\%, although overflow clarities remained. excellent. Therefore, liquid-solid separation of sollds from an ambient leach operation can be made in a decanter, although longer detention times and lower overflow velocities will be required.

The other filters used in the pilot plant - on leach residues, process makeup water, decanter overflow, and the analyzers' sample filter - functioned as expected. Since regeneration is quantitative, a leach polish filter will not be required commercially and conventional criteria can be used for design of a process water filter. As has been pointed out previously; an elaborate sample filter w111 not be needed commercially, and the solubles purge stream can be treated with conventional continuous backwash filters prior to decopperization. 


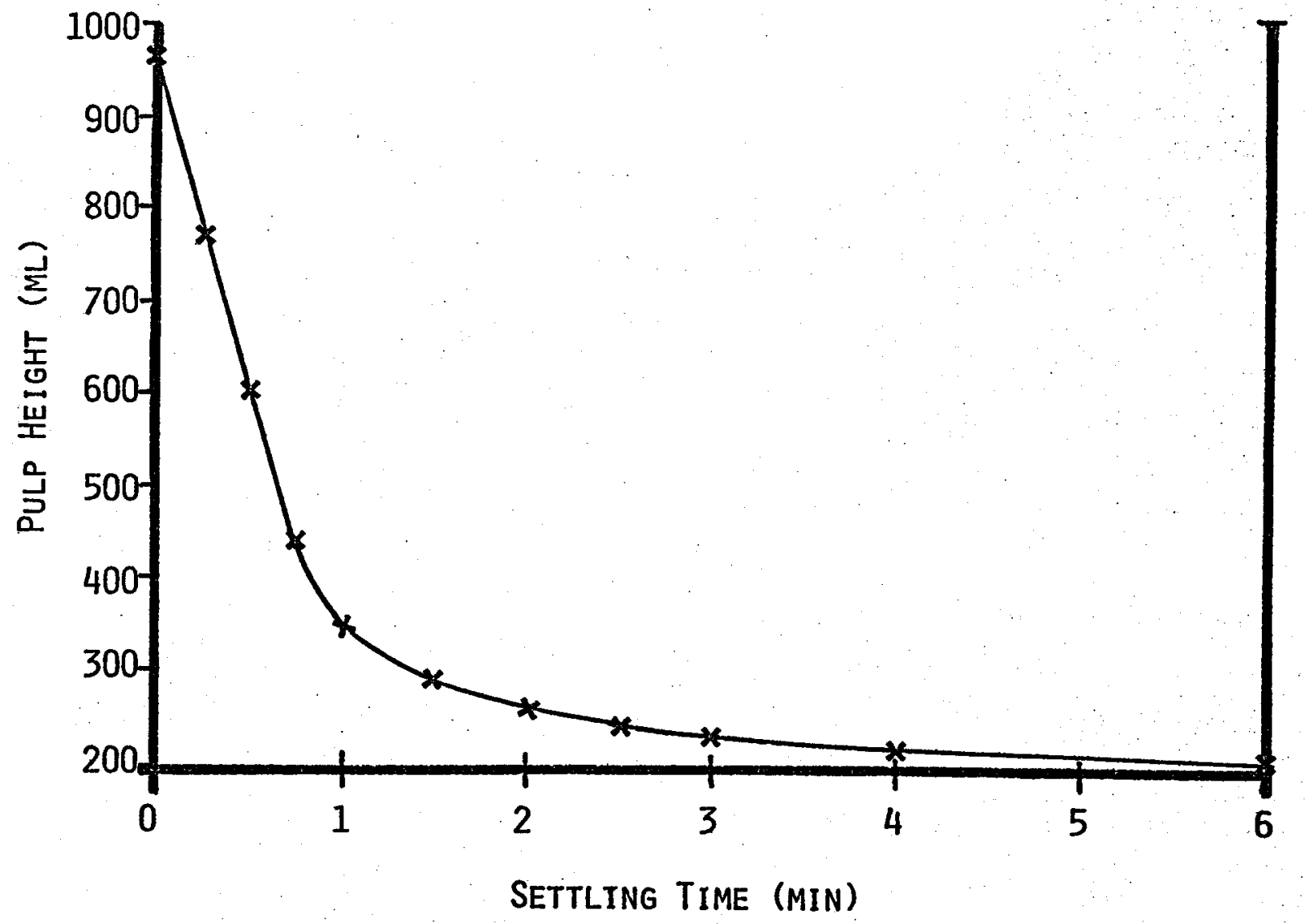

Fig. 28. Settling rate of purge slurry. 


\subsection{Purge Stream Treatment}

Reliable, efficient operation of the purge stream decopperization step is critical to the process, since loss of copper in the purge stream would impose severe economic and perhaps environmental.penalties. Analyses of the various process possibilities for selective removal of copper from the purge stream carried out in the second phase of this program suggested that the use of fixed bed solid ion exchange would be the preferred choice in most circumstances. Since we considered selective removal of soluble copper from a relatively clean stream to be known technology, it was not demonstrated continuously in the pilot plant. Facilities were provided, on SkId 4, to do off line purge treatment tests if desired but very little work was actually done on the purge stream during the test campaign. However, approximately $500 \mathrm{gal}$ of purge liquid were drumed up during the sixth run series and reserved for off site testing.

Previous laboratory work had shown that if the purge stream were neutralized, copper could be removed with a selective cation exchange resin. The resin would be regenerated with strong acid or, less efficiently, with a portion of the unneutralized feed. This concept was retested in an ion exchange equipment vendor's labs and was found to be technically feasible but economically unattractive. The unneutralized feed alone was insufficiently actdic to effectively regenerate strong cation exchange resins. Thus, unless strong acid were imported, resin utilization would be poor and/or the stripped tails would still contain relatively large amounts of copper. A series of tests was then carried out on a weak, copper selective anion exchange resin.

This resin was found to have an adequate loading capacity for the removal of copper from the unneutralized purge, and utilization capacities exceeding $20 \mathrm{~g} / \mathrm{l}$ were obtained at copper recoveries of at 1east $99 \%$. Furthermore, the resin could be easily regenerated with. aqueous amonia which is advantageous from an overall process point of view since the inlet steam will usually contain insufficient amonia to neutralize all the acid formed in the scrubbing reactions. Therefore, a series of pilot scale tests was carried out in Chemical Separations Corporation's facilities to demonstrate the process concept on the 500 gallon of purge reserved from the field tests. Test results are summarized in Table 10.

These tests were run in Chemical Separations proprietary continuous counter current flow equipment. The extremely high copper recoveries, exceeding $99.5 \%$, and low ammonia consumptions were obtained at a temperature of $50^{\circ} \mathrm{C}$ and a feed-to-resin flow rate ratio of 7.5. Analysis of the trace element content of the product and effluent streams showed that the resin was Indeed highly selective and recycle of the recovered copper would not lead to the buildup of objectionable levels of other cations in the system. 
Table 10

Average Results from Codes 6-38 Test Run (1)

\begin{tabular}{lcc}
\hline & Copper Content & pH \\
\hline Feed & $2.74 \mathrm{~g} / \mathrm{l}$ & 1.25 \\
Stripped Effluent & $12.4 \mathrm{ppm}$ & 1.55 \\
Product & $27.4 \mathrm{~g} / \mathrm{l}$ & 7.36 \\
\hline
\end{tabular}

$\overline{(1)}$ Chemical Separations Corporation, $2 / 80$. 
About $75 \%$ of the nickel in the purge was recycled, but this element would not be present at high concentrations in an integrated process in which the amount of makeup chemicals used is low. The tests also showed that sorption kinetics could be improved even further by operation at $80^{\circ} \mathrm{C}$ and that no unusual operating problems would be experienced with this feed stock at either temperature.

This pilot scale demonstration confirmed the feasibility of using copper selective solid ion exchange resins to recover copper for recycle. The use of more conventional dual fixed bed units might lower capital costs vis-a-vis the moving bed approach, but would not be as efficient in the use of ammonia or in copper recovery. Effluent from the ion exchange unit, of whatever design, would then be neutralized prior to further treatment. The decopperized purge stream contains significant quantities of ammonium sulfate and boric acid, which might be recovered individually for sale, or it might be diluted with a 25 fold excess of cooling tower blowdown and reinjected or evaporated to dryness and the solids disposed of in a landfill.

\subsection{Fouling of Heat Transfer and Other Surfaces}

The test plant for the pilot plant called for periodic flushing and inspection of the equipment to be followed by a serles of tests with water as the heat transfer fluid. These data were to be compared with water test data obtained in the initial phase of testing in order to quantify the rate of fouling of heat transfer surfaces. Shut downs between runs provided ample opportunity for inspection of system components and with the exceptions noted below, no visual evidence of fouling was found. The results of heat trans-: fer tests at the beginning and end of the campaing are sumarized in Table 11.

Heat transfer coefficients were determined by measuring flow rates and temperature changes so that dutles and terminal differences could be computed. Since heat transfer areas were known, coefficlents could be computed direct1y. In the case of the reactors jacket, the test procedure involved heating the reactors contents (water) with steam to about $250^{\circ} \mathrm{F}$, suddenly inftiating flow of cooling water through the jacket, and measuring the rate of decrease in temperature. Since the thermal mass of the system, heat transfer area, and temperature differences were known the coefficient of heat transfer was easily calculated. Within the accuracy of the measurements, there was no observed fouling over a period in which HX102 and $\mathrm{HX103}$ had been in service for about 1500 hours. Since leaching was carried out batchwise, $\mathrm{HX} 201$, HX202 and the reactor jacket were in service for only 300-500 hours, although cooling water had been circulated through them - and HX102 - for about 3000 hours.

Post run inspection following the first 100 hours of scrubbing showed that the last four plates, the hot end, of HX101 were badly fouled on the 
Table 11

Initial and Final Heat Transfer Coefficients

\begin{tabular}{|c|c|c|c|}
\hline \multirow[b]{2}{*}{ Heat Exchanger } & \multirow[b]{2}{*}{ Flow Rates/Conditions } & \multicolumn{2}{|c|}{$\begin{array}{l}\text { Heat Transfer } \\
\text { Coefficient } \\
\end{array}$} \\
\hline & & Initial & Final \\
\hline $\begin{array}{l}\text { HX101, Purge/ } \\
\text { Makeup Exchanger }\end{array}$ & $\begin{array}{l}\text { 7.3 GPM Purge } \\
\text { 7.0 GPM Makeup }\end{array}$ & 580 & (2) \\
\hline $\begin{array}{l}\text { Hx102, Auxiliary } \\
\text { Cooler for Purge }\end{array}$ & $\begin{array}{l}8.3 \text { GPM Purge, } \\
60 \text { GPM Cooling Water }\end{array}$ & 310 & 316 \\
\hline $\begin{array}{l}\text { HX103, Auxiliary } \\
\text { Cooler, then Heater } \\
\text { for Makeup }\end{array}$ & $\begin{array}{l}7.6 \text { GPM Makeup } \\
\text { Steam } 20 \text { psig }\end{array}$ & (3) & 163 \\
\hline $\begin{array}{l}\text { HX201, Purge } \\
\text { Slurry Heater }\end{array}$ & $\begin{array}{l}160 \text { GPM Circulation } \\
\text { Steam } 53 \text { psig }\end{array}$ & 250 & 306 \\
\hline $\begin{array}{l}\text { HX202, Leach } \\
\text { Effluent Cooler }\end{array}$ & $\begin{array}{l}145 \text { GPM Effluent } \\
220 \text { GPM Cooling Water }\end{array}$ & 319 & 402 \\
\hline $\begin{array}{l}\text { V201, Reactor's } \\
\text { Cooling Jacket }\end{array}$ & $\begin{array}{l}\text { Cooling Water Inttially } \\
250 \mathrm{GPM} \text {, Finally } 320 \mathrm{GPM}\end{array}$ & 115 & 140 \\
\hline
\end{tabular}

(1) Overall U, BTU/hr ft ${ }^{2}{ }^{\circ} \mathrm{F}$.

(2) Removed from service, see text.

(3) Not determined initially in service as a heater, see text. 
makeup $\mathrm{CuSO}_{4}$ side. The deposits were thick ( $1 / 16^{\prime \prime)}$, difficult to remove, and had layers of greenish salts found to be basic copper sulfate. The exchanger was cleaned and reassembled and bypassed for startup of the next run. It was brought into service very carefully to insure that the makeup flow was continuous and heated slowly. Improper gasket seating caused numerous leaks and the unit was bypassed after a few hours operation for repair. Upon disassembly, however, it was found that the deposits - though thinner - had reappeared in the third pass of the unit. Since this fouling was too rapid to be tolerated, the exchanger was cleaned, reassembled, but bypassed and HX103 was converted from an auxiliary cooler to a heater.

Energy balances carried out on HX101 while it was in service indicated that the onset of fouling occurred at a temperature between 250 and $300^{\circ} \mathrm{F}$. Operation of HX103 was controlled to keep temperatures below this and no fouling was observed. The relatively low value of the heat transfer coefficient reported in Table 11 was most likely due to incomplete condensate drainage from the highly baffled shell side of the exchanger.

As previously reported, no other evidence of tenacious fouling was found In post run and final inspections of the major items of equipment, auxiliaries, or interconnecting piping or valves. If ever present, it was removed by flushing with water. The solids accumulations found in the scrubber's sump, on the tray from time to time, and on the bottom of the demister pads can be eliminated by proper design.

\subsection{Materials of Construction Testing - Scrubber and Auxiliaries}

An extensive evaluation of the suitability of various materials of construction for all operations in the process had been carried out in the second phase of the program, and the results are simmarized in the second section of this report. That the scrubber and its components would be subject to crevice corrosion if fabricated of $\mathrm{c} 20 \mathrm{Cb} 3$ alloy was confirmed in these tests. The occurrence of this type of corrosion was so widespread that it is difficult to conceive how a commercial sized system could be designed to eliminate it completely. Therefore titanium, originally considered a backup material because of its higher cost, must be considered the material of choice for a commercial scale system.

The scrubbing vessel was put into service for steam-water testing in an "as received" condition; that is, it was not cleaned and passivated after fabrication and shipment to the site, nor was it systematically examined for fabrication defects. A careful inspection was carried out before scrubbing was initiated, however, and several large shallow pits were found at various spots in the plate, along with a general discoloration. These pits were ground out and passivated with an aqueous $\mathrm{HNO}_{3}$ solution. The vessel was reinspected after the first 100 hour's run, and a large number of shallow pits were found in the plate along with a large number of smaller but deeper pits on the filler material of the welds. Deep pits were ground out and rewelded, 
and shallow pits were simply ground smooth. After a number of runs, no more pits occurred in the plate, but pitting on welds continued to the end of the test campaign. Welded specimens had been tested in the lab without problem, and the 8" scrubber tested in the second phase of the program had not been attacked. We conclude, therefore, that improper welding technique had been used for some of the joints on the large scrubber - the problem was much worse on small nozzles than on seam and girth welds which were X-rayed - and use of the proper technique could eliminate this problem.

The plate used in the vessel shell and heads showed a slight darkening in spots but no general loss of metal was found in post test ultrasonic testing. One area of general corrosion was found above a demister support ring, with metal loss approaching $1 / 32$ " in some spots, after the fifth test series. However, no further loss was observed and the reason for this type of attack was not determined. By the end of the campaign, significant crevice corrosion had occurred at the flanges of the scrubbing tray which was of segmental design. Crevice corrosion was also observed under the gasket of the sight glass pad located in the scrubber's sump. In addition, there was extensive loss of metal on the inside of the steam inlet nozzle's segmental projection into the sump. It is likely that scrub solution was carried, by backflow, to the nozzle where copper was depleted by the high $\mathrm{H}_{2} \mathrm{~S}$ content of the inlet steam and the residual acid attacked the metal.

Sporadic examples of crevice corrosion occurred in the slurry circulating piping loop which appeared to be related to gasket misaligment. Nelther Teflon envelope nor plain asbestos gaskets alone were apparently significant in promoting or retarding this type of corrosion. Extensive pitting corrosion was observed after about 200 hours service on the cast C20 body of the slurry circulating pump. Shop inspection by the manufacturer suggested that the primary cause was casting defects. Some evidence of crevice type. corrosion and attack of the cast body was also noted on the 4" and 6" gate valves which isolated one circulating pump, but it was not severe. The Teflon lining of the plug valve which isolated the other circulating pump, as well as the lining of the magnetic flow transmitter in the slurry circulating loop, developed numerous blisters after a few hundred hours exposure. The number and height of the blisters eventually stabilized, and the liner manufacturer reported that this occurrence was not unknown. Their experience in similar service is that its occurrence does not usually lead to fallure of the lining.

When it became obvious that titanium would be used comnercially, some C20 trim components were replaced. Specifically, an 18" long, 4" IPS Ti Grade 2 spool plece was put in the slurry circulating line and one of the circulating pumps was replaced with a cast $T i$ version. These components, as well as $\mathrm{Ti}$ blanking strips on the scrubber tray, were exposed to over 1100 hours service with no evidence of any attack on main parts, at welds or in 
crevices. In addition, a series of coupon corrosion tests at scrubber conditions was initiated, and the results are summarized in Table 12.

These data confirm the results of previous laboratory tests: austenitic stainless steels would be acceptable materials if they were not subject to crevice corrosion. The tests with titanium confirm that it is not subject to this mode of attack and remains passive at all locations in the scrubber. The data for the sample of titaniun demister mesh tested are particularly encouraging. The wire in these pads is only $0.011^{\prime \prime}$ diameter and is highly stressed, yet must tolerate intermittent wetting in the absence of a large excess of passivating agent (copper) without losing integrity. We belleve that the actual corrosion rate is lower than indicated, since some of the reported welght loss occurred when individual strands of wire were separated mechanically from the pad and lost.

An attempt was made to make continuous measurements of the corrosion rate in the scrubber by using Magna Corp. Corrosimeter probes. A great deal of difficulty was encountered because of corrosion of the probe bodies themselves, but a brief $(24 \mathrm{hr})$ test serfes was carried out by PG\&E at the end of the campaign which confirmed the results of the coupon testing. Measured inftial corrosion rates were $5.5 \mathrm{MPY}$ for $304 \mathrm{~s} / \mathrm{s}, 7.3 \mathrm{MPY}$ for $316 \mathrm{~s} / \mathrm{s}$, and $<0.1$ MPY for C20Cb3. Attempts to measure corrosion rates using electrochemical probes falled, probably due to the simultaneous occurrence of redox reactions in the scrubbing fluid.

\subsection{Materials of Construction Evaluation - Other Components}

All other components of the pilot plant were Inspected at the end of the campaign for evidence of corrosion. A general conclusion drawn from these tests is that care must be taken to insure that all joints in the system are made up properly. Even small leaks are difficult to stop once Initiated due to the presence of solid $\mathrm{CuSO}_{4}-\left(\mathrm{NH}_{4}\right)_{2} \mathrm{SO}_{4}$ residues, and leaked scrub and makeup solutions are very corrosive to unprotected carbon steel components.

No evidence of corrosive attack was noted on any component of the system in contact with fluids at temperatures below $250^{\circ} \mathrm{F}$. Even the tube sheet of $\mathrm{EXI02}$, which was in contact with slurry at $350^{\circ} \mathrm{F}$ - but which was cooled on the water side - showed only the very slightest etching. Thus, all recomendations for materials of construction remain unchanged except for the scrubber and trim as noted.

\subsection{Materials Testing in the Scrubbed Steam}

Two series of material tests were carried out in the scrubbed steam after the titanium demister had been Installed. One test involved exposure 
Table 12

Coupon Corrosion Tests at Various Scrubber Locations

\begin{tabular}{|c|c|c|c|c|c|}
\hline Alloy & Location $^{(1)}$ & $\begin{array}{l}\text { Configu- } \\
\text { ration (2) }\end{array}$ & $\begin{array}{l}\text { Exposure Time } \\
\text { (hours) }\end{array}$ & $\frac{\text { Corrosion }}{\text { Initial }^{(3)}}$ & $\begin{array}{l}\text { ate, MPY } \\
\text { Overa11 }\end{array}$ \\
\hline $304 \mathrm{~s} / \mathrm{s}$ & $\begin{array}{l}\mathrm{S} \\
\mathrm{T} \\
\mathrm{D}\end{array}$ & $\begin{array}{l}\mathbf{P} \\
\mathbf{P} \\
\mathbf{P}\end{array}$ & $\begin{array}{r}1150 \\
1150 \\
600\end{array}$ & $\begin{array}{l}3.9 \\
4.2 \\
2.1\end{array}$ & $\begin{array}{l}3.2 \\
3.2 \\
1.6\end{array}$ \\
\hline $316 \mathrm{~s} / \mathrm{s}$ & $\begin{array}{l}\text { S } \\
T \\
D\end{array}$ & $\begin{array}{l}\mathbf{P} \\
\mathbf{P} \\
\mathbf{P}\end{array}$ & $\begin{array}{r}1150 \\
1150 \\
600\end{array}$ & $\begin{array}{l}4.8 \\
4.4 \\
2.6\end{array}$ & $\begin{array}{l}3.9 \\
4.0 \\
2.1\end{array}$ \\
\hline $\mathrm{C} 2 \mathrm{OCb} 3$ & $\begin{array}{l}S \\
T \\
D\end{array}$ & $\begin{array}{l}\mathbf{P} \\
\mathbf{P} \\
\mathbf{P}\end{array}$ & $\begin{array}{r}1150 \\
1150 \\
600\end{array}$ & $\begin{array}{l}3.1 \\
2.8 \\
0.9\end{array}$ & $\begin{array}{l}2.3 \\
2.4 \\
0.8\end{array}$ \\
\hline TI, Grade 2 & $\begin{array}{l}\text { S } \\
\text { T } \\
\text { D }\end{array}$ & $\begin{array}{l}\mathbf{P} \\
\mathbf{P} \\
\mathbf{P}\end{array}$ & $\begin{array}{r}1150 \\
1150 \\
600\end{array}$ & $\begin{array}{l}2.0 \\
0.9 \\
0.14\end{array}$ & $\begin{array}{r}0.24 \\
0.31 \\
-(4)\end{array}$ \\
\hline Ti, Grade 7 & $\begin{array}{l}\mathbf{S} \\
\mathbf{T} \\
\mathbf{D}\end{array}$ & $\begin{array}{l}\mathbf{P} \\
\mathbf{P} \\
\mathbf{P}\end{array}$ & $\begin{array}{r}1150 \\
1150 \\
600\end{array}$ & $\begin{array}{l}2.0 \\
1.3 \\
-(4)\end{array}$ & $\begin{array}{r}0.30 \\
0.39 \\
-(4)\end{array}$ \\
\hline $\begin{array}{l}\text { Ti Demister } \\
\text { Mesh }\end{array}$ & D & $\mathbf{P}$ & 600 & 0.68 & 0.48 \\
\hline $\mathrm{Ti} / \mathrm{Ti}-\mathrm{Pd}$ & $\mathbf{T}$ & C & 600 & $0.4 / 0.2$ & $0 /-^{(4)}$ \\
\hline
\end{tabular}

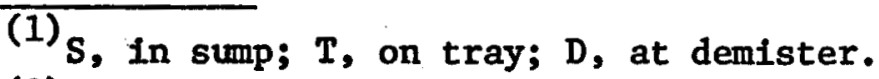

${ }^{(2)}{ }_{P}$, plain, $C$, creviced.

(3) Initial exposure ranged from 130-280 hours.

(4) Slight weight gain. 
of turbine blade materials to scrubbed and unscrubbed steam. The materials were stressed cyclicly at varying levels and the number of cycles to failure determined. There was a considerable amount of scatter in these data, particularly at lower stress levels where times to fallure were long. While the samples exposed to scrubbed steam were noticeably cleaner than those exposed to unscrubbed steam, there was 1ittle difference in the time to failure at a given stress level. A more extensive test program would be required to distinguish the difference, if any, from the uncertainty in the data.

The other tests involved the exposure of various stressed alloys to scrubbed and unscrubbed steam to determine their corrosion rates in a static condition. The results of this test series are summarized in Table 13. The samples were mounted on probes inserted in large. vessels through which steam passed at a relatively low velocity, $<0.1 \mathrm{ft} / \mathrm{sec}$. Thus, the samples were not subjected to erosion and any entrainment in the steam would have had a chance to be disengaged. Stresses ranged from 23 to $30 \mathrm{ks} 1$ for the stainless coupons and from 17 to $22 \mathrm{ksi}$ for the steel ones. Exposure times ranged from 110 to 510 hours, but no effect of stress level or exposure time on corrosion rate are evident in the data. It is clear, however, that the scrubbed steam was no more, and frequently was less corrosive to both carbon and stainless steels than is raw steam under the same test conditions.

\subsection{Corrosion of Downstream Piping}

As has been previousiy reported, excessive amounts of entrainment passed through the demister prior to the use of Teflon sausages and then the titanium demister. This continued for about $40 \%$ of the test campaign, and during this time we found significant amounts of fine, black particulates in the condensate draining from. a low point on the outlet steam line and coating the steam flow control valve FCV101B. This material was found, by $X$-ray diffraction, to be magnetite $\left(\mathrm{Fe}_{3} \mathrm{O}_{4}\right)$ which can form in the presence of $\mathrm{CO}_{2}$ at $\mathrm{pH}^{\prime} \mathrm{s}$ below 5.5 at steam temperature.

The liquid entrainment leaving the scrubber had an upward velocity component and impinged on the top of the $16^{\prime \prime}$ steam outlet line about $2^{\prime}$ from the outlet nozzle. Reentrained liquid would also impinge on the far side of an elbow at. which the steam outlet line changed direction by $90^{\circ}$. In fact, locally severe corrosion - leading to fallure - occurred at these points. Ultrasonic testing of the pipe in the immediate vicinity showed essentially no loss of metal. Fallure due to local erosion/corrosion also occurred just downstream of FCV101B, where steam at sonic velocities was directed at a small area of pipe. Local corrosion also occurred in a dead headed section of vertical pipe, but it was felt that this was due to refluxing which increased the $\mathrm{CO}_{2}$ concentration to the extent that condensate pH's dropped below 5.5 even in the absence of entrained acidic scrub solutions. 
Table 13

Corrosion In Scrubbed and Unscrubbed Steam (1)

\begin{tabular}{llc}
\hline A1loy & \multicolumn{2}{c}{$\begin{array}{c}\text { Unscrosion Rate, MPY (2) } \\
\text { Scrubbed Steam }\end{array}$} \\
\hline $304 \mathrm{~s} / \mathrm{s}$ & Unscrubbed Steam & 0.4 \\
$316 \mathrm{~s} / \mathrm{s}$ & 0.7 & 0.3 \\
$\mathrm{C20 \textrm {Cb3 }}$ & 0.5 & 0.3 \\
$1010 \mathrm{c} / \mathrm{s}$ & 0.7 & 22 \\
\hline
\end{tabular}

(1) Tests carried out by PG\&E.

(2) Average for various exposure times and stresses. 
Since dry cleaned steam had been shown to be Iess corrosive than unscrubbed steam, and ultrasonic testing showed that unwetted areas of the outlet piping were not attacked, we believe downstream corrosion can be eliminated by a combination of proper disentrainment and attention to piping detail. 


\subsection{UPDATED PROCESS DESIGN CRITERIA}

The design criteria used for equipment selection and the operation of the $5 \mathrm{MW}$ pilot plant are presented in detail in the final report for DOE Contract No. EY-76-C-02-2730.*000. Supporting documentation constitutes over 130 pages of the third volume of that report and will not be reproduced in its entirety here. Instead, we will present only those changes to the original criteria which were developed as a result of these tests. Sufficient detail is presented to revise purchasing specifications, and the information is organized so as to be compatible with the original grouping by class or category of equipment.

\section{Pressure Vesse1s}

C101, Scrubbing Tower. Material of construction for vessel and trim, titanium. Conical bottom head, eliminate pad type level gauge. Use staged demister, lower demister to be washed continuously, have high vapor handling capacity and tolerance for high solids loads. Upper demister to be high efficiency metal wire mesh demisters, unwashed.

No other changes.

\section{Storage Tanks}

No changes, except care must be taken at installation to insure that FRP tanks are properly grouted at installation.

\section{Contro11er Loops}

AIT-105, Purge Analyzer. Provide voltage stabilizing transformers and spare lamp. Modify lamp holder for quick change out. Set controller to fail last position.

PHE-106, pH Analyzer. Mount probe horizontally and Increase sample flow to $1 \mathrm{l} / \mathrm{min}$. Provide for high point alr vent on probe mounting tee.

KC-301, Demister Wash Cycle TImer. Eliminate; lower demister wash to be continuous.

DPT-103, LT-104, DPT-109. Tray and Demister Pressure Drop and Sump Level Transmitters. Provide diaphragm type, flush mounting transmitters.

No other changes. 


\section{Agitators}

A101, Slurry Storage Tank Agitator. Provide gas dispersion agitator, turbine type, for ambient leaching. Tank T101 to be provided with sparge ring to suit agitator.

No other changes.

\section{Heat Exchangers}

HX101, Energy Recovery Exchanger. Limit heat transfer area to maintain temperature of makeup solution below $250^{\circ} \mathrm{F}$. Provide bypass piping for servicing in case of fouling.

Hx102, Purge Slurry Aftercooler. Rerate to cool purge slurry from $300^{\circ} \mathrm{F}$ to $140^{\circ} \mathrm{F}$.

Hx103, Makeup Copper Sulfate Exchanger. For service as standby heater, design for steam on shell side.

No other changes.

\section{Filters}

F101/F101A. Sampling Stream Filters. Use porous metal type flow through filters.

F201/F201A. Leached Copper Sulfate Polish Filters. Eliminate.

No other changes.

Pumps and Compressors

P101/P101A. Scrubbing Slurry Circulating Pumps. Wetted parts to be titanium.

P304. Demister Wash Water Pump. Wetted parts to be stainless steel.

P305. Seal Water Supply Pump. Specify Identical to $\mathbf{2 3 0 4}$ for $100 \%$ spare.

Control Valves and Actuators, Hand Valves and Local Instrumentation

FCV103. Slurry Flow Control Valve. Wetted parts to be titanium.

No other changes. 


\section{Instrument Contro1 Panel and Miscellaneous}

No changes on identified items.

As a general criteria eliminate if possible or minimize the use of carbon steel, or aluminum trim (e.g., service bolts, brackets, etc.) on standard items. If their use is unavoldable, provide protective coating of zinc rich or chemical resistant epoxy paint. 


\subsection{UPDATED PLANT DESIGN AND COST ESTTMATE}

\subsection{Changes in System Configuration}

The revised design criterla, derived from the field test campaign, are summarized in Section 4.0. Incorporation of these criteria in a commercial plant design will change the configuration of the system presented In the final report of the first two phases of the development program.* Some of these changes simplify the system and reduce costs, while others increase costs beyond the $30 \%$ due to inflationary increases.

The change which has the greatest impact on process costs is the specification of titanium as a material of construction for the scrubber and auxiliaries. The scrubber vessels themselves would be of clad construction, but the staged demisters and the contacting tray, the slurry circulating pumps and piping, and the energy recovery exchangers will be fabricated titanium items. A material reduction in complexity and cost results from the elimination of the polish leach reactor and its auxiliaries, but the savings are not sufficient to offset increases resulting from the use of titanium. Other changes have a lesser effect on the process configuration. Limiting the maximum temperature of the makeup $\mathrm{CuSO}_{4}$ will result in the condensation of more steam within the scrubber. For steams containing typical amounts of $\mathrm{H}_{2} \mathrm{~S}$, the exothermic heats of reaction in the scrubbing and regeneration steps will be sufficient to reevaporate this condensation. If the inlet steam contains large amounts of molsture, however, some use of steam may be required, in addition to general process use, to maintain the desired system water balance.

\subsection{System Description}

The process flow diagram and material and energy balance for an abatement facility designed to remove $98 \%$ of the $\mathrm{H}_{2} \mathrm{~S}$ from the steam passing to two adjacent $55 \mathrm{MW}$ turbine generators is shown in Fig. 29. The raw steam is assumed to contain $250 \mathrm{ppm} \mathrm{H}_{2} \mathrm{~S}$ and $150 \mathrm{ppm} \mathrm{NH}_{3}$, corresponding to the composition at No. 7 Unit. While separate scrubbers are used to treat each turbine's steam, a single regeneration facility is used to regenerate the precipitated copper sulfides for recycle. Prior to being introduced to a scrubber, the steam is passed through separator units for removal of molsture and particulates. At 1east $80 \%$ of the. NH3 plus lesser amounts of $\mathrm{H}_{3} \mathrm{BO}_{3}$, "rock dust" and other materlals are removed from the steam as it is contacted, on a single crossflow sleve tray, with a scrub solution containing mainly $\mathrm{CuSO}_{4}, \mathrm{H}_{2} \mathrm{SO}_{4},\left(\mathrm{NH}_{4}\right)_{2} \mathrm{SO}_{4}$ and precipitated sulfide solids.

*Final Report, Contract No. EY-76-C-02-2730.*000. 


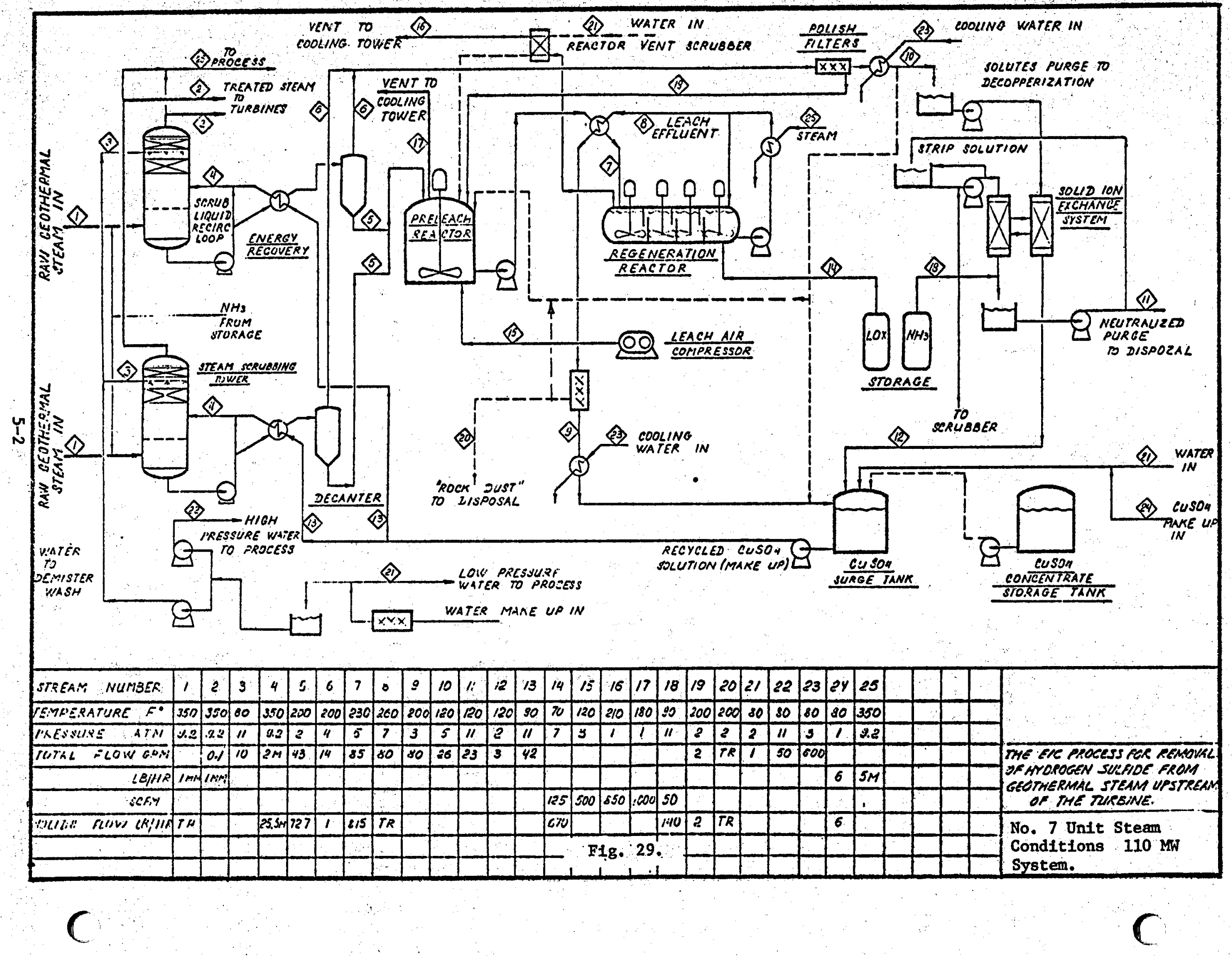


Process conditions are carefully controlled to maintain the scrub solution pH in the desired range and to insure that the copper concentration is sufficlent to provide the required degree of removal efficiency. The scrubbed steam passes through staged, washed demisters for removal of entrained particulates and acidic scrub solution and then to the turbines for power extraction.

A portion of the recirculating scrub solution is purged from each scrubber and passes through an energy recovery exchanger, where makeup $\mathrm{CuSO}_{4}$ solution is heated prior to being introduced to the scrubber. The cooled purge solution - actually a slurry containing precipitated sulfide solids - is introduced to a continuous decanter which separates it into a clarified stream for solubles removal and a more concentrated slurry for regeneration of $\mathrm{CuSO}_{4}$. $^{\circ}$ The clarified purge, streams, containing soluble impurities and reaction products, pass through polish filters for the removal of fines. The filters are continuously backwashed to the regeneration section while the solids-free purge streams are combined and treated for copper removal by solid ion exchange. The copper is removed from the purge by contact with a weak anion exchange resin. Ammonia is added to a portion of the decopperized purge which is used to regenerate the resin. The balance of the purge is then neutralized to remove residual acidity and reinjected along with condensate from the cooling towers, while the solution containing regenerated copper is recycled to the process.

The decanter underflow and backwashed polish filter solids are held in a large, agitated, covered storage tank which serves both to provide surge capacity to isolate scrubbing and regeneration operations and as a preleach reactor. The slurry is contacted with air at near ambient conditions and a significant portion of the sulfide fines are leached in this step. The preleached slurry is then transferred to the pressure 1each reactor, being preheated by countercurrent exchange with leached reactor effluent. Regeneration takes place in a staged vessel at a higher temperature and under oxygen pressure so that essentially quantitative conversion is obtained. The cooled, leached effluent passes through a continuously backwashed polish filter which is provided to remove "rock dust" if present and unleached sulfide solids from the leach effluent. The cleaned effluent is cooled further and transferred to storage for recycle. Unleached sulfide, which might pass through the reactor during an upset condition, would be recycled to the preleach reactor.

Makeup $\mathrm{CuSO}_{4}$ is added to the system to offset miscellaneous losses and water is added, primarily in the demister wash step, at a rate at least sufficient to balance the water requirements of the solubles purge stream. oxygen is consumed in the regeneration reactor, ammonia is used to neutralize the net acid produced in the scrubbing - regeneration reactions and to regenerate the ion exchange resin, and makeup resin is supplied to offset 
decrepitation losses. Nominal amounts of power and cooling water are required continuously, but the system is automated and alarmed to permit unattended operation. Some operator attention will be required on one shift per day to check the inventories of solutions and slurries, review operating logs, obtain record samples, and perform normal housekeeping duties.

\subsection{Capital and Operating Cost Estimates}

Purchased equipment costs are summarized in Table 14, by category, for the equipment shown in Fig. 29. Each of the scrubbers represents almost forty percent of the total cost, and all other items account for about one quarter of the total. Vendor estimates or quotes were obtained for most of the items shown in Fig. 29, amounting to approximately three quarters of the total estimated costs of all equipment other than the scrubbers. The remaining non scrubber costs are associated with small, standard items such as pumps and heat exchangers, for which published cost data were readily available. Major cost increases occurred in the tankage and miscellaneous equipment accounts. The increases in tankage costs resulted from the specification of more surge capacity to dampen out composition fluctuations resulting from changes in steam composition. Inclusion of the purge treatment system subcontract caused the increase in the miscellaneous equipment category.

Total equipment costs, however, are dominated by the cost of the scrubbers. This estimate is based on the use of a single, sixteen-foot diameter titanium clad scrubber for each $55 \mathrm{MW}$ plant, so that some field fabrication would be required. These costs were obtained by surveying titanium suppliers, fabricators of clad plate, and equipment fabricators to determine the costs of materials and labor for vessels in the 12-foot to 16-foot diameter range. Vendors of internals components were also surveyed to determine the costs of these items. The major uncertainties in these estimates arise from the difficulties in estimating field fabrication costs at The Geysers and in obtaining firm quotations for the cost of titanium sheet to be delivered in a years time.

Total costs for a commercial installation were estimated by using the appropriate factors for the costs of installation, piping and instruments, auxiliaries and services, and indirect costs such as engineering and construction expenses, fees and an appropriate contingency. The factors, taken as percentages of the purchased equipment costs, are based on "typical" historical costs for various types of plants and judgment must be used in applying them to an installation at The Geysers where little of this type of construction has been carried out until very recently. It is known that construction and civil costs are high at The Geysers because the site is remote, soil conditions are poor, and seismic and wind loads are severe. While instrumentation and control costs will be higher than normal to 


\section{Table 14}

Purchased Equipment Cost Estimate

\section{MW Plant}

\begin{tabular}{|c|c|}
\hline Equipment Category & $\begin{array}{l}\text { Estimated Cost } \\
1980 \$ \times 10^{3(1)}\end{array}$ \\
\hline Scrubbers ${ }^{(2)}$ & 2,600 \\
\hline Reactors $(3)$ & 150 \\
\hline Tankage & 275 \\
\hline Pumps and Agitators & 140 \\
\hline Heat Exchangers & 85 \\
\hline Liquid-Solid Separation & 55 \\
\hline Miscellaneous $^{(4)}$ & 195 \\
\hline & 3,500 \\
\hline
\end{tabular}

(1) M\&S Equipment Cost Index 625.

(2) Two scrubbers, Including internals, platforms, and ladders.

(3) Ambient preleach and pressure leach vessels.

(4) Includes purge stream decopperization system subcontract. 
permit unattended operation in a remote, severe environment, the requirements for additional services and site work will not be great since only a small amount of additional power ( $500 \mathrm{~kW}$ connected) and water (600 GPM) are needed and only a relatively few, large items of equipment need be Installed.

The total fixed capital cost estimate for a 110 . MW commercial plant at The Geysers is summarized in Table 15. In developing this estimate, we carried out a more careful evaluation of the installation costs of the scrubbers than is usually done for a factored estimate. PreIIminary piping layouts were prepared and vendor quotes obtained for the titaniun piping. Steel piping was estimated from an item count developed from these layouts, and instrumentation was also based on an 1tem count. The costs of foundations, insulation, electricals, etc. were based on factors for similar construction in non alloy materials. Within the accuracy of this estimate, the total fixed capital investment required for a $110 \mathrm{MW}$ plant at The Geysers will be of the order of $\$ 90 / \mathrm{kW}$. The total costs are strongly dependent on the erection and installation costs of the scrubbers which are likely to be fairly site specific. The use of two scrubbers per $55 \mathrm{MW}$ plant, to improve reliability or avoid the necessity for field fabrication, could increase total costs in this account by as much as one-third because of the increased complexity.

Total operating costs for a $110 \mathrm{MW}$ plant are summarized in Table 16. Materials, supplies and utilities consumptions are based on operation of the process for $7500 \mathrm{hr} / \mathrm{yr}$ ( $85 \%$ stream factor) while unit costs are based on $7000 \mathrm{hr} / \mathrm{yr}$ of turbine operation ( $80 \%$ on-line factor). The rational for the use of different stream factors is that the upstream scrubbing process would be used to clean steam vented during periods when the turbines were temporarily tripped off-line. Oxygen and ammonia consumptions are fixed by the steam composition and total flow rate and are not likely to vary considerably. The majority of the copper consumption is due to miscellaneous losses - spills - within the plant, while the resin replacement cost is based on a three year replacement schedule. While little steam is required for direct process use, an allowance has been made for the consumption of some steam for tracing and miscellaneous uses. The labor costs estimated here represent the commitment of one operator, on day shift, for routine record and housekeeping duties and for casual attention, inciuding walkthrough inspections, on off-shifts. Maintenance costs, estimated as a percentage of the fixed capital costs of the plant, include materials and labor.

As was the case in the original estimate, total operating costs are dominated by capital charges which are, in turn, strongly dependent on the Installed costs of the scrubber vessels. Thus, about $40 \%$ of the total operating costs are fixed by the capital charges associated with these 


\section{Table 15}

Total Fixed Capital Investment Cost Estimate . 110 MW Commercial Plant ${ }^{(1)}$

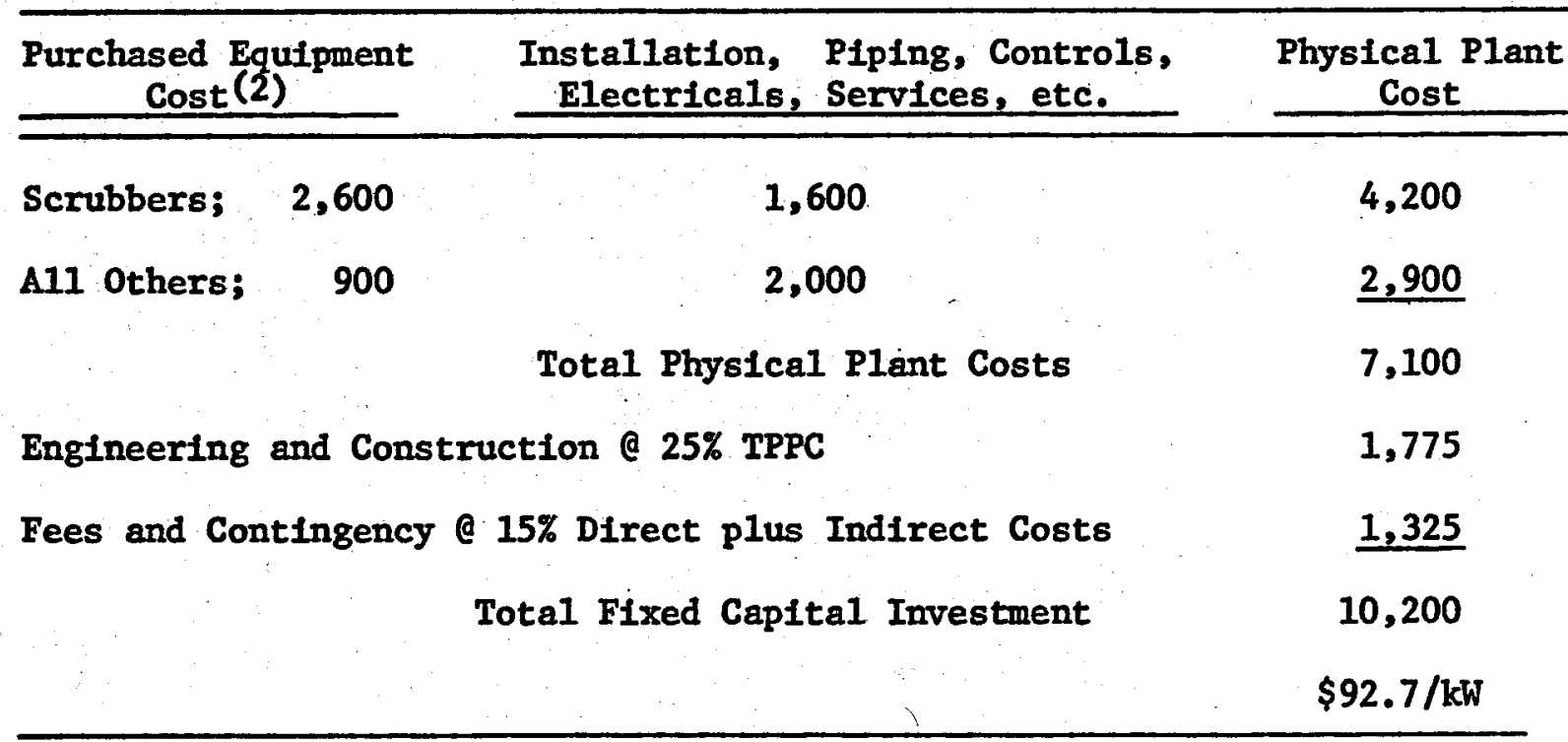

\footnotetext{
(1) A11 costs in thousands of $1980 \$$. ${ }^{(2)}$ See Table 14.
} 
Table 16

Operating Cost Estimate for a $110 \mathrm{MW}$ P1ant

Steam of No. 7 Unit Composition

Materials and Supplies

Oxygen $\$ \$ 90 /$ ton

Ammonia e \$190/ton

Copper Sulfate e $\$ 550 /$ ton

Ion Exchange Resin @ $\$ 600 / \mathrm{ft}^{3}$

Miscellaneous, allow.

Total Materials and Supplies

Operating Cost

$\$ \times 10^{3} /$ Year $^{(1)}$

226

98

12

20

14

370

Utilities and Fuel

Power @ $4.5 \mathrm{c} / \mathrm{kWh}$

94

Water

Steam @ $\$ 1.5 / 10001 \mathrm{~b}$

Fue1

Total Utilities and Fuel

56

$-$

150

Labor

Direct $^{(2)} @ \$ 35,000 / \mathrm{MY}$

Supervision and G\&A e 100\% Direct

Total Labor

70

140

\section{Maintenance}

Materials, Supplies and Labor @ 2\% TFI

Total Direct Operating Costs

Total Direct Operating Cost

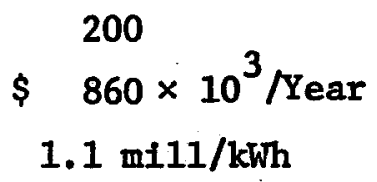

Capital Charges

Taxes, Insurance, Depreclation, Interest, and

Other Charges @ $18.5 \%$ TFI

Total Operating Cost
Total Operating Cost

1,890

$\$ 2,750 \times 10^{3} /$ Year

$3.6 \mathrm{mi11} / \mathrm{kWh}$

\footnotetext{
(1) In 1980 dollars.

(2) Including fringes and shift differential.
} 
vessels, whose sizes are determined by the flow rate of steam to be treated. Another $40 \%$ of the total costs are fixed by the capital charges associated with the balance of the plant plus the costs of materials and supplies, both of which are determined by the amount of $\mathrm{H}_{2} \mathrm{~S}$ removed and the composition of the steam. The balance of the total costs are distributed between utilities, labor and maintenance, and would not be strongly dependent on either steam flow rate or composition.

\subsection{Alternatives for Control of $\mathrm{H}_{2} \mathrm{~S}$ Emissions}

While it is not the purpose of this report to carry out a comprehensive evaluation of the technical and economic characteristics of alternative $\mathrm{H}_{2} \mathrm{~S}$ control technologies, a brief review of possible abatement strategies brings useful perspective to this work.

While no other upstream $\mathrm{H}_{2} \mathrm{~S}$ control technology is now being used at The Geysers, two downstream control processes are in operation. The first approach developed, in use at Units 3, 4, 5, 6, 11 and 12, involves addition of iron salts and $\mathrm{H}_{2} \mathrm{O}_{2}$ to the circulating cooling water to promote oxidation of the dissolved $\mathrm{H}_{2} \mathrm{~S}$ to elemental sulfur. Caustic is added to the ejectors' barometric condensers to remove $\mathrm{H}_{2} \mathrm{~S}$ from the non-condensible gases. The sulfur, insolubles from the steam, and iron hydroxide and sulfide precipitates are removed from the circulating water by settling and centrifuging. It has been shown that $90-95 \%$ removal is a reasonable expectation under most operating conditions. It has also been found that the addition of iron salts at the operating $\mathrm{pH}$ of the system causes significant corrosion problems to arise in the cooling system and that the liquid-solid separation step is very troublesome because of the slimy nature of the solids formed. Because of these difficulties, and the 1imited degree of $\mathrm{H}_{2} \mathrm{~S}$ removal possible, this approach will not be used on newly constructed plants.

A11 units following No. 13 will employ surface condensers, which replace the direct contact condensers now in use, to keep the condensate volumes which are in direct contact with $\mathrm{H}_{2} \mathrm{~S}$ containing gases to a minimum. Sma11, modular Stretford units will be used to remove $\mathrm{H}_{2} \mathrm{~S}$ from the ejector non-condensible gases and oxidize it to elemental sulfur. Steam condensate will be treated with chelating agents and $\mathrm{H}_{2} \mathrm{O}_{2}$ to oxidize dissolved $\mathrm{H}_{2} \mathrm{~S}$ to form soluble sulfur compounds. The costs of this approach are quite sensitive to the "partitioning" of $\mathrm{H}_{2} \mathrm{~S}$ which takes place in the condenser. For minimum costs, the condenser must promote the mass transfer of sufficient $\mathrm{CO}_{2}$ into the condensate to neutralize the $\mathrm{NH}_{3}$ which will be sorbed. Unless the $\mathrm{pH}$ is kept relatively low by this mechanism - or by the direct addition of acid - or there is virtually no $\mathrm{NH}_{3}$ present in the steam, a significant amount of bisulfide will be dissolved in the condensate. Limited operating data from two units currently in operation suggest that the fraction of $\mathrm{H}_{2} \mathrm{~S}$ remaining in the condensate will range from about $20-40 \%$ of that entering for 
steam of low and high $\mathrm{NH}_{3}$ contents respectively. Long term operating data are not yet available to assess the effects of fouling, noncondensibles blanketing, or other operating problems on generation efficiency.

Neither of these downstream abatement techniques addresses the problem of controlling emissions from steam which is vented when the turbines are tripped off line. While such events are infrequent and of relatively short duration, it has been. estimated* that they contribute an additional $4 \%$ of the emissions in the vicinity of the power plant. Emissions of equal magnitude may occur in the steam field operations, but their control is beyond the scope of this work. Most of the work which has been carried out in this area has been directed towards obtaining more effective, rapid mechanical means of reducing pre-plant emissions. Such techniques as rapid throttling to $50 \%$ flow and redirection of steam to other plants through the use of crossties offer the potential of substantially reducing this problem.

Other upstream abatement processes are being evaluated but are at an earlier stage of development. The use of a scrubber using consumptive. chemicals, such as caustic and $\mathrm{H}_{2} \mathrm{O}_{2}$, may prove effective but will be very expensive unless an unusual situation exists with respect to the disposal of spent chemicals and resupply of makeup materials. The use of an upstream condenser/evaporator with treatment of noncondensible gases for $\mathrm{H}_{2} \mathrm{~S}$ abatement will not lower capital costs vis-a-vis the use of a downstream surface condenser-Stretford plant, but may reduce direct operating costs if the partitioning coefficient is improved. An operating penalty will be pald, however, in the form of significantly increased pressure drop.

Reliable capital and operating cost estimates are available for the iron-caustic-peroxide and surface condenser-stretford-supplemental abatement system, since plants using these technologles have been installed and operated. These cost data, developed by The Pacific Gas and Electric Company for conditions at No. 7 Unit, are summarized in Table 17 along with estimates developed here for the EIC process and the operating characteristics of each. Operating costs for the surface-stretford-supplemental abatement system have been estimated for No. 7 Unit conditions on the assumption that one third of the extra $\mathrm{H}_{2} \mathrm{~S}$ in its steam is removed by supplemental abatement with two pounds $\mathrm{H}_{2} \mathrm{O}_{2}$ /pound $\mathrm{H}_{2} \mathrm{~S}$.

The iron-caustic-peroxide system requires the lowest capital investment but entails the highest operating cost for the consumption of $\mathrm{H}_{2} \mathrm{O}_{2}$ and for disposal of voluminous wastes. The use of a surface condenser-stretford plant without supplemental abatement would not impose high operating costs,

*"Resource, Technology, and Environment at The Geysers", Weres et al., 1977. 
Table 17

Cost and Performance Characteristics of Alternative Hydrogen Sulfide Abatement Processes

\begin{tabular}{|c|c|c|c|c|}
\hline & $\begin{array}{l}\text { Iron - Caustic- } \\
\text { Peroxide }\end{array}$ & $\begin{array}{l}\text { Surface Condenser- } \\
\text { Stretford Plant }\end{array}$ & $\begin{array}{l}\text { Surface-Stretford, } \\
\text { Supplemental } \mathrm{H}_{2} \mathrm{O}_{2}\end{array}$ & $\begin{array}{c}\text { EIC } \\
\text { Process }\end{array}$ \\
\hline CapitaI Cost ${ }^{(2)}, \$ \times 10^{6}$ & 7.0 & 8.0 & 9.0 & 10.2 \\
\hline Capltal Cost, $\$ / \mathrm{kW}$ & 64 & 73 & 82 & 93 \\
\hline $\begin{array}{l}\text { Direct Operating and Mainte- } \\
\text { nance Cost, } \$ \times 10^{6} / \text { Year }\end{array}$ & 3.5 & 0.6 & $1.6^{(5)}$ & 0.9 \\
\hline D.O. \& M.C. (3), mill $/ \mathrm{kWh}$ & 4.5 & 0.8 & 2.1 & 1.2 \\
\hline $\begin{array}{l}\text { Total Operating Costs } \\
\$ \times 10^{6} . \text { Year }\end{array}$ & 4.8 & 2.1 & $3.3^{(5)}$ & 2.8 \\
\hline T.O.C. ${ }^{(3)}, \mathrm{m} 111 / \mathrm{kWh}$ & 6.2 & 2.7 & 4.2 & 3.6 \\
\hline Percent $\mathrm{H}_{2} \mathrm{~S}$ Abatement & $90-95$ & $65-80$ & $>95$ & 98 \\
\hline Preplant Emission Controls & None & None & None. & Incorporated \\
\hline Waste/Byproduct Disposal & offsite & Reinject/Sale & Reinject/Sale & Reinjection \\
\hline
\end{tabular}

(1) For No, 7 Unit conditions, 1980 dollars.

(2) For a $110 \mathrm{MW}$ plant.

(3) Based on $7000 \mathrm{hr} /$ year turbine operation.

(4) Including capital charges at $18.5 \%$ TFI.

(5) For No. 15 Unft conditions. Additional $\mathrm{H}_{2} \mathrm{~S}$ in No. 7 UnIt steam Increases operating costs for $\mathrm{H}_{2} \mathrm{O}_{2}$ by $\$ 0.6 \mathrm{~min} / \mathrm{yr}, 0.8 \mathrm{mlll} / \mathrm{kWh}$. See text. 
but will not provide sufficient $\mathrm{H}_{2} \mathrm{~S}$ abatement for steam containing more than a few parts per million NH3. Addition of a supplemental abatement system increases capital costs slightly and operating costs significantly due to the consumption of $\mathrm{H}_{2} \mathrm{O}_{2}$. Overall abatement efficiencies exceeding $90 \%$ are possible with this system, and would be achieved by increasing the consumption of $\mathrm{H}_{2} \mathrm{O}_{2}$ in the supplemental abatement system. The EIC process shows the highest capital costs, due primarily to the use of titanium scrubbers, but low operating costs since it is not consumptive of large amounts of expensive chemicals.

Only the surface-Stretford-supplemental abatement process is capable of obtaining degrees of abatement comparable to the EIC process, although overall abatements are somewhat lower in the former case since pre-plant emissions are not controlled. Serious operational and waste disposal problems are associated with the production of iron-sulfur sludges in the Iron/caustic/peroxide system, while the Stretford plants can produce sufficient byproduct sulfur to result in an operating cost credit of up to 0.1 mili/kWh at current full market prices. We have assumed that the soluble purge stream from the EIC process will be reinjected as is the case with the effluent from the surface condenser's supplemental abatement system which contains about a third as much soluble sulfur compounds. If reinjection is not allowed, ammonium sulfate and boric acid can be recovered, for sale or disposal, from the purge stream from the EIC process since they are present at a relatively high concentration. Evaporation to dryness with landf1ll disposal of solids is also possible. This option is not practical for the surface condenser's condensate in which these compounds are diluted by 50-100 fold.

In summary, the data in Table 17 show that of the options presented which are capable of obtaining the required degrees of abatement, the EIC process provides the highest degree of overall $\mathrm{H}_{2} \mathrm{~S}$ abatement at the lowest direct and total operating costs for conditions at No. 7 Unit. Design criteria for the process have been supported by the operation of a one-tenth scale pilot plant, but operating experience in a commercial scale demonstration plant is required to verify these estimates and provide data on process reliability. 